\title{
THEORY AND PRACTICE IN THE FILTRATION OF WATER.
}

By WaLTER CLEMENCE, Member, of Shortlands, Kent.

Open sand-filters for purifying waters for potable purposes have now been in use for nearly a century, and since 1830 they have been continuously used in connexion with the London Water Supply.. The first sand-filtration plant, designed by James Simpson for the Chelsea Water Company, consisted of decanting basins in which the raw water could be kept at rest for twelve hours, and open filterbasins in which a layer of fine sand 2 feet 6 inches deep was placed on a bed of gravel of about the same thickness. In the gravel bed brick collecting drains with arched covers were constructed. These large drains were found to induce a too rapid flow of the water through the sand immediately over them, and in later practice smaller drains were used which were distributed over the whole area of the floor of the filter to secure an even speed through the bed.

During the last twenty years what is known as the "mechanical filter" has been introduced, in which the arrangement of the filtering materials differs little, in section, from that adopted in open sand-beds, but the water under treatment is passed through [The T.MeCH.E.]

R 2 
the materials at a speed from twenty to sixty times greater than that which has been found in practice to represent a safe limit of speed with slow sand-filters, in order to obtain complete purification of the water. This limit is generally agreed to be from 50 to 75 gallons per square foot per 24 hours, and it is obvious that, if the process of purification is found to be incomplete in the slow filter on exceeding this speed, it must be much more so in the rapid filter.

With filters of fine sand working at a slow speed, it is found that practically all matters in suspension in the water, whether living organisms (other than bacteria) or silt particles, are retained on the surface of the filtering medium, where they eventually form an impervious layer, and it becomes necessary to remove this in order to restore the permeability of the bed. This has long been recognized as one of the greatest drawbacks to slow sandfiltration, yet the theory became established that the efficiency of the filter as an agent for the purification of water depended almost entirely on the layer of slimy mud which has been observed to form on the surface of the filter after it has been brought into use. Many articles have been published giving details of the various matters of which this layer has been found on examination to be composed, and in some cases it has been claimed that the presence of specific plants or other organisms in the layer has an effect, detrimental or otherwise, on the action of the filter. But while it is frequently pointed out that this film retains some 98 per cent. of the bacteria found in the raw water, the important fact that the majority of these bacteria are nitrifying organisms, and the most active agents in the organic purification of the water, is too frequently overlooked.

It has been established in practice that, with filters on which a filtering layer is allowed to form (the italicized words are important), the efficiency of the filter is impaired if the layer is disturced, and that after its complete removal when a filter is cleaned, the chemical and bacterial efficiency of the filter is not restored until a film has again formed. But the formation of the film is attended with a practical disadvantage in the working of the filter, as it is accompanied 
by a constant increase in the "loss of head" or pressure required to force the water through the filter, so that by the time the filter is in a condition to yield a water of sufficient purity for potable purposes, the output has been considerably reduced, and constantly decreases until it becomes necessary to remove the "filtering film," when the process of ripening and working with constantly diminishing output must be repeated. These are the conditions under which sand-filters were worked for a period of seventy years, and in a large number of cases the conditions are the same to-day.

The chief disadvantages of sand-filtration under such conditions are:-

(1) Owing to the time occupied in cleaning and ripening each filter and the limited time during which it can be worked at its maximum rate of delivery, it is necessary to provide a much larger total filtering surface than would be necessary if the filters could be worked at something approaching their maximum rated speed for prolonged periods.

(2) The labour required for cleaning the filters, and removing washing and replacing sand, is considerable.

(3) There is a constant waste of water (which in the majority of cases has to be pumped from a lower level) whenever a filter is emptied for cleaning, or when the effuent is run to waste during the process of ripening a filter and also for washing sand, an operation which must always be carried out with filtered water.

Much attention has been paid by engineers in recent years to the improvement in the conditions of working and the design of filters. The interest aroused in connexion with this subject has resulted in the formation of two distinct methods of practice based on widely divergent theories.

On the one hand, those who support the theory, that the bacterial purification of water by filtration is chiefly due to the mechanical action of straining, have developed the mechanical filter, in which a film is created artificially by the use of a coagulant, and a high speed is adopted.

On the other hand, Armand Puech proved by experiment and observation that the formation of a film on the surface of a filter 
was a hindrance rather than an aid to purification, and Puech and Chabal have developed the system of multiple filtration which is founded on the now ascertained fact that the formation of a film, either natural or artificial, on the surface of the filtering medium is unnecessary and undesirable. In the system of multiple filtration the slow sand-filter is retained, but the water is previously clarified by passing through successive layers of gravel and sand. During this preliminary treatment all solid matters in suspension are eliminated, together with the spores of algæ, so that no film can form on the surface of the final filter. As the nitrifying bacteria are not retained on the surface of the sand, they penetrate into the filter itself to a considerable depth, so that the bed becomes an active agent of purification, and not merely a support for the filtering layer of limited efficiency on its surface. Tet it is found that slow sand-filters, which form the final elements in a system of multiple filtration, will, without the formation of a film, give far better results chemically and bacteriologically than filters on which a film is allowed to form.

\section{Mechanical Filters.}

Although there are many types of filters, for each of which special advantages are claimed, the diagram, Fig. 1, shows the essential features common to all mechanical filters. The filtering surface varies from 50 to 230 square feet in each unit, and the speed of working is modified according to the water to be treated, but is rarely less than 8 feet 6 inches vertical fall per hour, and is sometimes as much as 50 feet. From ten to twenty minutes appears to be the usual time allowed for the passage of the water from inlet to outlet. When the filters are open at the top and depend on gravity for their working head, it is rarely possible to obtain a speed of more than 20 feet vertical fall per hour, and at that speed the filters require cleaning frequently, as it is impossible to maintain the necessary working head, which constantly increases as the filtering medium becomes foul.

For high rates of filtration, from 20 to 50 feet vertical fall per 
hour, the head is induced or the filters are closed in so that they may be put under pressure from the inlet main. Each unit is controlled by four valves lettered $\mathrm{B}, \mathrm{C}, \mathrm{D}$, and $\mathrm{E}$ on the diagram,

Fig. 1.-General Arrangement of a Mechanical or Rapid Filler.

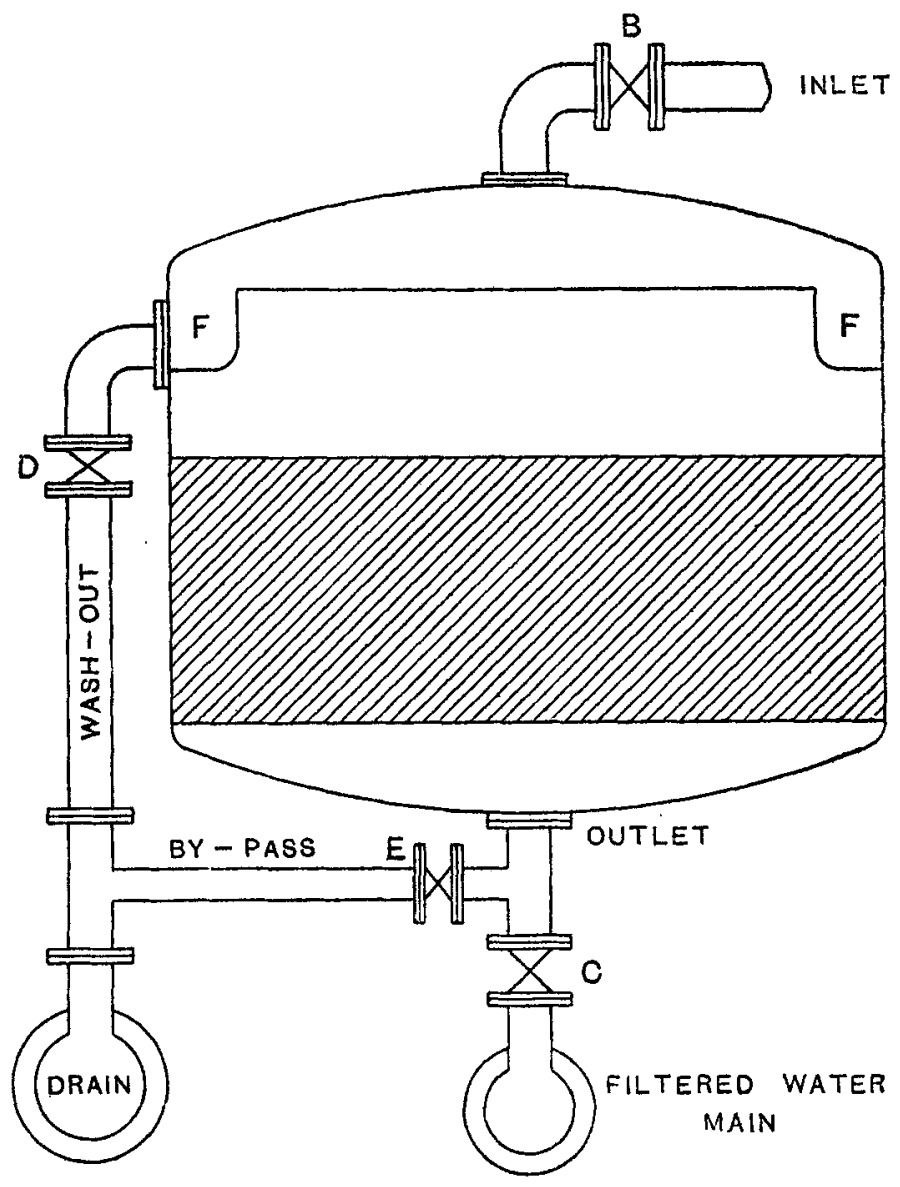

and when the filter is in use $\mathrm{D}$ and $\mathrm{E}$ are closed. Raw water is admitted at $B$, and, after passing vertically downwards through the filter, is carried to the collecting main through the outlet pipe controlled by the valve $C$. In order to clean the filter, the valve $D$ 
on the wash-out pipe is opened and the inlet valve B is closed. In the case of filters of the enclosed or pressure type, this is sufficient to cause a reversal of the flow, as the filtered water main is under pressure from other units of the battery, and the water flows upwards through the filtering medium into the collecting channel $\mathrm{F}$, and thence to the drain through the wash-out valve $D$.

With filters of the open or gravity type, the outlet valve $\mathrm{C}$ is closed as well as the inlet, and an auxiliary valve on a pipe connected to the space below the filtering medium is opened to admit filtered water from the supply mains, if these are under sufficient pressure, or from an auxiliary pump. When the filtering medium is sufficiently clean, the valve $D$ is closed, and it is then usual to start the filter and run the filtrate to waste for a time by closing the main outlet valve $\mathrm{C}$ and opening an auxiliary outlet valve $\mathbf{E}$ connected to the drain.

Another feature common to all mechanical filters is the provision of means for breaking up and agitating the filtering medium during the process of cleaning. This is accomplished either by the use of mechanical rakes or stirrers buried in the medium, and which may be revolved by gearing, or by the use of steam or compressed air which is admitted at the bottom of the filter with the wash water. Owing to the high speed employed, there would be little or no reduction in the number of bacteria without the formation of an artificial film. Sulphate of alumina is generally used as a coagulant, and in the case of soft waters lime must be added; by this means a gelatinous film is formed on the filtering medium.

The apparatus used to mix and add the chemicals employed is very similar to that used in water-softening installations, and generally consists of a combination of measuring weir and tipper with float controls. It will be seen therefore--

(1) That the practice of mechanical filtration is based on the theory that a filtering film is essential.

(2) That the speed of the filters is always high, so that the length of time during which the water is under treatment is not considered of importance. 
(3) That when cleaning, the filtering materials are violently agitated throughout their mass.

(4) That the bacteriological purification of the water is dependent on a single operation carried out with extreme rapidity, and that the sole line of defence against the passage of pathogenic organisms through the filter consists of an artificial gelatinous film.

\section{Multiple Filtration.}

The theories which have led to the development of multiple filtration are directly opposed to those which have been considered in connexion with mechanical filtration. It is now an accepted fact that the reduction of organic matters in solution in water, and their resolution into mineral matters or nitrates, is due to the action of bacteria, and it is believed that the vast majority of microbes found in organically impure waters belong to the class of nitro-bacteria first discovered by Winogradsky. The nitro-bacteria are said to consist of several species having different characteristics, but all are aerobic-that is, they thrive only in the presence of free oxygen. They exist in water and appear to thrive and form colonies in soil or sand, but they are not found in soil at a depth of more than a few feet from the surface. Careful experiments by Reinsch and others have shown that in ordinary sand-filters having a depth of about 3 feet of sand, the number of bacteria found in samples of water drawn at various depths in the sand-bed is gradually reduced from top to bottom, the number varying with the speed.at which the water is passed through the bed.

The Author has observed that in slow sand-filters forming the final elements in a system of multiple filtration, a section of the sand in a filter which has been at work for some months shows a brown stain extending downwards through the bed. This stain decreases in shade from the surface downwards and appears to be due to the presence of innumerable colonies of nitro-bacteria, which coat the grains of sand to a considerable depth instead of being retained in the "filtering layer" on the surface of the sand as in filters which are fed with water that has not been previously clarified. 
It is found in multiple filtration that the slow sand-filters will yield good results if put to work again at their maximum speed after scraping, provided the sand has not been allowed to become dry. This is shown by a reference to the diagram, Fig. 10 (pages 268-9), showing the working of the Cawnpore filters during 1913. It will be seen that filter No. 5 was scraped on 15th June and was again brought into use on 16th June with a delivery of $1,200,000$ gallons (the area of the filter being 20,000 square feet; this equals 60 gallons per square foot per 24 hours). This filter was worked until the end of June at speeds varying from 55 to 67 gallons per square foot per 24 hours. The number of bacteria in the effluent on 16th June was 44 per $\mathrm{cm}^{3}$ and on ten other occasions between 17 th June and the end of the month the figures were, $28,14,28,8,22,20,20,14$, 16, and 12.* After re-sanding a filter, the results are for a short time less perfect than with sand which has been in use for some time. They are still, however, sufficiently satisfactory to permit the water to be used if the filter is run for a short time at a slow speed.

These facts were carefully considered in the development of the system of multiple filtration. It was seen that the filtering film, composed in the main of a felted mass of alga, fine silt particles and debris of all kinds, owed its limited efficiency as an agent in the purification of water to the presence of nitrifying bacteria in the film, but that the alga and other materials were in themselves detrimental to the efficiency of the filter, as it was impossible to remove the layer of silt, etc., from the surface of the sand without at the same time removing the principal agent of chemical and bacteriological purification. The efficiency of the filter is found to be greatly increased if the nitrifying organisms are allowed to spread through the whole mass of the filtering materials and their vitality maintained by a constant supply of oxygen. Formerly the formation of the film prevented this, and the fuct that the filter

* Report by Captain C. L. Dunn, I.MI.S., on the working of the PuechChabal Multiple Filtration Installation at Cawnpore, Table 1-Allahabad Government Press, 1913. 
became inefficient after scraping indicated that the sand itself had no influence on the chemical and bacteriological character of the water.

The first problem to be considered is how to prevent the blocking of the filter by the accumulation on its surface of the matters in suspension in the water, while at the same time allowing the nitrifying bacteria to gain free access to the filtering materials. When this is accomplished, the colonies of nitrifying bacteria form a slimy layer on the sand grains in the upper part of the bed and gradually spread downwards until the filter is in a condition to deal actively with the organic matters in solution during the passage

FIGS. 2 and 3.-Arrangement of Filtering Muterials.

In an Ordinary

Slow Sand-Filter.
In Multiple Filtration.

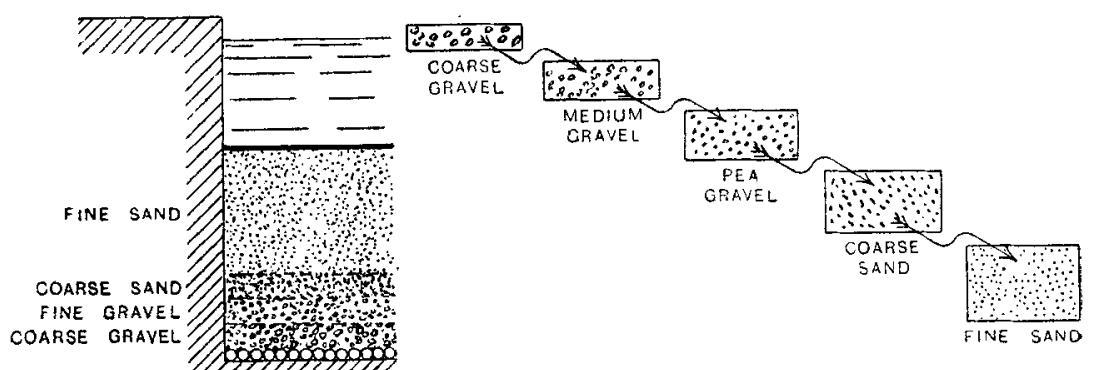

of the water tinrough the sand, so that as the thickness of the layer containing the purifying organisms increases, so the speed of the filter can be increased with perfect safety, for the really effective agent of purification is now spread through a considerable depth of the mass of sand instead of being limited to a thin film on the surface. It is found in practice that the formation of this natural bacterial slime in the filter has very little effect in restricting the passage of the water through the sand.

If the action of a sand-filter is chiefly confined to a "filteringfilm" on the surface of the sand, represented by the thick black line in Fig. 2, it may be argued with some reason that little work is done by the filtering materials themselves, except that they form 
a convenient support for the film, and while there are obvious practical reasons for the disposition of the layers of gravel and sand shown by the diagram, the theory under consideration requires that the arrangement should be reversed and the water passed through the layers of coarser materials first.

To reverse the disposition of the filtering layers in an ordinary sand-filter, even if it were practicable, would necessitate the employment of the same speed of filtration in each layer, and it is found in practice that if very turbid water is passed at a slow speed through a layer of coarse gravel, the surface will become blocked with mud in a comparatively short time, and that a layer of pebbles forms a more efficient strainer if the speed of the water is so regulated that a coating of mud may be left on every pebble in the mass. These considerations require that various layers of pebbles and sand shall be placed in separate basins and disposed according to their grading from coarse to fine in successive stages as in Fig. 3.

Nitro-bacteria in water are active in destroying organic matter at all times, and a certain reduction in organic matter takes place even during the comparatively rapid passage of the water through the degrossisseurs, as the first elements in a system of multiple filtration are called, so that the total time during which a water is under treatment, from the raw water inlet to the outlet from the final filters, must be carefully considered in the design of an installation. Reduction in the number of bacteria proceeds also with the reduction in organic matter, and the water is reduced to a condition of comparative safety before reaching the final filters. It appears probable that pathogenic organisms disappear in the process of multiple filtration, not because they are retained by the mechanical process of straining, but because water from which organic matters in suspension and solution have been entirely removed is not a suitable environment for their continued existence. Such organisms thrive in organic matter and a high temperature, and it appears reasonable to suppose that they are devitalized in water at a temperature considerably lower than blood heat, and that they perish rapidly in the absence of organic matter and possibly owing to the action of nitro-bacteria in the filters. 
Having enumerated some of the considerations which have led to the development of the system of multiple filtration in its present form, it may be said the theory that the "filtering film" is not necessary for the successful working of slow sand-filters appears to be established by the results of practice, and while first consideration must always be given to details affecting the purity of the filtrate, an enormous reduction in the cost of working of multiple-filters has been secured by the adoption of mechanical methods of cleaning the various units forming the plant for treatment of the water antecedent to filtration, while the absence of a film on the final slow sand-filters, and the fact that these are now supplied with a physically clear water, renders unnecessary the expensive operation of scraping except at very rare intervals.

The first large installation of multiple filters for a potable water supply was constructed by the authorities of the City of Paris at Ivry in 1900 at a time when sand-filters were first used in France on a large scale. The sand-filters are twenty-seven in number, with a total area of 230,000 square feet, and they are supplied with water strained in four successive stages in sixteen degrossisseurs or strainers, with a total area of 47,500 square feet. The strainers are supplied with filtering layers of pebbles only, and the suspended impurities in the raw water, which is drawn from the Seine, are removed to such an extent that the sand-filters run on an average for three months. A similar plant was constructed about two years later at the Sunbury Works of the Metropolitan Water Board for dealing with $10,000,000$ gallons per 24 bours. In these installations no provision is made for aeration of the water or for cleaning the degrossisseurs by mechanical means, and although the results show a great improvement in all respects over ordinary sand-filtration combined with decantation, they are not to be compared with the results obtained in more modern installations.

As the system has progressed, three notable features have been introduced:-

(1) It is now the practice to introduce a pre-filter of coarse sand 
between the degrossisseurs and final filters. This has the effect of almost completely eliminating suspended matters and greatly prolongs the life of the final filters.

(2) For potable waters, cascades are introduced between the successive stages of straining so that the supply of dissolved oxygen is fully maintained.

(3) The degrossisseurs are fitted with an apparatus for rapidly removing the silt collected by the straining materials, by means of air and flushing with unfiltered water. The pre-filters are also frequently fitted with an apparatus for cleaning the surface of the sand while the basins are submerged.

The diagrams Figs. 4, 5, 6, and 7 (pages 251, 255, 260-1) show the arrangement of four modern installations which it is proposed to describe, giving in each case particulars of the raw water, and showing how the principle of multiple filtration has been adapted to suit local requirements, for, as no two waters present the same characteristics, it is essential that these should be studied carefully in the design of any installation intended to effect purification.

The four examples of multiple-filtration installations [1. Magdeburg.-River Elbe, a water usually turbid and polluted with refuse from factories. 2. Deruent Valley.-An upland water charged with peaty acids. 3. Acrra, Gold Coast Colony.-River Densu, a water polluted with decaying vegetation from swamps. 4. Cawnpore.-River Ganges, a water organically pure, but usually turbid with clay and silt particles] hereafter described have been designed to deal with waters differing widely in character. In each case the slow sand-filter is relied on for final purification, the rest of the plant being designed to bring the water to such a condition before reaching the final filters that the best possible results may be obtained from these. It will be noted that the arrangement of the degrossisseurs and pre-filters is varied in each case, according to the character of the water and the nature of the difficulties to be encountered in working the final filters. 


\section{Magdeburg, Fig. 4.}

The source of supply is the River Elbe, which is usually turbid and polluted with the refuse from factories, etc., the quantity of organic matter being largely increased in the winter months by refuse from beet-sugar refineries. The plant * has a capacity of 9,900,000 gallons per 24 hours, and consists of four series of degrossisseurs or strainers, with cascades between each series, pre-filters of coarse sand, and slow sand-filters. The latter have been in existence for many years, and are covered with brick arches on which a layer of 3 feet of soil is placed.

Formerly these filters were supplied with water previously

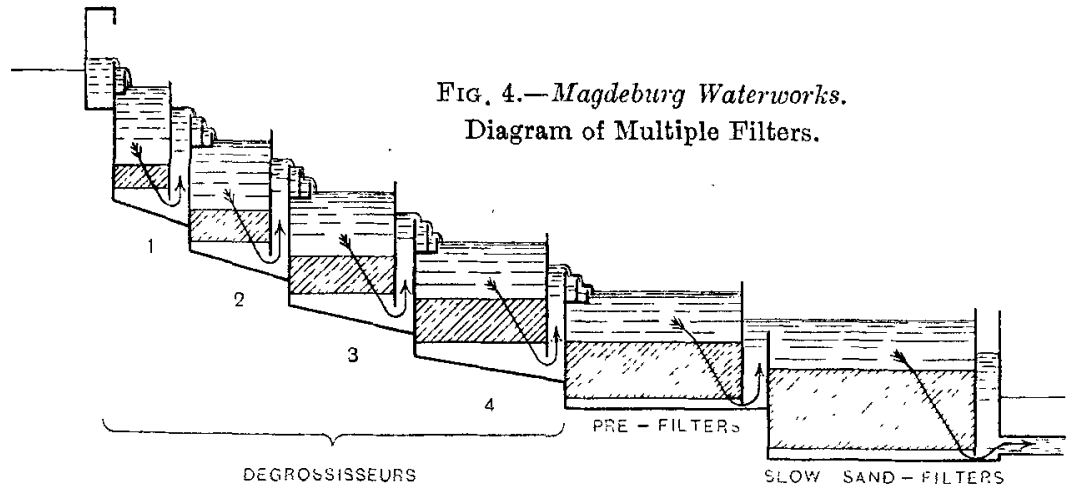

passed through decanting basins, but as these proved ineffective they were transformed into simple roughing filters. These were designed for too high a speed, and the filtering layer was unnecessarily thick, so that, as the whole mass of filtering materials became foul after some months" working, it was exceedingly dificult to clean them. They were therefore reconstructed, and the whole installation transformed into a multiple-filtration plant by the addition of degrossisseurs.

The degrossisseurs are in four series and 32 units with a total filtering surface of 22,900 square feet, while the total area of the pre-filters is 43,000 square feet, and of the final sand-filters 193,700 square feet. The speed adopted is as follows:-

* Engineer ing, 28th January and 4th and 11th February 1910. 


\begin{tabular}{|c|c|c|c|c|c|}
\hline & & & & & $\begin{array}{l}\text { Vertical spe } \\
\text { feet per } h\end{array}$ \\
\hline Degrossisseurs 1 & 1. & . & . & . & . $38 \cdot 38$ \\
\hline ” & 2 & . & . & . & . $21 \cdot 94$ \\
\hline , & 3. & . & . & . & $.11 \cdot 98$ \\
\hline$"$ & 4. & . & . & . & . $5 \cdot 22$ \\
\hline Pre-filters & . & . & . & . & . $1 \cdot 53$ \\
\hline Sand-filters & . & $\cdot$ & . & . & . $0 \cdot 34$ \\
\hline
\end{tabular}

The effect of the simple device of cascading the water between the various stages is shown as follows:-

\section{Dissolved Oxygen in Cubic Centimetres per Litre.}

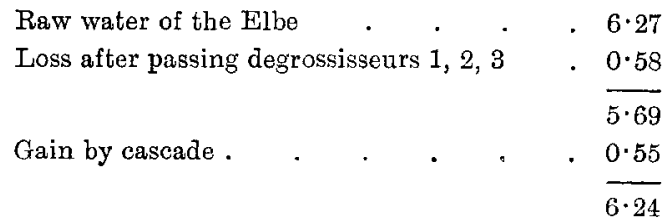

Loss on passing degrossisseurs series $4 \quad$. $0 \cdot 71$

$$
\overline{5 \cdot 53}
$$

Gain by cascade . . . . . . $1 \cdot 02$

$6 \cdot 55=$ Saturation

in dissolved oxygen at time of test, with temperature $18.5^{\circ} \mathrm{C} .\left(65^{\circ} \mathrm{F}.\right)$.

The bacteriological results obtained from the multiple filters at Magdeburg have been remarkably regular. A Table showing the results of 454 analyses made during the month of November 1910 was published in Enginsering, 13th January 1911. A summary of the results gives the following figures:-

\begin{tabular}{|c|c|c|c|c|c|}
\hline & $\begin{array}{c}\text { No. of } \\
\text { Samples }\end{array}$ & Bac & teria per & $\mathrm{m}^{3}$ & Bacterial \\
\hline $\begin{array}{l}\text { Raw water } \\
\text { After degrossisseurs } \\
\text { After pre-filters } \\
\text { Sand-filters : } \\
\text { Collecting well } \\
\text { Service reservoir : } \\
\text { Town mains. }\end{array}$ & $\begin{array}{r}30 \\
30 \\
30 \\
326 \\
30 \\
5 \\
3\end{array}$ & $\begin{array}{r}\text { Highest. } \\
144,000 \\
10,000 \\
1,900 \\
18 \\
14 \\
17 \\
14\end{array}$ & $\begin{array}{c}\text { Lowest. } \\
4,200 \\
1,500 \\
130 \\
1 \\
3 \\
6 \\
4\end{array}$ & $\begin{array}{c}\text { Average. } \\
43,523 \\
3,771 \\
636 \\
5 \cdot 65 \\
7 \cdot 4 \\
11 \cdot 6 \\
8 \cdot 0\end{array}$ & $\begin{array}{c}\text { Per cent. } \\
-- \\
91 \cdot 33 \\
98 \cdot 51 \\
99 \cdot 987 \\
- \\
-\end{array}$ \\
\hline
\end{tabular}


The figure for albuminoid ammonia is reduced from 50 to 80 per cent, according to the season, while the free ammonia is always entirely eliminated, showing a reduction in organic matter in solution which is due to the length of time allowed for nitrification and the arrangements made for maintaining a supply of free oxygen during the process of purification.

The character of the raw water of the Elbe varies considerably, as may be seen from the following analyses made during the summer season:-

\begin{tabular}{|c|c|c|c|}
\hline Analysis in Milligrar & nmes per litre. & 5 July 1907. & 2 May 1908. \\
\hline Total solids & . & $783 \cdot 3$ & $395 \cdot 8$ \\
\hline Loss on ignition . & . & $81 \cdot 7$ & 53 \\
\hline Sodium oxide $\left(\mathrm{Na}_{2} \mathrm{O}\right)$ & . & $235 \cdot 1$ & $105 \cdot 2$ \\
\hline Potassium oxide $\left(\mathrm{K}_{2} \mathrm{O}\right)$ & . & $13 \cdot 4$ & $2 \cdot 8$ \\
\hline $\operatorname{Lime}(\mathrm{CaO})$ & . & $92 \cdot 4$ & $55 \cdot 1$ \\
\hline Magnesia (MgO) . & . & $32 \cdot 1$ & $20 \cdot 3$ \\
\hline Oxide of iron $\left(\mathrm{Fe}_{2} \mathrm{O}_{3}\right)$ & . & 0.3 & $0 \cdot 3$ \\
\hline Alumina $\left(\mathrm{Al}_{2} \mathrm{O}_{3}\right)$ & . & $1 \cdot 1$ & $1 \cdot 7$ \\
\hline Chlorine & . & 287 & 133 \\
\hline Sulphuric anhydrido & . & $79 \cdot 7$ & $46 \cdot 2$ \\
\hline Silice . . . & . & $7 \cdot 2$ & $5 \cdot 7$ \\
\hline Carbonic anhydride & . & 60 & $37 \cdot 7$ \\
\hline Nitrogen as nitrates & . & $11 \cdot 7$ & $7 \cdot 7$ \\
\hline Nitrites & . & Traces & Traces \\
\hline Freo ammonia & . & 0.04 & $0 \cdot 06$ \\
\hline Albuminoid ammonia & . & 0.22 & $0 \cdot 15$ \\
\hline Oxygen consurned & . & $7 \cdot 60$ & $5 \cdot 4$ \\
\hline Dissolved oxygen . & $\mathrm{cm}^{3}$ per litre & $5 \cdot 62$ & $7 \cdot 5$ \\
\hline Total hardness & degrees & $13 \cdot 73$ & $8 \cdot 4$ \\
\hline Permanent hardness & . degrees & $7 \cdot 85$ & $4 \cdot 3$ \\
\hline
\end{tabular}


The work acomplished in a given period by any filter, slow or rapid, is best understood by a statement as to the number of cubic feet of water which have passed through each square foot of filter area, or in other words, the height of a column of water which has passed through the filter. Results stated in this way are easily comparable whatever the area or speed of the filter. The physical effect of multiple filtration on the life of the final or slow sandfilters of the system is well illustrated by the following particulars relating to one of the Magdeburg filters. When supplied with water from settling-tanks, this filter required cleaning on thirteen occasions in six months, the average height of a column of water passed between scrapings being 54.79 feet. On each occasion the filter was worked to its maximum " loss of head" of 39 inches. When supplied with water previously passed through the degrossisseurs and pre-filters, the height of a column passed through the same filter was 1,022 feet with a loss of head of 3 inches only. It has been already shown (page 246) that in multiple filtration it is possible to start a sand-filter, immediately after scraping, at its maximum speed without running the water to waste, and that good results are at once obtained.

This is borne out by the Tables of bacteriological results already quoted, and appears to support the theory that a sand-bed, if left undisturbed, and through which water is allowed to pass continuously, becomes charged with nitrifying bacteria which have a most important effect in bringing about complete purification.

\section{Derwent Valley Water Board, Fig. 5.}

The large installation at Bamford, Derbyshire, deals with water from the impounding reservoirs at Derwent and Howden. The installation has a capacity of 12,000,000 gallons per 24 hours for the supply to Nottingham, Leicester, and Derby. The plant consists of three series of degrossisseurs divided into sixteen compartments, any one of which may be isolated for cleaning without interrupting the working of the remainder. There are no pre-filters, and the water passes direct from the degrossisseurs to the slow sand-filters. 
The degrossisseurs are fitted with an apparatus for cleaning the gravel by means of air, and the amount of labour required for working the installation is very small. The sand-filters have a total filtering surface of 189,000 square feet, and the degrossisseurs 28,200 square feet. The speed adopted is as follows :-

\begin{tabular}{|c|c|c|c|c|}
\hline & & & & $\begin{array}{l}\text { Vertical speed in } \\
\text { feet per hour. }\end{array}$ \\
\hline Degrossisseurs, & Series 1 & & . & . $21 \cdot 62$ \\
\hline$n$ & Series 2 & . & . & . $15 \cdot 04$ \\
\hline$"$ & Series 3 & $\cdot$ & - & . $\quad 5 \cdot 75$ \\
\hline Sand-filters & • & • & . & 0.5 \\
\hline
\end{tabular}

There is usually a large amount of acidity in the raw water due to the peat in the drainage area, and it is found that the

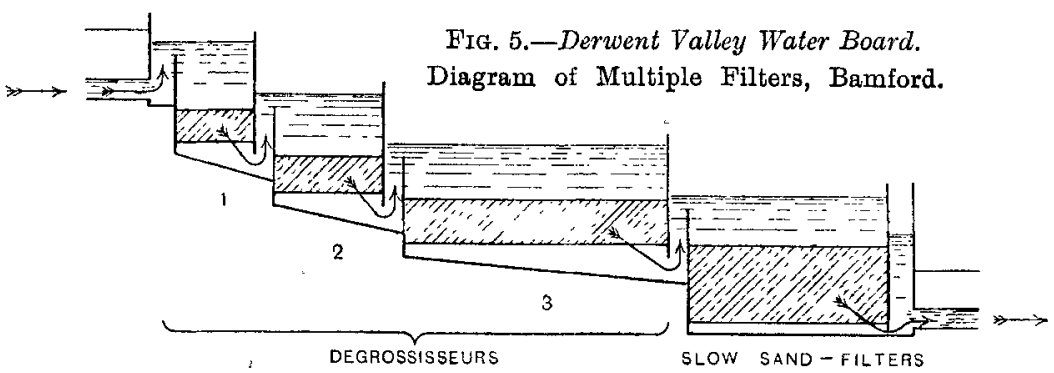

acid increases after heavy rains. The degrossisseurs, series $l$ and 2, contain crushed limestone as the filtering medium, which has been found to effect complete neutralization of the peaty acids in the water. In the third series the filtering medium is screened calc spar, and Leighton Buzzard sand is used in the final filters. The filters were first brought into use in 1912, and the following figures have been obtained as a result of the working of the installation in 1913 and 1914.

Test to ascertain the Effect of the Degrossisseurs on the Period between Scrapings of the Sand-Filters: Bamford Filters, Derwent Valley Water Board.

Water that had previously passed through the degrossisseurs was supplied to sand-filter No. 7. The filter was scraped on 
15th September 1914, and it again required scraping on 10th November 1914. Length of run, 56 days. Area of filter, 27,000 square feet. Quantity of water filtered, 67,512,000 gallons; average, $1,206,000$ gallons per 24 hours. Average speed, 0.298 foot per hour. Height of column passed between scrapings, $400 \cdot 71$ feet.

Sand-filter No. 2 was also supplied with water from the degrossisseurs during the same season, and worked for 57 days between scrapings. The quantity of water filtered was $83,774,000$ gallons, an average of $1,470,000$ gallons per 24 hours, or 0.363 foot vertical fall per hour. The height of the column passed between scrapings was 497 feet.

No. 1 filter was scraped on 18th September 1914, and was supplied with raw water. It required scraping four times during the period ending 16 th November 1914. During this period the filter was actually in use on 51 days. The total quantity filtered was $59,309,000$ gallons, or 1,163,000 gallons per 24 hours. The average quantity filtered between scrapings was $14,827,000$ gallons. The average speed, $0 \cdot 287$ foot vertical fall per hour. Height of column passed between scrapings, 88 feet.

In order to obtain an exact comparison, all the filters were stopped for scraping when the maximum loss of head of 3 feet 6 inches had been reached. Although in this particular installation the system of multiple filtration has only been partially adopted, it will be seen that the result of preliminary straining through three successive layers of gravel is to increase the life of the final filters between scrapings from $4 \frac{1}{2}$ to nearly 6 times, with a resulting great saving in labour.

The following Table shows the acidity in the raw water in a number of samples taken from the inlet to the degrossisseurs:-

Acidity in Terms of $\mathrm{cm}^{3}$ of $\frac{\mathrm{N}}{10}$

Solution of Sodium Carbonate

1914. required to neutralize

80 July $100 \mathrm{~cm}^{3}$ of the Water.

6 Aug. $0.23 \mathrm{~cm}^{3}$.

13 Aug. 20 Aug. 0.25, - 0.35, 0.27 


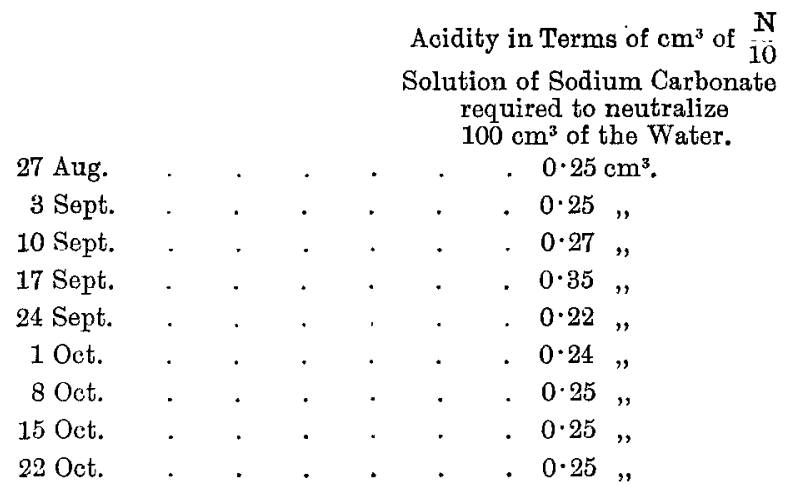

The raw water has always been acid, except for the period from 24th July 1913 to 11th September 1913, when the reaction of the weekly samples was neutral. This period was the close of the long drought of that dry summer. The effect of passing the water through the limestone in the first two series of degrossisseurs is to neutralize the acid completely, and to reduce to a safe figure the lead-dissolving power of the water. The hardness is naturally slightly increased.

The results of a test made on 1st January 1913 were as shown on page 258 .

The working expenses in connexion with the multiple filtration plant at Bamford have been found to be exceedingly low, and for the year 1913 amounted to $48.6 d$. per million gallons, or $0 \cdot 054 d$. per 1,000 gallons.

This figure, of course, includes the cleaning of the degrossisseurs, with maintenance of the oil-engine and blower used in cleaning, scraping of sand-filters, etc. The late Mr. W. B. Bryan gave the cost of working ordinary sand-filters at the works of the Metropolitan Water Board at $\frac{1}{1} d$. per 1,000 gallons, or about 5s. 11d. per million gallons.*

The filters at Bamford are constructed in concrete and brickwork throughout, with the exception of the apparatus for cleaning the degrossisseurs by air. This part of the work is in ferro-concrete.

\footnotetext{
* Proceedings, I.Mech.E., 1909, page 107.
} 
Results of Tests of Samples of Water from Bamford Filters at Different Stages of Filtration: Derwent Valley Water Board

\begin{tabular}{|c|c|c|c|}
\hline $\begin{array}{c}\text { Description of Sample. } \\
\text { 1st January 1913. }\end{array}$ & $\begin{array}{c}\text { Acidity in Terms } \\
\text { of } \mathrm{cm}^{3} \text { of } \frac{\mathrm{N}}{10} \\
\text { Solution of } \\
\text { Sodium Car- } \\
\text { bonate required } \\
\text { to neutralize } \\
100 \mathrm{~cm}^{3} \text { of the } \\
\text { Sample of Water. }\end{array}$ & $\begin{array}{l}\text { Hardness in } \\
\text { Degrees } \\
\text { on Clark's } \\
\text { Scale. }\end{array}$ & $\begin{array}{l}\text { Amount of } \\
\text { Lead dissolved } \\
\text { after } 24 \text { Hours } \\
\text { in Lead Pipe, } \\
1^{\circ}=\frac{1}{50} \text { Grain } \\
\text { of Lead per } \\
\text { Gallon of } \\
\text { Water. }\end{array}$ \\
\hline $\begin{array}{l}\text { Sample of water from } \\
\text { inlet to degrossisseurs }\end{array}$ & $0 \cdot 26$ & $\begin{array}{c}\text { Degrees. } \\
2 \cdot 0\end{array}$ & $\begin{array}{l}\text { Degrees. } \\
33 \cdot 0\end{array}$ \\
\hline $\begin{array}{l}\text { Sample of water after } \\
\text { passing degrossisseur } \\
\text { No. 1, containing coarse } \\
\text { limestone }\end{array}$ & 0.17 & $2 \cdot 3$ & $31 \cdot 5$ \\
\hline $\begin{array}{l}\text { Sample of water after } \\
\text { passing degrossisseurs } \\
1 \text { and } 2 \text {, No. } 2 \text { con- } \\
\text { taining medium grade } \\
\text { limestone }\end{array}$ & Noutral & $2 \cdot 75$ & $6 \cdot 3$ \\
\hline $\begin{array}{l}\text { Sample of water after } \\
\text { passing degrossisseurs } \\
1,2 \text {, and } 3 \text {, No. } 3 \\
\text { containing fine crushed } \\
\text { calcium spar }\end{array}$ & Neutral & $2 \cdot 9$ & $6 \cdot 3$ \\
\hline $\begin{array}{l}\text { Sample of water after } \\
\text { passing } 3 \text { degrossisseurs } \\
\text { and sand-filters }\end{array}$ & Neutral & $2 \cdot 9$ & $6 \cdot 6$ \\
\hline
\end{tabular}

The annual capital charges on the installation, calculated at $12,000,000$ gallons per 24 hours, or 4,380,000,000 gallons per annum, are $£ 18 s$. $2 d$. per million gallons $=0 \cdot 338 d$. per 1,000 gallons.

The total amount of crushed limestone used as the filtering and acid neutralizing medium in degrossisseurs 1 and 2 is 506 cubic yards. This material can be obtained locally at $6 s .6 \mathrm{~d}$. per cubic yard, but the actual cost of the material under the contract was $9 s$. per cubic yard, placed in the filters, or $£ 22714 s$. 
Careful note has been taken of the action of the acid water on the limestone, and after passing 9,000 million gallons of water through the filters the total loss was found to be 300 cubic yards, costing, at 9s. per yard, $£ 135=3 \cdot 6 d$. per million gallons, or $0.0036 d$. per 1,000 gallons. A certain amount of this loss is no doubt due to attrition during the process of cleaning the gravel by air, but, on the other hand, this simple method of cleaning effectively removes all deposit from every particle of the filtering medium, leaving the maximum surface of limestone exposed to the action of the acid water.

It is found that the water takes up just sufficient calcium carbonate to neutralize the acidity, so that the method is both safe and economical, as, if the alkali were measured and added, it might sometimes ocour that too little was added and sometimes too much. Under the system adopted at Derwent Valley the whole process is automatic and the cost exceedingly low, as no expensive apparatus has to be provided to add the lime. The cost of filtration at Derwent Valley is therefore $0 \cdot 396 d$. per 1,000 gallons, including working expenses, interest on sinking fund, and all outgoings.

Some notes on the use of sulphate of alumina with these filters for the purpose of removing colour are given in Appendix I (page 294).

\section{Accra, Gold Coast Colony, Fig. 6.}

This installation, although dealing with only 500,000 gallons per 24 hours, is very complete and provides for treatment of the water in six successive stages.* The source of supply is the small river Densu, which is much contaminated with water from swamps full of decaying vegetation. As a result of a series of analyses of the raw water, Mr. Bertram Blount estimated that the maximum organic impurity might be represented by the following figures:-

Oxygen consumed (4 hours at $80^{\circ} \mathrm{F}$ ) . . 1.00 part per 100,000 .

Albuminoid ammonia

- $0.05, ", "$

* Engineering, 5th November 1915. 
It is hoped to reduce these figures within safe limits by aeration and slow filtration without the use of chemicals. The whole of the installation is constructed of ferro-concrete and consists of four degrossisseurs in series and sets of five pre-filters and six slow sand-filters. A raw water reservoir holding twenty-four hours' supply is placed over the sand-filters, the floor of the reservoir being slightly higher than the inlet to the filtration plant. The reservoir is of the same area as the sand-filters and is carried on ferro-concrete columns. The spaces between the outer columns are filled in with ferro-concrete panels, so that light

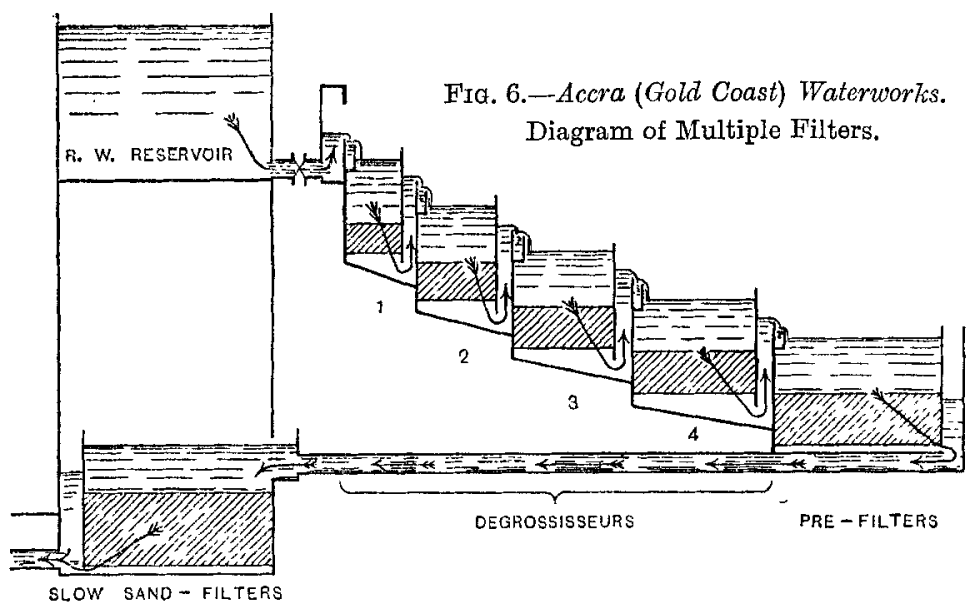

is excluded from the final filters. The pre-filters and also the degrossisseurs are fitted with apparatus for cleaning by air, which is supplied from an electrically driven blower. One native "boy" easily controls the plant. The combined filtering area of the degrossisseurs and pre-filters is 4,870 square feet, and of the sandfilters 12,200 square feet. A slow speed has been adopted throughout, as will be seen from the figures on the following page.

As the installation has only been working for a short time, it has not yet been possible to work it at its full capacity, but some notes on results recently obtained from a partial trial of the installation are given in Appendix II (page 296). 


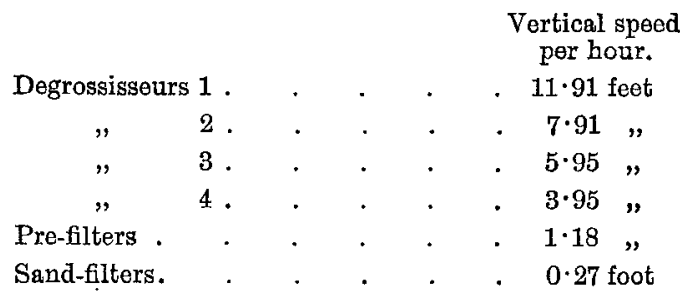

\section{Cawnpore Waterworks, Fig. 7.}

The filtering installation at Cawnpore, India, was constructed in 1882 , and consisted of three settling-tanks and open sand-filters,

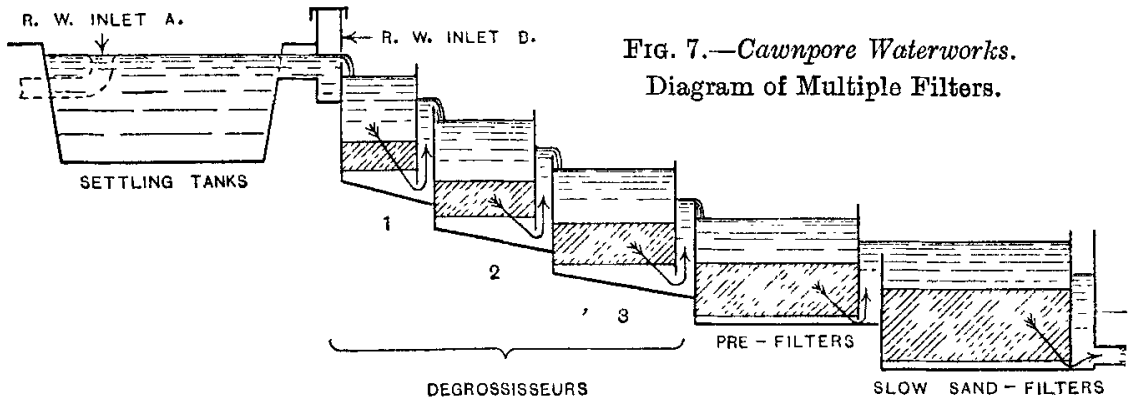

each 200 feet by 100 feet. In 1909 there were seven such filters, which were capable of dealing with $4 \frac{1}{2}$ million gallons daily at all seasons when supplied with water previously decanted in the settling-tanks; but to do this it was necessary to employ $140 \mathrm{lb}$. of sulphate of alumina at $£ 5128$. per ton for each million gallons treated. The raw water of the Ganges is always turbid, and exceedingly so in the monsoon season and for three months afterwards-that is to say, from July to December inclusive.

In 1910 it was decided to increase the capacity of the installation to 7 million gallons daily, and three schemes were considered :-

(a) An increase on the existing lines by the addition of a new settling-tank and five new sand-filters, estimated to cost $£ 10,416$. 
(b) Mechanical filters of the gravity type as " roughing filters," estimated to cost $£ 12,666$.

(c) The conversion of the installation into a multiple filtration plant by providing degrossisseurs and pre-filters and increasing the average speed on the final filters, at an estimated cost of $£ 11,466$.

Comparisons are sometimes made between the cost of various systems of filtration, and these are frequently misleading, as local circumstances are not taken into consideration. It may, therefore, be of interest to consider the local conditions in connexion with the three estimates given above. Mechanical filters are obviously more costly in India than they would be in Europe or America, as they require skilled labour for their manufacture, particularly if special nozzlès, gearing and other devices are employed, and they must be erected in India under skilled supervision.

On the other hand, Indian labour is cheap, and ordinary straight brickwork such as is required in the construction of sand-filters, etc., can be completed for $10 \mathrm{~s}$. per cubic yard for labour and materials. Ferro-concrete is expensive owing to the high cost of cement (from $£ 55 s$. to $£ 515 s$. per ton delivered at inland stations), and to the fact that skilled supervision is required; so that of the above estimates-

(a) Is lowest because only brickwork and earthwork were required.

(b) Is highest for the reasons already stated.

(c) Included a considerable amount of ferro concrete work and special fittings imported from Europe, which counterbalanced the advantage gained by constructing the walls of the filters in brickwork, and the total cost may be taken as equal to the cost of similar work in Europe.

As to working costs, scheme (a) would have cost the same per million gallons as the original plant; $(b)$ would have required nearly double the expenditure on sulphate of alumina per million gallons, and with frequent cleaning of the mechanical filters during the monsoon period night labour would have been necessary.

For the increased water supply at Cawnpore, scheme (c) was adopted on the recommendation of Messrs. James Mansergh and 
Sons, London. The multiple filters and certain modifications to the existing sand-filters were completed in the autumn of 1912, and the installation* has been under observation for two seasons. The plan Fig. 8 (page 264) shows the general arrangement of the settling-tanks, degrossisseurs, and pre-filters and the final filters. The dotted lines show the space which would have been occupied had the installation been enlarged on the original system of working with decanting basins and sandfilters. The general arrangements of the original plant have not been altered in any way, and the sand-filters can still be supplied from the settling-tanks.

The filters are drained by a double layer of standard bricks arranged over the whole surface of the floor. In the bottom layer the bricks are placed on edge in parallel rows leading towards the collecting drain constructed on the long axis of the basin. These rows of bricks are laid with a space of $6 \frac{1}{2}$ inches between each row. The upper layer consists of bricks on flat side, laid close together at right angles to those in the lower layer. The filtering materials consist of 2 inches of pebbles superimposed by a layer of 4 inches of coarse sand and 2 feet 6 inches of fine sand. The latter is obtained locally from the bed of the Ganges in the dry season, and is very much finer than the sand usually employed for slow sand-filtration. A photomicrograph of this sand is given, Fig. 13, Plate 1. Suitable "loss of head" gauges are fitted to each filter.

The multiple filters may be supplied direct from the raw water rising mains, or from the settling-tanks. As, however, the full water level in the latter is only 2 feet above the level of the inlet to the degrossisseurs, it will be seen that the tanks, which are 10 feet deep, cannot be used as decanting basins when used in combination with the multiple filters. The arrangement was adopted in order to avoid abandoning existing works representing a considerable capital expenditure. A small canal has been formed in the bank between settling-tanks 1 and 2, Fig. 8, and the bank between tanks

* A full description of these works as modified will be found in Engineering, 12th December 1913. 
Figs, 8 and 9.-Cawnpore Waterworks.

Plan of Filtration Plant,

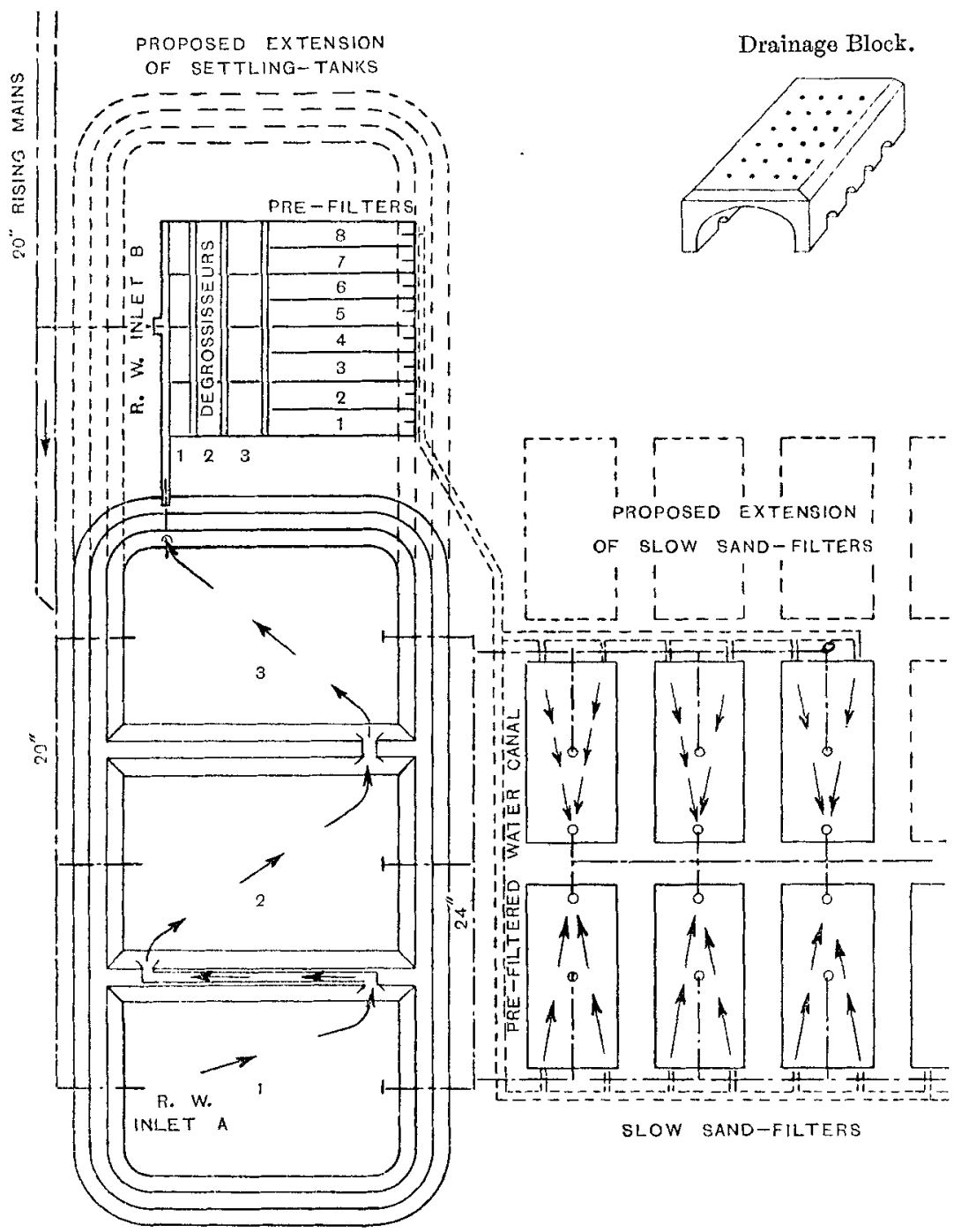

SETTLING - TANKS 
2 and 3 has been cut, so that by admitting water to tank No. 1 it may be circulated through the three tanks in the direction shown by the arrows. Careful experiments have shown that there is no advantage to be gained by this method of working, and the results obtained by supplying raw water direct to the degrossisseurs are generally better than those obtained with water previously circulated over the surface of the settling-tanks. The reasons for this will be discussed later on.

The multiple filters consist of three series of degrossisseurs, each of four units, and eight pre-filters. The degrossisseurs are cleaned by air supplied from a Root's blower driven by an oil-engine. The pre-filters are at present cleaned by hand, but have been arranged with the dividing walls 28 feet from centre to centre, on which rails may be placed to carry a travelling bridge with Boistel automatic scraper, as fitted to similar pre-filters at Paris, Roubaix, and elsewhere. By means of this apparatus* the filters may be scraped with the minimum amount of labour without emptying the basins.

The pre-filters are provided with a special form of drainage block, now largely employed with multiple filters where the speed of the water is somewhat higher than is possible in ordinary slow filtration. Fig. 9 (page 264) shows the form of this block, which is made in cement or terra-cotta. The blocks are perforated with small holes at intervals of 1 inch in each direction, so that the water has a tendency to fall vertically through the filtering materials over the whole surface of the filter. When solid blocks or ordinary bricks are employed with sand-filters, the water passes in the direction of the joints between the blocks, and experiment has shown that there is a marked improvement in the performance of sand-filters fitted with perforated drainage blocks over those with drains formed of solid bricks. A diagrammatic section of the filtering installation at Cawnpore is given in Fig. 7 (page 261).

The filtering surface is divided as follows: degrossisseurs, 12,250 square feet; pre-filters, 33,500 square feet; and final filters, 140,000 square feet.

* A description appeared in Engineering, 17th February 1911. 


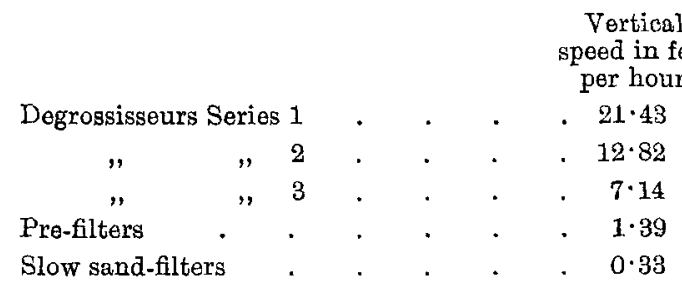

Careful records of the working of the Cawnpore filters have been kept for many years, and systematic observations of the working of the new installation were made during the hot weather and monsoon rains in 1913 and 1914. These observations were carried out without varying the ordinary routine of the waterworks in any special way. During 1914 the recorded observations were limited to the period from 20th May to 12th August; but as this covers the hot season and the monsoon period to the maximum rise of the Ganges, it is possible, by comparing the records for the same season for four successive years, to estimate the advantages of multiple filtration over ordinary sand-filtration following decantation. The results are shown by the Table on page 267.

In comparing the years 1913 and 1914, it should be stated that all the filters in use were scraped at the commencement of the period of observation in 1913, and the figure of $126 \cdot 11$ feet represents correctly the average amount of work done by each filter between scrapings, as expressed by the height of a column of water which had passed through. Figs. 10 and 11 (pages 268-71) record the working of the filters from 20th May to 12th August 1913 and 1914, and the days when the filters were cleaned are marked by shaded vertical columns. It will be noted that in 1914 each filter was cleaned only once, although they had all been working for considerable periods before the observations were commenced. The actual time of working of each filter was :-

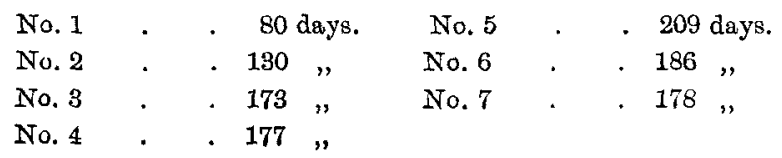


Records of Working of Sand-Filters: Cawonpore Waterworks.

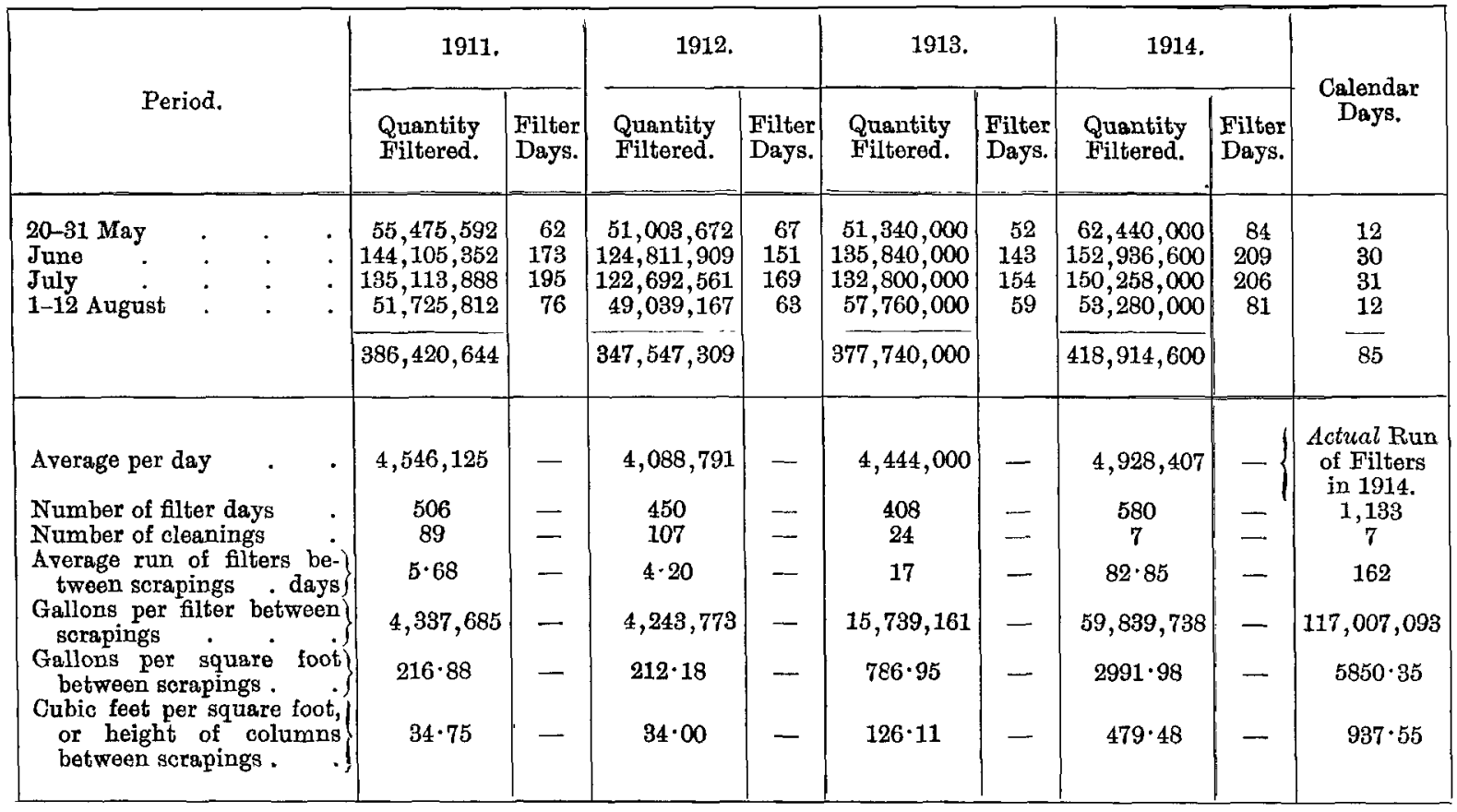


FIG. 10.-Cawnpore Waterworks, 1913. Daily Record of Working of Sand-Filters.

The Loss-of-head is shown to 36 inches only. In some cases it reached 44 inches. Where not shown, it is to be taken as exceeding 36 inches. The shaded columns indicate the dates when the Filters were scraped.

FILTER NOI.

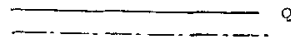

QUANTITY FILTERED.

C...... LOSS OF HEAD.

lis

JUNE.

MLY.

August.

1.000,000-

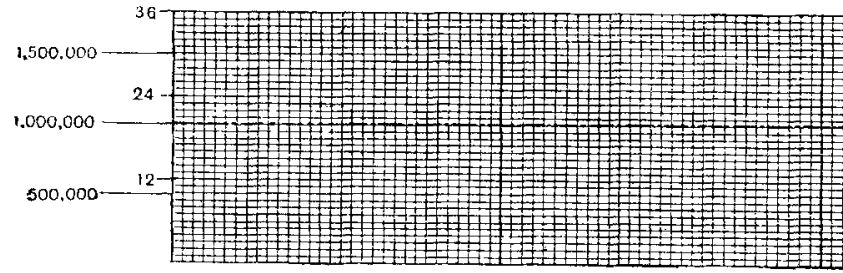

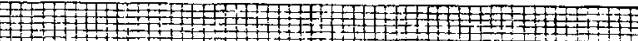

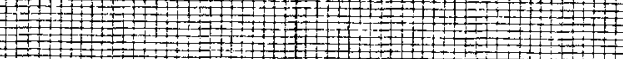

, NO2.

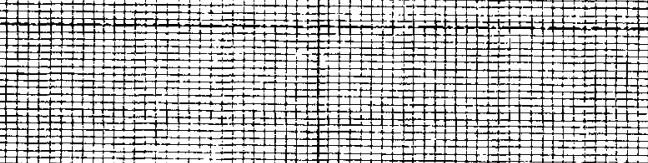

36 -

24 \begin{tabular}{c}
\hline \\
\hline
\end{tabular}

" No 3.

$12-$

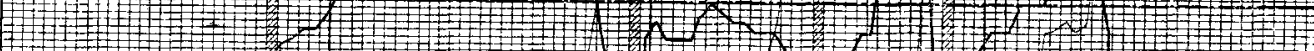

500.000

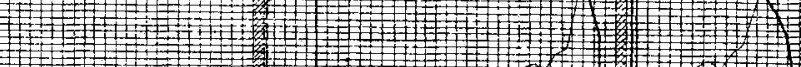

\begin{tabular}{l}
\hline $1+1$ \\
1
\end{tabular} 


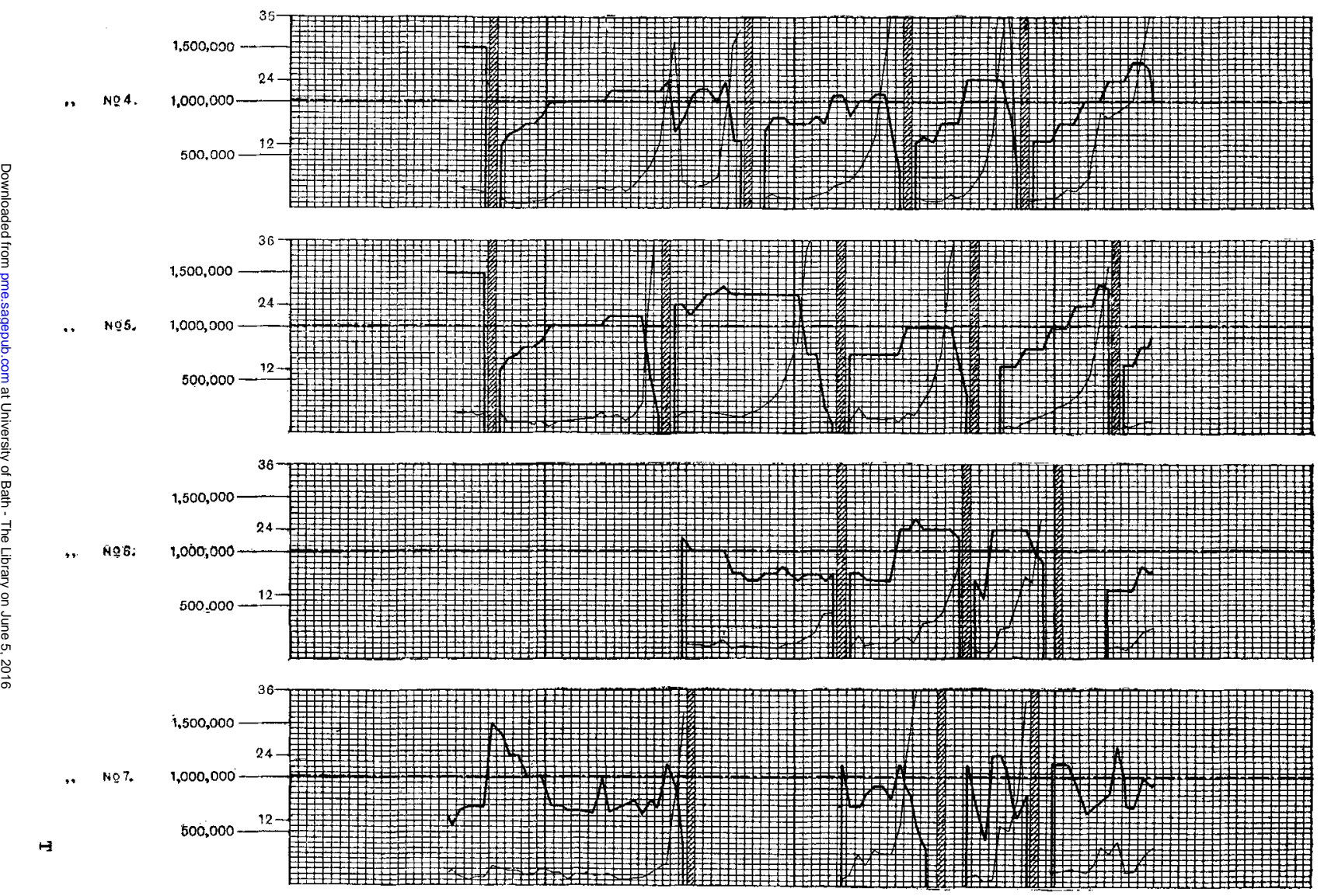


FIG. 11.-Cawnpore Waterworks, 1914. Daily Record of Worting of Sand-Filters.

The Loss-of-head is shown to 36 inches only. In some cases it reached 44 inches. Where

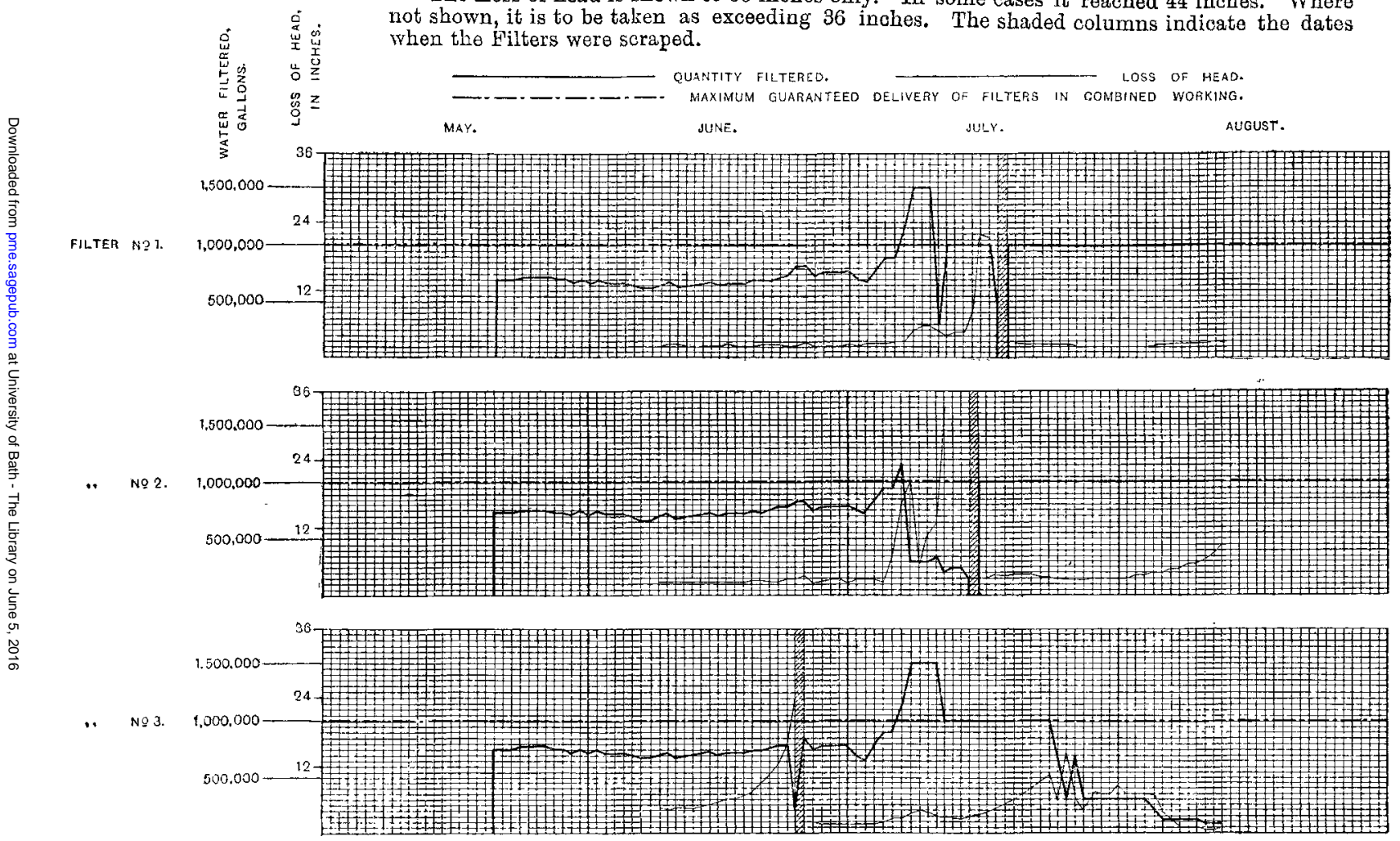


. No $4 . \quad 1,000,000$

$500,000-12-$

1 1

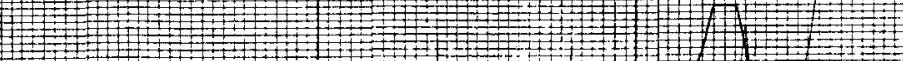
$1 \div+1+1+1+1$ $1+1+1$ $1+1$ $+1+1+1+2$

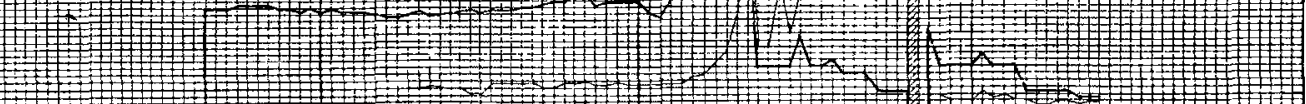

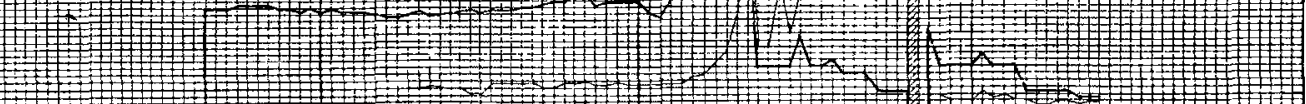

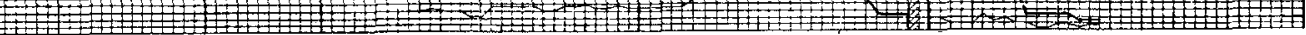

24

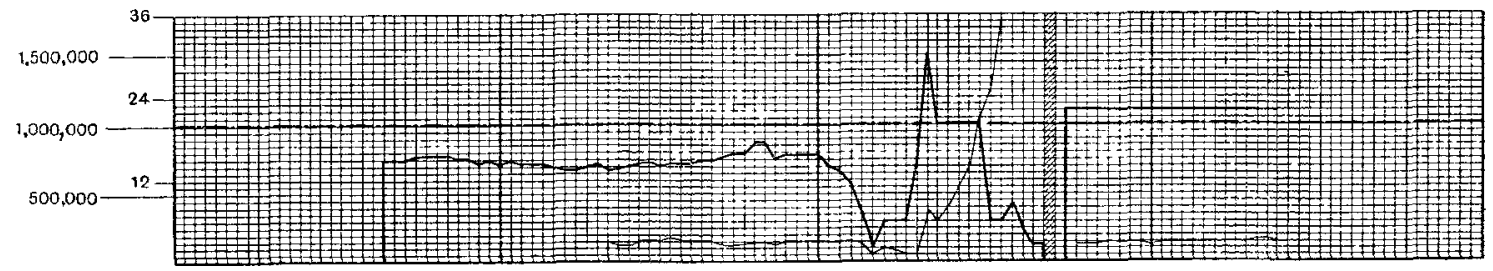

36

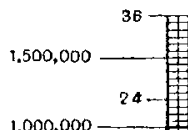

i) (4)

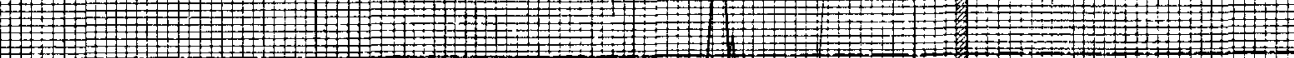

№6

$500,000-12-$ (1) $1+1$

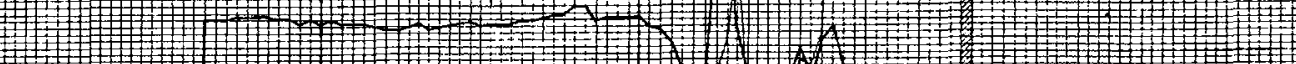

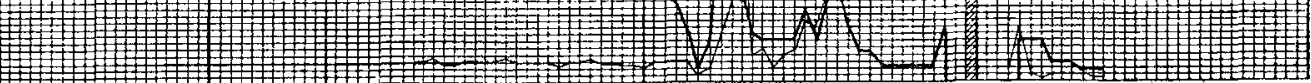

\section{(1)}

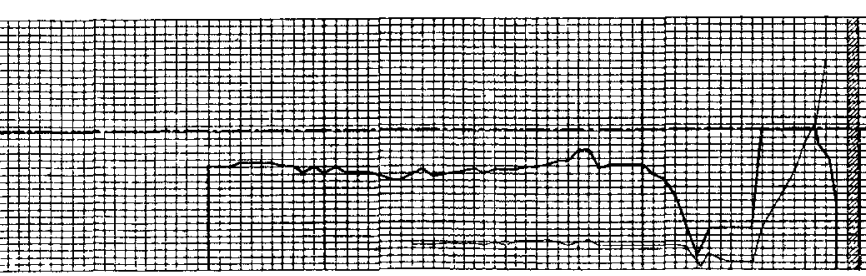

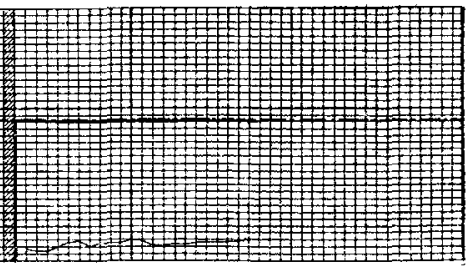


The average run was 162 days. Total filter days worked, 1,133; number of scrapings, 7 .

The average number of gallons passed through each filter was $117,007,093$, or $5,850 \cdot 35$ gallons per square foot. This represents a column of water 937.55 feet high, and this result was obtained during the most trying period of the year, and without the use of sulphate of alumina or any other chemical. For the whole year the average height of a column of water passed between scrapings is very much higher than this, as, except during the hot weather and monsoon, the final filters do not require cleaning.

Captain C. L. Dunn, I.M.S., who had charge of the observations on the working of the multiple, filters at Cawnpore in 1912-1913, reported to the Sanitary Board of the United Provinces as follows:- "It is evident that in the period commencing with the end of one monsoon until about one month before the breaking of the next, the final filters require no scraping or cleaning whatever." This shows a great improvement on the condition of affairs prevailing before the adoption of multiple filtration, when the same sand-filters had to be frequently scraped at all seasons of the year. In the year ending 31st March 1912 it was necessary to scrape the filters on 270 occasions, distributed over the year as follows: April 1911, 33 ; May, 42 ; June, 37 ; July, 22 ; August, 18 ; September, 13; October, 16; November, 14; December, 20; January 1912, 17 ; February, 20; March, 18. The total quantity filtered during this period was $1,426,860,274$ gallons, an average of $5,284,667$ gallons for each scraping. As the filters are each 20,000 square feet in area, this gives 264 gallons or $42 \cdot 34$ cubic feet per square foot between scrapings as an average for the whole year, compared with $34 \cdot 75$ feet for the same filters in May to August 1911 during the hot weather and rains, as shown in the comparative Table of four years' working already referred to. The figure of $937 \cdot 55$ feet for 1914 also covers May to August, so that by comparing the results for the same season in 1911 and 1914 , it will be seen that the same filters when forming the final units in a system of multiple filtration, in which no chemicals are used, are nearly twenty-seven times as efficient as when dealing with the same water previously treated with sulphate of alumina in settling tanks. 
Referring again to Figs. 10 and 11 (pages 268-71), these diagrams show, for each of the seven final filters, the quantity of water filtered each day, and the recorded "loss of head" required. The horizontal dotted line indicates a delivery of one million gallons per day for each filter, a quantity which represents the maximum calculated capacity of the installation. For local reasons the conditions in 1913 and 1914 were not favourable to obtaining the best results, and in both years there was a serious deficiency in the thickness of sand in the final filters, which should vary between 2 feet as a minimum to 2 feet 6 inches as a maximum. The actual thickness during the period represented by the diagrams was as follows :-

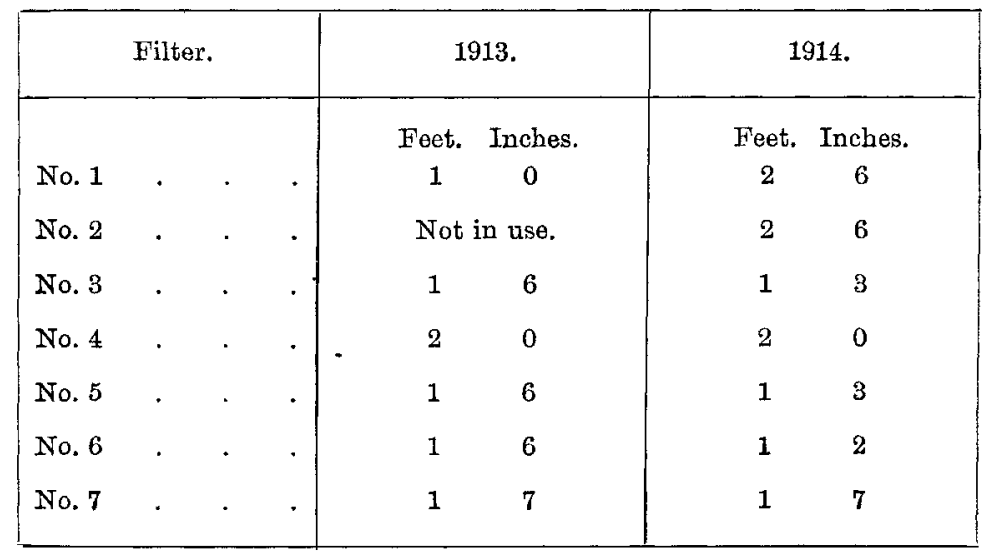

The number of scrapings during the monsoon of 1913 showed a great improvement over previous years, although the filters were in charge of a new and inexperienced staff, and were worked in a very irregular manner, as shown by the diagram, as, although the total daily demand varied very slightly, the speed of the filters in use was altered from day to day quite unnecessarily. It was found from observation that some of the pre-filters were not yielding the results anticipated, and analyses by Dr. Rideal showed an increase in the amount of free ammonia and oxygen consumed in the water after passing through certain units. This led to inquiries, and it was found that during the construction of the works a considerable 
quantity of imperfectly washed sand had been placed in four out of eight of the pre-filters. The remaining four pre-filters were filled with carefully washed sand, which was examined by the Author before being placed in the basins.

In the report of Captain Dunn, I.M.S., on his observations on the working of the installation during 1913, the figures given relate almost entirely to the results from pre-filters Nos. 1 to 4, which contained the unwashed sand. During June, July and August 196 analyses were made on effluents from these pre-filters, and the average number of bacteria on agar after 48 hours is given as 88 per $\mathrm{cm}^{3}$. An analysis from pre-filter No. 6 filled with washed sand gave 10 per $\mathrm{cm}^{3}$.

Fig. 10 (pages 268-9) shows that so long as the filters are worked at a regular speed, the line for loss of head remains nearly parallel to the line representing the quantity filtered. If, however, a sudden load is put upon the filter, it is found that the increased loss of head required for the higher quantity must be maintained even after the output is reduced, and the filter must soon be laid off for scraping. This appears to be due to compression of the upper layer of fine sand owing to the sudden increase in the load, as it is found that the sand-filters in a multiple-filtration plant can be run for very long periods without scraping if the speed is increased gradually when an extra output is required.

From 9th June to 8th August 1913 the installation was supplied with raw water delivered direct on to the degrossisseurs. For the remainder of the period the water was passed through No. 3 settling-tank, but as will be seen from the plan, Fig. 8 (page 264), the distance from the inlet to the settling-tank to the outlet to the degrossisseurs is very short, and consequently there was no particular advantage to be gained by this method of supply.

Although some useful information was obtained from the observations made in 1913, the Local Government of the United Provinces desired a more satisfactory test to be made, and requested the Author to arrange for further trials in 1914. Before these were commenced, it was decided to cut the banks of the settlingtanks as already described, in order to circulate the raw water over 
the surface of the three basins. The unwashed sand in pre-filters 1 to 4 was entirely removed and cleaned, but as this necessitated the use of the entire sand-washing plant for three months, it was impossible to bring the sand in the final filters to its proper thickness. Two filters, however, Nos. 1 and 2, were supplied with the full thickness, 2 feet 6 inches, of fine sand. The settling-tanks were very foul, and unfortunately they were not cleaned before the commencement of the trial.

Under these conditions the installation was placed in charge of a foreman who had previous experience of multiple filtration in hot climates, and he remained in charge during the period covered by the diagram, Fig. 11 (pages 270-1). The settling-tanks quickly gave trouble. By the end of May a dense growth of an alga, vaucheria sessilis, almost completely blocked the tanks, which are 10 feet in depth. As a consequence the water formed channels for itself round this mass of vegetation and scoured the mud from the sloping sides of the tanks. It will be evident that, had the water been passed direct to the final filters, the latter would have become choked very quickly with algæ developed from spores carried forward from the growth in the settling-tanks. But, as a matter of fact, the spores were completely arrested by the pre-filters, and for two years there has been no development of algæ on the final filters, which formerly were rapidly blocked from this cause.

As Fig. 11 shows, the work of filtration, during May and June, was divided evenly over the whole of the seven filters. Any variation in the demand was met by increasing the speed of all the filters, and it will be noted that the lines representing the daily delivery are nearly parallel. The lines showing the "loss of head" show a rise and fall corresponding with the speed of the filters except in the case of No. 3, the "loss of head" of which increased rapidly from 12th June to 24 th June, when the filter was scraped after working for 173 days. The thickness of sand on this filter was, however, only 1 foot 3 inches.

After the monsoon had set in, the Government desired the filters to be tested to 75 gallons per square foot per 24 hours, equal to $10,500,000$ gallons per 24 hours over the whole of 
the filters, a very severe test for an installation designed for a maximum output of $7,000,000$ gallons. As a result, the whole of the filters had to be scraped shortly afterwards, although the test enabled some useful information to be obtained as to the capabilities of the plant. In the case of filters Nos. 1 and 2, the only filters having the proper thickness of sand, the yield of No. 1 filter was increased from 35 gallons per square foot per 24 hours to 75 gallons with an increase in "loss of head" from 3 to 6 inches. On 10th July the output was suddenly dropped from 75 gallons to 15 gallons, and as suddenly increased on the following day to 50 gallons. The result of this irregular working was that in a few days the "loss of head" rapidly increased and the filter was scraped on 18th July. It was set to work again on the following day at its maximum designed speed of 50 gallons per square foot per 24 hours, and was kept at this speed until the conclusion of the trials on 12th August when the "loss of head" required to yield the maximum delivery was 3 inches only. Considering the turbidity of the Ganges at this season, the result shown is quite remarkable.

It is to be regretted that the severe test referred to above was applied to all the filters, as it has so far been impossible to ascertain, in a satisfactory manner, the maximum length of run which can be obtained from these filters under normal working conditions. No. 5 filter, though working with only 1 foot 3 inches of sand, had been working for 209 days when it was scraped on $22 \mathrm{nd} \mathrm{July}$, as a result of the sudden load put upon it on 10th July. After scraping, it was run continuously at 55 gallons per square foot per 24 hours with a "loss of head" of only 3 inches. Careful records were kept of details of the cleaning of the various units of the installation from 20th May to 12th August. The quantity of water filtered has already been stated, and from the information obtained during the trials, it is possible to calculate the actual labour involved in working the installation for each million gallons of water filtered. In considering these- figures, it should be remembered that they relate to a period of the year when the river reaches its maximum turbidity, and the working costs per million gallons for the whole year would be considerably less. 
Summary of Working 20th May to 12th August 1914:

Cawnpore Waterworks.

\begin{tabular}{|c|c|c|c|c|c|c|c|c|}
\hline \multirow[t]{2}{*}{ Dates. } & \multicolumn{3}{|c|}{ 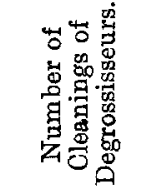 } & \multirow[t]{2}{*}{ Total. } & $\begin{array}{c}\text { Total } \\
\text { Time } \\
\text { Cleanings }\end{array}$ & 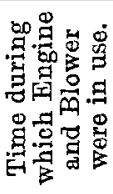 & \multirow[t]{2}{*}{ 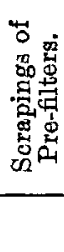 } & \multirow{2}{*}{$\begin{array}{l}\text { Quantity } \\
\text { Filtered. }\end{array}$} \\
\hline & 1 & 2 & 3 & & H. M. & H. M. & & \\
\hline 20-31 May & 23 & 23 & 23 & 69 & 113 & 45 & 4 & $62,440,000$ \\
\hline 1-30 June & 39 & 39 & 39 & 117 & $190 \quad 12$ & $80 \quad 13$ & 13 & $152,936,600$ \\
\hline 1-31 July & 13 & 25 & 32 & 70 & $128 \quad 38$ & $42 \quad 41$ & 23 & $150,258,000$ \\
\hline 1-12 Aug. & 5 & 16 & 12 & 33 & 56 & $23 \quad 54$ & 6 & $53,280,000$ \\
\hline Totals. & 80 & 103 & 106 & 289 & $487 \quad 55$ & $191 \quad 54$ & 46 & $418,914,600$ \\
\hline
\end{tabular}

In similar installations in Europe, where the degrossisseurs are cleaned by air, the work is easily performed by one man. At Cawnpore, where coolie labour can be obtained for two or three annas per day, three or four are employed, though the Author found that an intelligent Indian mistry could do the work by himself quite as well as a European workman. The above Table shows that the actual time occupied in cleaning the units of this part of the installation (that is, from the time the unit was isolated for cleaning to the time it was brought into use again) was 487 hours 55 minutes for $418,914,600$ gallons, or 1 hour and 10 minutes per million gallons. The time during which the oil-engine and blower were in use was 191 hours 53 minutes, or 27 minutes per million gallons. The blower absorbed about 8 b.h.p. and a 12 b.h.p. oil-engine was used.

The pre-filters were scraped 46 times, and as the area of each is 4,191 square feet, it was necessary to scrape 192,786 square feet while filtering 418,914,600 gallons, or 460 square feet per million gallons. Allowing for $\frac{1}{2}$ inch of sand removed at each scraping, it is necessary to remove, wash, and replace $19 \cdot 16$ cubic feet for each million gallons of water filtered. To estimate the labour required 
in the final filters, it is necessary to go beyond the period covered by the diagrams and Tables, and to take the quantity actually filtered from the previous scraping to the dates when the filters were scraped in June and July.

As already stated, the average run for the seven filters was 162 days, and the quantity filtered for each scraping $117,007,093$ gallons. The area of each filter is 20,000 square feet, so that 171 square feet of surface were scraped for each million gallons filtered, and allowing $\frac{1}{2}$ inch of sand removed at each scraping, it is necessary to remove, wash, and replace $7 \cdot 12$ cubic feet of sand for each million gallons filtered. It is, however, probable that the figures for the sand-filters will show considerable improvement in future, as the run of the filters, on which the average figures are based, was curtailed owing to the severe test to which they were put at the height of the monsoon season. Under the old conditions in 1912 it was necessary to scrape 20,000 square feet of surface for $4,243,773$ gallons filtered at the same season of the year-that is, 4,713 square feet per million gallons, or $196 \cdot 25$ cubic feet of sand to remove, wash and replace for every million gallons of water filtered, against $26 \cdot 28$ cubic feet from the pre-filters and sand-filters combined under the new system.

Settling-Tanks at Cawnpore.-The question of the advantage or otherwise of utilizing the settling-tanks at Cawnpore has received careful consideration since the multiple-filtration plant was completed. As already stated, the water is merely circulated over the surface of the three tanks, and the most that can be expected is that a certain quantity of the coarser silt will be deposited. But a very few grains of fine sand may easily weigh as much as many thousands of the extremely fine particles of silt or clay granules to be found in waters of rivers like the Ganges which flow through alluvial plains. A series of observations has been made at Cawnpore $(a)$ on the effect of decantation with sulphate of alumina; $(b)$ on the elimination of silt effected at each stage in multiple filtration; and $(c)$ on the effect of passing the water over the surface of the settling-tanks followed by multiple filtration. 
The following are some of the results obtained:-

Effect of Settling-Tanks used as Decanting Basins with Sulphate of Alumina as Coagulant.

\begin{tabular}{|c|c|c|c|}
\hline - & k & $\begin{array}{c}\text { No. } 1 . \\
\text { 18th July } 1912 .\end{array}$ & $\begin{array}{l}\text { No. } 2 . \\
\text { 30th August } 1912 .\end{array}$ \\
\hline Raw water & - & 79 parts per 100,000 & 101 parts per 100,000 \\
\hline After decantation & . & $28 \quad, \quad$, & $32,, \quad$, \\
\hline Percentage reduction & . & 64.55 per cent. & $68 \cdot 31$ per cent. \\
\hline
\end{tabular}

Effect of Multiple Filtration with Raw Water supplied direct to Degrossisseurs. No Chemicals used.

\begin{tabular}{|c|c|c|c|c|c|c|}
\hline \multirow{2}{*}{-} & & & \multicolumn{2}{|c|}{ No. 3. 4th Sept. 1912.} & \multicolumn{2}{|c|}{ No. 4. 13th Nov. 1912.} \\
\hline & & & $\begin{array}{c}\text { Parts per } \\
100,000 .\end{array}$ & $\begin{array}{l}\text { Reduction. } \\
\text { Per cent. }\end{array}$ & $\begin{array}{c}\text { Parts per } \\
100,000 .\end{array}$ & $\begin{array}{l}\text { Reduction. } \\
\text { Per cent. }\end{array}$ \\
\hline Raw Water & . & • & $121 \cdot 75$ & - & 37 & -- \\
\hline Degrossisseurs & & - & $46 \cdot 6$ & $61 \cdot 72$ & 25 & $32 \cdot 43$ \\
\hline$"$ & 2 & . & $31 \cdot 9$ & $73 \cdot 79$ & 20 & $45 \cdot 94$ \\
\hline " & 3 & . & $21 \cdot 1$ & $82 \cdot 66$ & 18 & $51 \cdot 35$ \\
\hline Pre-filters & - & • & $13 \cdot 4$ & $88 \cdot 99$ & 14 & $62 \cdot 16$ \\
\hline \multicolumn{2}{|c|}{ Slow Sand-filters } & • & $15 \cdot 7$ & $87 \cdot 10$ & 16 & $56 \cdot 75$ \\
\hline & & & \multicolumn{2}{|c|}{ No. 5, 1st July 1913.} & \multicolumn{2}{|c|}{ No. 6. 15th July 1913 . } \\
\hline Raw Water & . & 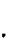 & 58 & 一 & 55 & - \\
\hline Degrossisseurs & s 1 & - & $50 \cdot 5$ & $12 \cdot 93$ & $27 \cdot 5$ & 50 \\
\hline$"$ & 2 & - & 25 & $56 \cdot 89$ & 26 & $52 \cdot 72$ \\
\hline$"$ & 3 & - & 20 & $65 \cdot 51$ & 19 & $65 \cdot 45$ \\
\hline Pre-filters & - & • & 14 & $75 \cdot 86$ & 15 & $72 \cdot 72$ \\
\hline
\end{tabular}




\begin{tabular}{|c|c|c|c|c|c|c|}
\hline \multirow{2}{*}{\multicolumn{2}{|c|}{ Raw Water }} & \multirow{3}{*}{. } & \multicolumn{2}{|c|}{ No. 7. 29 th July 1913.} & \multicolumn{2}{|c|}{ No. 8. 12th Aug. 1913.} \\
\hline & & & 180 & - & 88 & - \\
\hline Degrossisseurs & 1 & & 115 & $36 \cdot 11$ & $23 \cdot 5$ & $73 \cdot 29$ \\
\hline$"$ & 2 & • & 100 & $44 \cdot 44$ & $27 \cdot 5$ & $68 \cdot 75$ \\
\hline$"$ & 3 & . & 60 & $66 \cdot 66$ & 19 & $78 \cdot 4$ \\
\hline Pre-filters & . & . & 27 & 85 & 23 & $73 \cdot 86$ \\
\hline
\end{tabular}

Effect of Multiple Filtration with Raw Water circulated over surface of Settling-Tanks before delivery to Degrossisseurs. No Chemicals used.

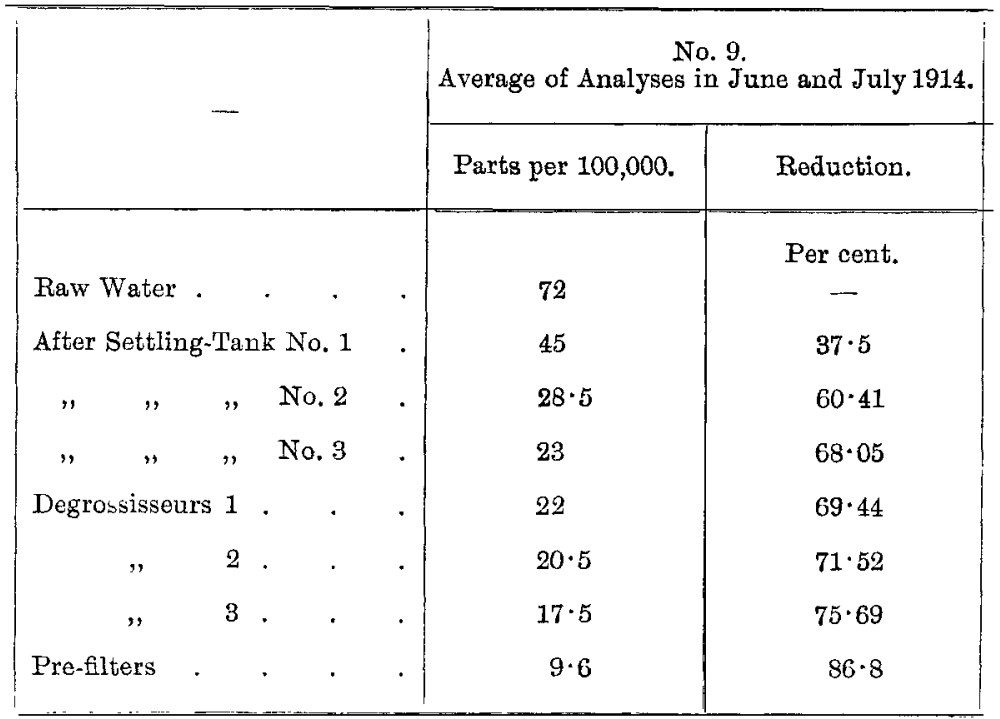

Of the above analyses, Nos. 1, 2, and 4 are by Dr. Hanbury Hankin, Government Bacteriologist, Agra; No. 3 is by Dr. S. Rideal, London; Nos. 5 to 8 by Assistant Surgeon Manohar Lal, Cawnpore; and No. 9 by Monsieur P. Bonzel of Lille, who superintended the arrangements for working the filters from May to August 1914. The average results in percentage reduction of total solids seem to show that the various methods of treatment of the 
water antecedent to slow sand-filtration may be classed in the following order :-

Per cent.

1. Settling-tanks as circulators, degrossisseurs and pre-filters, without chemicals

$86 \cdot 8$

$77 \cdot 66$

$75 \cdot 69$

$68 \cdot 3$

$68 \cdot 05$

$66 \cdot 43$

But a careful examination of the above Tables will show that the figure for total solids may be misleading, unless the nature of the silt is carefully considered. The settling-tanks are certainly more efficient in prolonging the life of the final filters when sulphate of alumina is used, and, although the analyses show that a greater weight of silt is removed if the water is first circulated through the settling-tanks, it must be remembered that this may be accounted for by a few large particles which, without the use of settling-tanks, would easily be arrested by the degrossisseurs in multiple filtration.

The great disadvantage attending the use of settling-tanks in any form is that the periodical cleaning of them is frequently neglected. So long as the suspended matters which have been deposited cannot be seen, their presence is forgotten, until an abnormal growth of algæ or diatoms appears on the final filters, developed from the vast accumulation of spores deposited in the settling-tanks. If the water is delivered direct on to the degrossisseurs in multiple filtration, the whole of the silt deposited on the gravel must be cleared away at frequent intervals, and there is no accumulation of solid organic matter in any part of the installation. In tropical countries especially, where the temperature of the water is comparatively high, it seems possible that pathogenic organisms could exist for a considerable time in an accumulation of organic matter at the bottom of a settling-tank, whereas any such accumulation is impossible in a multiple-filtration plant.

The comparative dimensions of the particles of sand in a filter, the interstices between the particles, and the silt and pathogenic organisms removed during the process of filtration, are illustrated 
by the photomicrographs on Plate 1. Of these, Figs. 12 and 13 show the surface of the sand used in the pre-filters and final filters at Cawnpore. Figs. 14 to 17, Plate 1, and Figs. 18 to 21,"Plate 2, show particles of silt in the raw water of the Ganges and after each successive stage of purification. These are from slides prepared from samples of the water taken at Cawnpore on 8th July 1914, when the installation was being worked at its maximum capacity of $7,000,000$ gallons per 24 hours. They are intended to show the largest particles which could be found in each preparation, and the number of particles in each photograph is of no value for purposes of comparison. The largest particle of silt in the raw water measures 0.18 millimetre at its greatest diameter, while in all the photographs a large number of particles measuring less than 0.001 millimetre may be seen. It will readily be understood that the loss of the large particles by decantation will make an enormous difference in a test for "total solids" by evaporation, without affecting the turbidity of the water in any marked degree or reducing the difficulty of effecting complete clarification by filtration.

The photomicrographs, Figs. 12 to 21, Plates 1 and 2, are by the Author, and are on exactly the same scale as given on the Plate. Pathogenic bacteria photographed on the same scale would be almost invisible. Figs. 22 and 23, Plate 2, therefore, which show B. Typhosus and Sp. Cholera Asiatica, are more highly magnified, and for purposes of comparison rings are drawn on the photographs of sand, Figs. 12 and 13, the rings representing the space which would be occupied by Figs. 22 and 23 if reduced to the same scale. The Author is indebted to Dr. E. J. Spitta for the photographs of bacteria which are from the original Plates used to illustrate "An Atlas of Bacteriology" by Drs. Slater and Spitta, and they are here reproduced by permission of the Authors.

On comparing the photographs of sand, Figs. 12 and 13, it will be noted that the red sand in the pre-filters is composed of much coarser grains than that used in the final filters, and it might be supposed that the water would pass more freely through the prefilters than through the final filters. A careful examination of both sands shows that this is not the case. 
The coarse sand is from the Jumna at Kalpi, and it will be seen that the grains are very smooth. The specific gravity of the sand is 2.57 and its proportions in mass are 63.8 per cent. solid to $36 \cdot 2$ per cent. void. The fine sand, Fig. 13 , is quartz sand from the bed of the Ganges at Cawnpore. It is very much finer than the sand usually employed in filtration, but the grains are sharp and angular. The specific gravity of this sand is $2 \cdot 63$ and the proportions 58.8 per cent. solid to $41 \cdot 2$ per cent. void. These figures show that a coarse sand does not necessarily allow a more rapid percolation of the water than a fine sand. As the void is divided about equally between the vertical and horizontal interstices, the actual area through which the water can pass downwards in filtration is only about 20 per cent. of the total area of the filter if a sharp sand is used, while it may be considerably less with a smooth sand. In referring to the speed of a filter it is convenient and customary to state the rate in inches per hour at which the water on the filter falls vertically, but the fact that the speed of the water through the sand-bed may be as much as five times that of the water above the sand is sometimes disregarded.

Loss of Head due to Friction through Sand-Bed.-In January 1911 the Author had an opportunity of testing one of the sandfilters at Cawnpore in order to ascertain the loss of head absorbed by friction with the very fine sand employed. The filter had been re-sanded to a depth of 2 feet 6 inches and was then filled with filtered water, which, for the purposes of the test, was run off at varying speeds.

At the normal maximum speed of 50 gallons per square foot per 24 hours the loss of head was 2 inches only. At a speed of 100 gallons it was increased to $7 \frac{2}{8}$ inches, while a loss of head of 15 inches was absorbed with a delivery of 162 gallons per square foot per 24 hours.

Daily readings of the thermometer taken during the hottest period of the year show that multiple filtration has no appreciable effect on the temperature of the water, although the whole of the filters at Cawnpore are exposed to the sun throughout the day. 
Cawnpore Waterworks, 1914. Temperature Records.

Degrees Fahrenheit. Averages of Daily Readings at 8 a.m.

\begin{tabular}{|c|c|c|c|c|}
\hline - & $\begin{array}{c}\text { Raw } \\
\text { Water. }\end{array}$ & $\begin{array}{c}\text { After Settling- } \\
\text { Tanks. }\end{array}$ & $\begin{array}{l}\text { After Pre- } \\
\text { filters. }\end{array}$ & $\begin{array}{l}\text { After Final } \\
\text { Filters. }\end{array}$ \\
\hline 20-31 May . & $81 \cdot 08$ & $82 \cdot 45$ & $81 \cdot 49$ & $81 \cdot 75$ \\
\hline 1-30 June . & $84 \cdot 5$ & $85 \cdot 4$ & $83 \cdot 73$ & $84 \cdot 7$ \\
\hline 1-31 July . & $83 \cdot 8$ & $84 \cdot 7$ & $84 \cdot 06$ & $84 \cdot 00$ \\
\hline 1-12 August & $84 \cdot 00$ & $84 \cdot 75$ & $84 \cdot 58$ & $84 \cdot 58$ \\
\hline \multicolumn{5}{|c|}{ Average for 85 Days. } \\
\hline 20 May-12 August & $83 \cdot 69$ & $84 \cdot 63$ & $83 \cdot 64$ & $84 \cdot 01$ \\
\hline
\end{tabular}

Chemicals are never employed in multiple filtration as coagulants to arrest the passage of bacteria. Bacterial action is relied on to effect nitrification by natural means, and it appears to be established that the bacteria themselves perish as a result of the disappearance of organic matter to support them. There is no physical reason why bacteria should not pass through a sand-filter, for if the particles of silt shown in photograph Fig. 21, Plate 2, will pass through a bed of sand 2 feet 6 inches in thickness, it is eviderit that bacteria which are infinitely smaller could also pass. There are now over 50 large installations in which the Puech system has been adopted-that is, where the formation of a film on the surface of the filtering medium is prevented. Yet it is shown by analysis that the effuent from such filters reaches a higher degree of purification than can be attained with sand-filters on which a film is allowed to form.

\section{Rapid Filtration.}

Rapid or mechanical filters have been adopted in many places during the past ten years, generally for the treatment of waters which are organically and bacteriologically pure, but which require special treatment by chemicals for the removal of peaty_acids or 
colour. In some instances, as at York and Cheltenham, they are used as scrubbers or roughing filters for the clarification of the water prior to filtration in open sand-beds. In both cases the speed adopted for the latter is unusually slow, at York 21 gallons per square foot per 24 hours (F. O. Oertel, Report to Government of the United Provinces, India, page 26), and at Cheltenham $31 \frac{1}{2}$ gallons per square foot per 24 hours (Proceedings of the Institution of Water Engineers, vol. xvii, page 74).

Mechanical filters have also been adopted by the Weardale and Consett Water Company as roughing filters and for treatment of a plumbo-solvent water with lime previous to sand-filtration.* Mr. Robert Askwith, the Engineer to the Company, has kindly supplied the Author with further information with regard to this plant. The sand-filters were formerly blocked rapidly with the lime used for neutralizing the peaty acids in the water. The roughing filters, which have a capacity of 2,000,000 gallons per 24 hours, cost $£ 3,228$ complete. In the article referred to, it is stated that when this class of plant is used by itself for filtering, it is rated at only half this capacity, so that the cost would then be $£ 3,228$ per million gallons. The quantity of lime used averages $95 \mathrm{lb}$. per million gallons, and the cost of lime is $£ 148$. $3 d$. per ton. The roughing filters are cleaned once in two days. The final filters are worked at an average speed of 43 gallons per square foot per 24 hours.

A rapid filtration plant of enclosed or pressure mechanical filters has recently been completed at Oldham, and is described in The Engineer, 30 July 1915. The total capacity of the installation is given as $3,360,000$ gallons per 24 hours, and the cost complete with auxiliary plant as $£ 20,000$, or $£ 5,952$ per million gallons. The speed adopted is 122 gallons per square foot per hour. Lime and aluminoferric are the chemicals used.

It is rare to find high-speed filtration relied upon as a single line of defence against water-borne diseases, and in India and elsewhere the resuits have not been satisfactory where rapid filters alone have been used for the treatment of polluted waters. The

* A description of these roughing filters appeared in The Engineer, 28th May 1915. 
system was tried in India, at Naini-Tal, for the treatment of water derived from a series of springs, the majority of which showed signs of pollution. Tests of the system were ordered by the Government and carried out in 1912 by Captain C. L. Dunn, who described the result of his investigations in a Paper read before the All India Sanitary Conference held at Madras in November 1912. The tests of the installation were carried out over a period of nearly five months under varying meteorological conditions. Captain Dunn stated "that on increasing the amount of sulphate of alumina the efficiency was greatly increased, but that coliform bacilli could still be recovered from $1 \mathrm{~cm}^{3}$ of the water which had passed through the filter." At the same Sanitary Conference, Major W. Clemesha, I.M.S., Sanitary Commissioner for the Province of Bengal, presented an interesting report on his investigations in the use of rapid filters in his district. This report deals with mechanical filters of the pressure and gravity type.

Major Clemesha does not consider the pressure filter safe under any circumstances when dealing with a polluted water, though he favours the gravity filter. He sums up the advantages and disadvantages of the two types as follows:--

\section{Pressure Filters.}

Advantage.--They are a very useful and compact arrangement for improving the appearance of small quantities of water that is already bacteriologically safe, for they remove many of the bacteria and a great deal of suspended matter and silt.

Disadvantages. $-(a)$ In order to get a decent result from a bacteriological point of view, the head on the filter should never fluctuate. This is extremely difficult to bring about mechanically.

(b) In some installations where settlement is impossible, the difficulties of adding the correct amount of alum are very considerable, and without the proper use of alum the filters give little purification.

(c) Pressure filters cannot be constructed with a greater diameter than 8 feet, hence they are practically useless for large installations on account of the initial cost, which for large installations of, say, 10,000,000 gallons per day would be absolutely prohibitive.

(d) It is practically impossible to run the filter at a constant rate of discharge. This is necessary if high bacteriological purity is desired. 


\section{Gravitx Finters.}

(a) A gelatioous film of aluminium oxide is added to the top layer of the sand in order to remove bacteria. This is brought about by adding alum to a water containing the oxycarbonate of lime.

(b) All gravity filters to give good results must work at a constant head and flow per square foot of surface until they become choked, when re-washing is necessary.

Advantages.-(1) A mechanical gravity-filter is capable of giving a pure water at the rate of 100 gallons per square foot per hour. This is fifty times as fast as an ordinary slow sand-filter of the same area which yields about two gallons per square foot per hour. It will be perfectly obvious that in certain places a small compact installation may possess many advantages as compared with the amount of space taken for slow sand-filters.

(2) With proper working there can be no doubt that a very pure water is obtained with this type of filter.

(3) The initial cost of these filters is considerably less than slow sandfilters.

(4) The amount of trouble caused by adverse conditions, such as a very muddy water, is overcome with much less difficulty and less deterioration in the quantity of the water than in slow sand-filters.

Disadvantages.-(1) All filters, including slow sand-filters, are liable to accidents; therefore the water on arrival should have passed the safety change. By this $I$ do not mean that it should be free from all traces of pollution, but that the true fæcal nature of the bacteria should have been altered by natural forces.

(2) The filters require washing up, and filtered water has to be provided for this.

(3) In places where the amount of silt is very great, the amount of water required for washing may at times reach as much as 20 per cent. of the total output of the plant.

(4) The working charges of these filters are high:-(a) The whole of the water to be pumped has usually to be raised to a greater height than is necessary for slow sand-filters. (b) The cost of alum is a big item. (c) The cost of pumping wash water is also a source of expense.

It would appear, however, that the advantages enumerated above relate to filters dealing with waters which have already been decanted with sulphate of alumina for twelve to fifteen hours, and Major Clemesha does not rely on rapid filtration unless the water before arriving at the filter has "already passed the safety 
change." It is clear that working costs may amount to a figure which, if the annual charge is capitalized, will far outweigh any initial saving in cost of construction over slow sand-filters. Also it will be seen from Major Clemesha's statement that, in extreme cases, in order to provide the amount of filtered water necessary for washing, the initial cost must be increased by one-fifth, and the annual working expenses also increased considerably, while at certain seasons only 80 per cent. of the water treated is available for the supply.

In effect, all that is here claimed for rapid filtration is, that at a high cost for chemicals and working expenses it will still further purify a water which has already passed the safety change by previous treatment.

With rapid filtration any reduction in organic matters in solution must take place during the decantation of the water before filtration, as the high speed adopted does not allow of nitrification during the passage of the water through the filtering materials, while the nitrifying organisms which might effect a chemical change are absent from the filter bed owing to the frequent disturbance of the sand for cleaning.

Much interesting information as to the comparative cost and efliciency of slow and rapid filters is contained in reports presented by the Edinburgh and District Water Trust in 1910-1912. At Edinburgh in $1911,3,157,000,000$ gallons were treated by slow sand-filtration, and $668,000,000$ gallons by rapid filtration with sulphate of alumina. The results were carefully compared and a report issued by Messrs. Ritchie and MeGowan. It was unfortunate that, during the period over which the inquiry extended, the raw water treated by rapid filtration was, from the chemical standpoint, relatively pure.

Filtration had practically no effect on the saline constituents in the water or on the free ammonia.

From the bacteriological standpoint, the raw water during the period of observation contained a very considerable number of bacteria developing at blood heat. It was also constantly under suspicion of containing excretal bacteria in relatively small amounts of the water, viz., one to ten cubic centimetres. 
The rapid filtration process did not satisfactorily remove organisms of the excretal type, and did not bring the filtered water up to the standard degree of purity usually required in potable waters, viz., that the water should not contain more than 100 bacteria per cubic centimetre.

There is evidence that after being washed, the filters did not at once attain their maximum capacity for acting on the water, and that at the end of the twenty-four hour period they were again working unsatisfactorily.

A comparison of nineteen observations on samples of effluent from the slow sand-filters and of twenty observations on samples from the rapid filters gave the following results :--

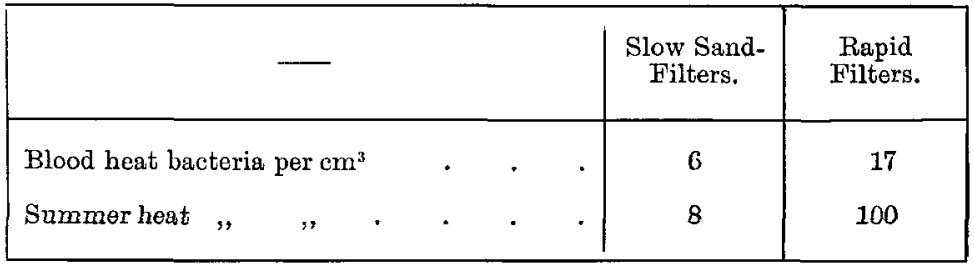

The general conclusions arrived at by Messrs. Ritchie and McGowan included an emphatic expression of opinion that the slow sand-filter is much more efficient as a bacterial purifier than the rapid filter.

A second report by the engineers to the Edinburgh and District Water Trust is equally interesting as affording a comparison between the cost of construction and working of slow and rapid filters in the same district, when the cost of labour is relatively the same for both systems.

From this report it would appear that the results from the rapid filters, referred to in the report of Messrs. Ritchie and McGowan, were obtained from a water treated in settling-tanks previous to filtration. The cost of filtration is stated in the engineer's report as follows :-

The capital cost of the six more recently constructed slow sand-filters was $£ 45,870$, and their total annual cost was $£ 2,514$, while the total quantity of water filtered by them was $3,157,000,000$ gallons. But to get really efficient filtration, the six filters should not pass more than about 2,520,000,000 gallons per annum, and that at $£ 2,514$ would be equal to 20 s. per million gallons.

Regarding the rapid filters, the total capital cost of twelve 8-feet filters, 
without taking into account any pipes, or drains, or land, for the filter-house and settling-tanks, amounted to $\$ 6,660$. The annual cost was $\$ 867$, and the total quantity of water filtered was $668,000,000$ gallons, that being equal to 26s. per million gallons; but the filters were capable of dealing with $2,000,000$ gallons per day, equal to $730,000,000$ gallons per annum. If the filters had been worked at their maximum capacity the result would have been $730,000,000$ gallons filtered for $\$ 867$, equal to $23 s$. $9 d$. per million gallons. It would therefore appear that the cost of filtering by ordinary sand-filtration might vary from 16s. to 20 s. per million gallons as compared with $24 s$, to $26 s$. per million gallons for rapid filtration.

The information available as to the comparative efficiency of slow and rapid filters when used as a single line of defence against water-borne diseases shows that the advantage is entirely with the slow filter, which without artificial aids will effect bacterial purification with greater regularity and certainty than the rapid filter, while it does not appear possible that nitrification can take place in the rapid filter, because the nitrifying organisms are removed at the very commencement of the process of straining.

Conclusions.-Rapid or mechanical filtration is therefore an entirely artificial process; the mechanical action of a gelatinous film is relied upon to eliminate bacteria by straining, and organic purification is brought about by using oxide of iron or other substances as a filtering medium or by chemical treatment of the water before or after filtration.

Multiple filtration aims at the complete clarification of the water by pre-filtration before final treatment by the well-known process of slow sand-filtration. By preventing the formation of a film on the surface, an endeavour is made to establish nitrifying action throughout the whole mass of the sand and to maintain the filter in this condition for the longest possible period. So far as bacterial purification and reduction of organic matter in solution are concerned, these are effected in multiple filtration by natural means. It is therefore important that the final sand-filters in this system should be as deep as possible, having regard to convenience in working, as the greater the depth, the more time will there be for the nitrifying action to take effect. 
As regards the cost of filtration, although it is frequently claimed that the capital cost of mechanical filters is less than that of slow sand-filters, it must be remembered that, in England at any rate, mechanical filters have chiefly been adopted in the case of upland waters of comparative purity, while polluted river waters are usually treated by the method of slow sand-filtration. It is obvious that the more polluted the water, the more elaborate must be the means of purification provided, and it is probable that for any given water there is little to choose between the capital cost of slow or rapid filters if both are provided on a sufficient scale to effect satisfactory purification.

The claim that mechanical filters can be cleaned more rapidly and at less cost than open sand-beds is fallacious. A given number of cubic feet of turbid river water will contain sufficient matter in suspension to block one square foot of filter surface, whether of a slow or rapid filter. If, therefore, a mechanical or rapid filter has one-hundredth part the area of a slow sand-filter, it will require cleaning one hundred times for one scraping of the slow filter supplied with the same water if no coagulants are used, but if a coagulant is used the mechanical filter will become blocked still more rapidly, as a considerable amount of the available "loss of head" is required to force the water through the artificial film on the filter.

The figures already quoted seem to show that, under equal conditions, the total cost of rapid filtration is greater than that of slow filtration in open beds. In multiple filtration the working costs are reduced to a minimum, as the final filters only require scraping at rare intervals, while with air-cleaning for the gravel beds, and a travelling scraper for cleaning the pre-filters, an installation capable of dealing with several million gallons per day can be controlled by one man, except on the rare occasions when it becomes necessary to scrape a final filter. But it is now recognized that pure water must be supplied at whatever cost, and the most important question is that of safety.

The Author has endeavoured to show that there are in theory and practice two methods of filtration, rapid and slow, and as 
success with high speeds necessitates the use of a coagulant film, the question of the "filtering film" is really the dividing line between the two methods. In dealing with waters liable to contamination, it would appear that greater safety is secured by adopting natural methods of purification by slow speed filtration than by economizing space, increasing the speed, and endeavouring to attain purification by artificial means. If the slow speed of the open sand-filter tends to greater security, this should outweigh all other considerations in the design of an installation for treating water for potable supplies.

Aids to Filtration.-In recent years many experiments have been made with various methods of sterilizing water in order to satisfy the demand for a water which would show zero as a result of a laboratory bacteriological test. The three methods which have been adopted are : (a) Chemical sterilization; $(b)$ Ozone ; $(c)$ Ultraviolet light. There can be no doubt that it is possible, by the careful application of any of these methods, to destroy all bacteria in a polluted water.

In the first method either chloride of lime or chloride of potash is used in sufficient quantity to destroy the bacteria. These chemicals must be employed before filtration, which is necessary to clarify the water and remove the chemical employed for sterilization. In this case, as all the bacteria including nitrifying organisms are destroyed as a preliminary to purification, there can be no reduction of organic matters in solution by nitrification in the subsequent process of clarification, so that the system is hardly applicable to the treatment of river waters liable to organic contamination. Chloride of lime is sometimes added to a water after filtration in very minute doses, but as Dr. Adolf Kemna frankly states, this is simply with a view of still further reducing the number of microbes, and he "is distinctly of opinion that there is no hygienical necessity for this in the case of a carefully filtered water, but it is an extra precaution, and is 'worth while, in that it gives the low bacterial 'counts' in which some of the local hygienists seem to revel." Dr. Kemna is referring to the practice at the Antwerp Waterworks.*

* Transactions, Institution of Water Engineers, vol. xvii, page 216. 
The systems of sterilization by ozone or ultra-violet rays are applied after filtration. The methods of application of these and also of the chlorine treatment were carefully tested at Marseilles during the summer of 1910.* Later developments of ozone and light treatment on the Continent had for their object the reduction in the area of the filter-beds used for clarification of the water, or an increase in the output from existing beds by increasing the speed while relying on sterilization for bacteriological purification. It should be stated that in order to obtain complete sterilization with ozone or ultra-violet light treatment, the water must first be rendered absolutely free from all matters in suspension, and with the latter method colour must also be eliminated. But at present the installation of either system costs more than the most elaborate filtration plant for treating a given quantity of water, while the working costs are many times heavier.

It seems to be established also that if a water containing organic matters in solution is sterilized, a sample from the sterilizer may show satisfactory bacteriological results on testing, while the same water after storage will show a very high bacterial content. In Engineering, 15th August 1913, there appeared a Table compiled from the weekly returns from the Paris Municipal Laboratory at Montsouris. This shows that at St. Maur the samples taken after sterilization by ozone gave on three occasions the low figure of 1,1 , and 4 microbes. per $\mathrm{cm}^{3}$, while samples of the same water taken from the delivery mains gave 144,420 , and 168 microbes per $\mathrm{cm}^{3}$ respectively. The explanation seems to be that in waters containing much organic matter in solution, nitrifying bacteria which gain access to the water after sterilization will continue to multiply until the organic matter is reduced by their agency, when the organisms themselves will disappear.

Rapid filtration can no doubt effect the complete clarification of water with the aid of chemicals and coagulants. Reduction of organic matters may be brought about by chemical treatment, and bacteria can be eliminated by various methods of sterilization. But

* Engineering, 27th January and 3rd February 1911, 
slow sand-filtration still remains the only method which, without artificial aid, will effect clarification, reduction of organic matters by nitrification, and elimination of pathogenic organisms.

The Paper is illustrated by Plates 1-2 and 11 Figs. in the letterpress, and is accompanied by two Appendixes.

\section{APPENDIX I.}

Notes on ax Experiment with Sulphate of Alumina for the Removal of Colour at the Multiple-Filtration Installation of the Derwent Valley Water Board a? BaMFord.

For this experiment a complete set of degrossisseurs was used, or one-fourth of the whole, and the quantity of water treated was $3,000,000$ gallons per 24 hours, representing the maximum speed for which the installation was designed.

The filtering materials originally in use were entirely removed and replaced by much finer materials, as follows:-

First strainer.- The coarse crushed limestone, $\frac{3}{4}$-inch gauge, was replaced by a bed of fine calc spar 12 inches thick which had passed through a sieve of 17 S.W.G., 4 meshes to the lineal inch, and was retained on a sieve of 18 S.W.G., 5 meshes to the lineal inch.

Second strainer.-The medium crushed limestone, $\frac{1}{2}$-inch gauge, was replaced by a bed of fine calc spar 12 inches thick, which had passed through a sieve of 18 S.W.G., 5 meshes to the lineal inch, and was retained on a sieve of 26 S.W.G., 16 meshes to the lineal inch.

Third strainer.-The finely crushed calc spar, $\frac{1}{4}$-inch gauge, was replaced by a bed of Leighton Buzzard sand 18 inches thick, screened 
through a sieve of 18 S.W.G., 5 meshes to the lineal inch, and retained on a sieve of 28 S.W.G., 24 meshes to the lineal inch.

A solution of sodium carbonate was first added to the water at the inlet to the main distributing channel to neutralize the acidity and make it slightly alkaline. The quantity of sodium carbonate used was about 1 grain per gallon.

The sulphate of alumina was added to the water at the inlet to the first strainer, the quantity used being $1 \frac{1}{4}$ grains per gallon.

It was found that the water after passing the three strainers was free from stain, and the effect of the treatment was to convert the brown and turbid raw water into a clear water of a pale bluish green when examined in a 2-foot glass tube.

The available loss of head on each of the first two strainers is 12 inches only, and on the pre-filter of sand 2 feet; these heads were absorbed after 48 hours, and it became necessary to clean the beds after treating 6,000,000 gallons of water. The existing air-cleaning plant, designed for use with coarse gravel, was found sufticient for washing the fine gravels and the sand bed in about $4 \frac{1}{2}$ hours. Raw water was used for flushing the beds during cleaning, the quantity used being about 5 per cent. of the water filtered. There was no precipitate (hydrate of alumina) in the treated water for the first 40 hours, when a very small quantity appeared.

The above information has been supplied to the Author, who wishes to point out that the installation was designed for use with much coarser filtering materials in the degrossisseurs than those employed during the experiments. Unfortunately, there are no pre-filters at Bamford between the degrossisseurs and the final filters, and the quantity of chemicals used was considerably in excess of what is required when using chemicals for the removal of colour in installations in which a pre-filter is provided.

In such cases sodium carbonate, if required, can be mixed with the water after the turbidity has been reduced in the first strainer, and the sulphate of alumina added at a later stage.

The experiments are interesting as showing that colour can be completely removed by multiple filtration if desired, while the fact 
that installations of this type are divided into a large number of compartments in successive stages secures a thorough mixing of the chemicals employed and consequent economy in the quantity required, while there is an obvious advantage in being able to add the chemicals at any stage of the multiple process of filtration.

\section{APPENDIX II.}

Notes on Some Results of the Working of the MultipleFilmation Plant at accra, Gold Coast Colony.

Owing to local conditions it has not yet been possible to work this installation at its full capacity. Chemical analyses have been made since October 1915 on samples from the various units of the plant working at speeds varying from 100,000 to 250,000 gallons per 24 hours, but with the area of the final filters reduced so as to give a rate of filtration equal to or above the designed speed.

The raw water has been found to be much more impure than had been supposed from the figures quoted by the Author of the Paper in the brief description of the installation.

Out of fifty-nine samples of raw water taken at various points between the river intake and the inlet to the filters, thirty-one samples, or over 52 per cent., gave a figure for albuminoid ammonia in excess of 0.05 part per 100,000 , the highest figure being 0.074 and the average of the thirty-one samples referred to giving 0.059 part per 100,000. The organic impurity of the water is therefore considerably greater than had been supposed, while the effect of storing the water in reservoirs has the effect of increasing the amount of albuminoid ammonia.

On three occasions series of samples have been taken of the water at the inlet to the filters and of the treated water after each stage of filtration. The samples were taken at such intervals of time that the analyses relate to the same water in its passage through the whole installation. 
The following Tables show the results obtained :-

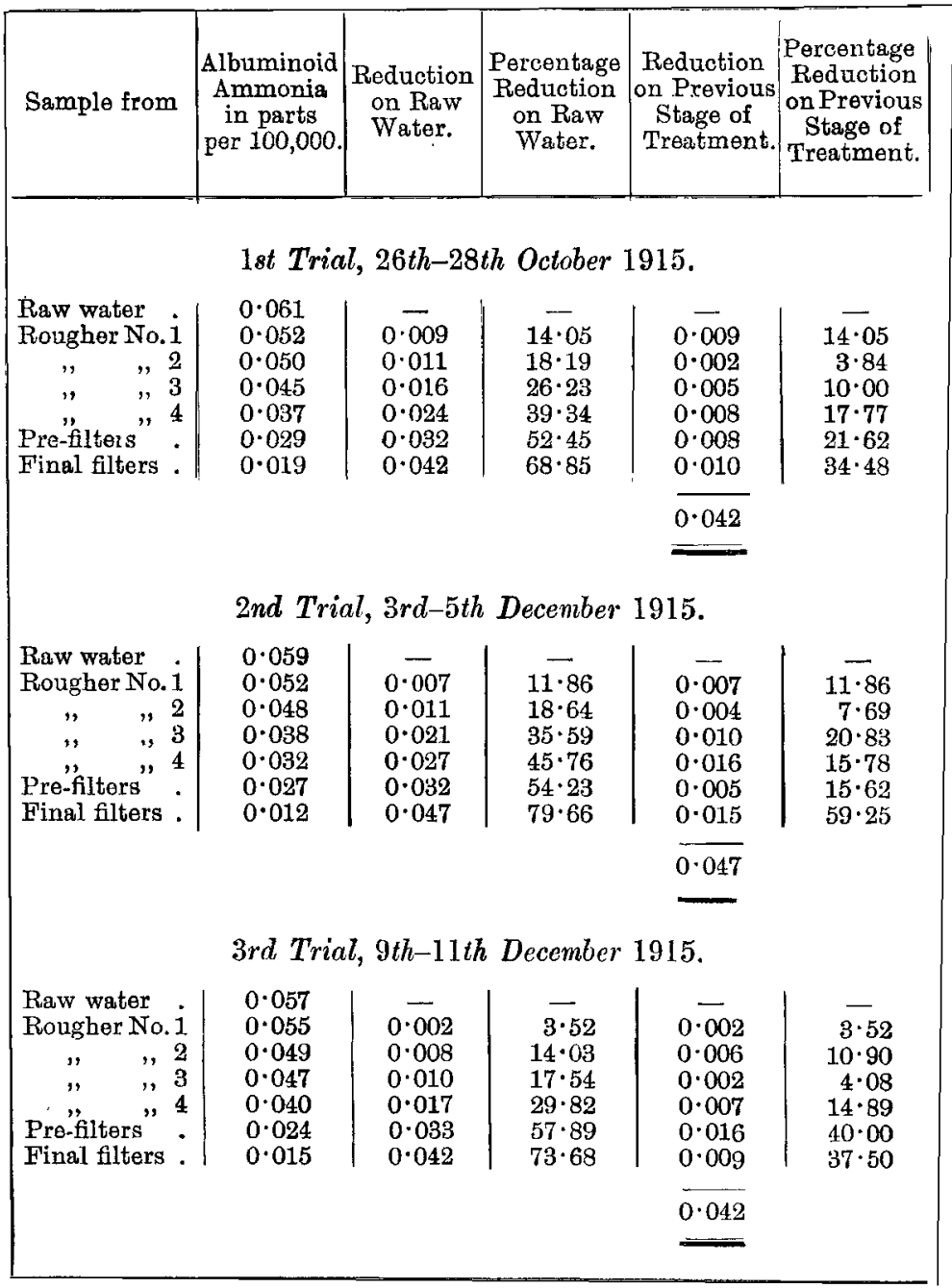

The results show a progressive reduction in organic matter through the successive stages of treatment of a very impure water. The second and third trials took place shortly after a serious breakdown of the pumping machinery, which necessitated a complete 
stoppage of the filters for several days. A considerable improvement on the results already obtained may therefore be looked for when it is possible to work the filters at a regular speed, but the figures show a very remarkable reduction in organic matter, by filtration and aeration of a polluted water, without the aid of chemical treatment.

In the Annual Report of the Resident Engineer to the Gold Coast Government for 1915, it is stated that since the multiple filters have been in use there has been a very large reduction in cases of guinea-worm disease, to which the natives were much subject. The Report adds: "This disease may be said to bave disappeared except for imported cases from the bush." This appears to show that this malady is essentially a water-borne disease contracted through drinking impure water, and that it may be eliminated entirely by efficient filtration.

\section{Discussion.}

The President, in moving a cordial vote of thanks to the Author for his Paper, said he was not a waterworks engineer, but he had found the Paper extremely interesting. He believed the system of slow sand-filtration, for the purification of water for town supply, was developed in London, and probably it had been used for nearly one hundred years practically without any change. In the course of time a theory seemed to have been developed of the action of sand-filters-the film theory-which, if the Author was correct, was an erroneous one. By taking the same materials that were used in the ordinary slow-filtration method and reversing their order-merely re-arranging them -if the Author was right, it was possible to achieve an equally good purification of the water at a very much more rapid rate, and therefore at very much less cost. As he was not an authority, he was not able to say whether the 
Author was correct in his conclusions; but the method which the Author had described, which was not now in an experimental stage, as it had been used on a large scale, he had found to be a most interesting one.

The resolution of thanks was carried by acclamation.

Mr. C. Lmberi Stmpson exhibited a drawing of the original filter, Fig. 24 (page 300), that was made by his grandfather, in conjunction with his father, as far back as 1829 . He was fortunate enough to find the drawing some years ago, and had since kept it. It was signed by James Simpson, who was then engineer to the Chelsea Waterworks. Sand-filtration came originally from Manchester, where space was very valuable, and the people interested in bleaching had to determine upon some method for filtering the water which could be used in that district. The original intake of water for the filter shown in the drawing was where the Grosvenor Road Station of the London, Brighton and South Coast Railway at present existed. Before the Act of Parliament was passed under which the water companies were compelled to move out of London to Hampton, they had a very large and long intake which went right out into the river, but which only allowed the water to come into the settling ponds at a certain period of the tide. In some of the pictures old drawings would be found showing the old Newcomen engines used for pumping the water at that period through wooden pipes into the Chelsea district.

With regard to the question of mechanical filtration, about twenty years ago he used an American filter called the Riddell filter for that purpose. It possessed the advantage in the case of an existing waterworks that it was possible to pump through the filter, and it was not necessary to put down a double set of pumps, one to deliver the water on to the filter-beds, and another to take up the pressure service and deliver the water into the town. It was interesting at that time, because water engineers had always been brought up to follow on the lines of the London water companies, where sand-filtration had been adopted and developed, but had 
(Mr. C. Liddell Simpson.)

been very little altered. Some years ago the question of additional storage at the York Water Company's works had to be considered by Mr. W. H. Humphreys, and it was then found that unless some means could be discovered of helping the existing filter-beds, a large capital expenditure would have to be incurred in building

FIg. 24.-Arrangement of the Original Slow Sand-Filter and Decanting-Basins, Constructed by Mr. James Simpson, at Chelsea, 1829.

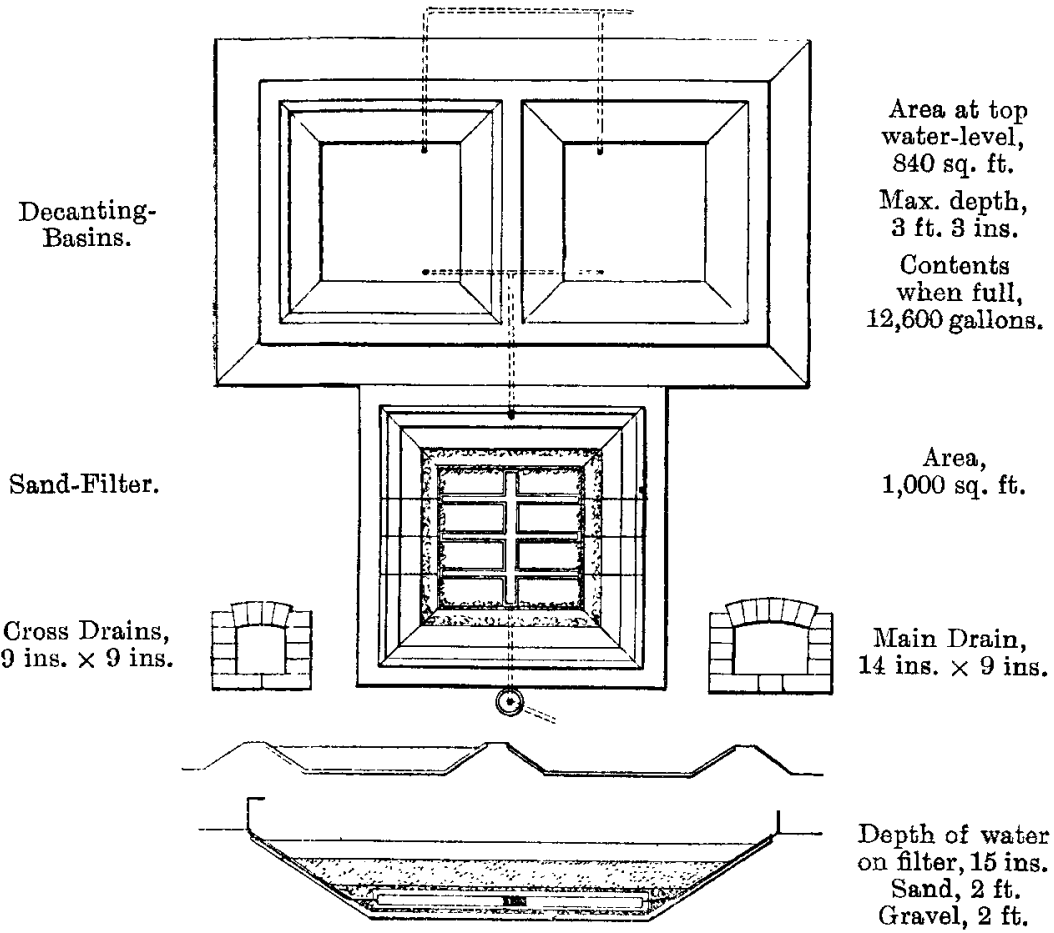

new settling reservoirs and new filter-beds. After carefully investigating the question, Mr. Humphreys decided to adopt the Jewell filter. The original waterworks at York were laid out by Smeaton, and later on they were designed by his (the speaker's) grandfather, the late James Simpson. There was sufficient depth between the settling reservoirs and the filter-beds to allow the 
Jewell filters to be installed. As a consequence, the filter-beds themselves ran for a very much longer period; they did not require so much cleaning, and the mechanical filters did most of the work. But before delivery into the town the water was passed through the sand-filters, in order to be quite sure that the traditions that had been laid down were not interfered with.

When he was in the United States, he saw a great number of waterworks in which mechanical filters had been adopted rather than the slow sand-filters, on account of the chesper cost of the first installation and also the greater convenience in running. Less labour was required, and the mechanical filters could be controlled mechanically far more easily than large sand-filters. To his mind the question resolved itself very largely into a consideration of whether space was available in which slow sand-filters could be put down on the well-known lines, or whether attention had to be given to a waterworks that must have an increased quantity of water required for town service, and it was necessary to utilize the space available. When the French decided to adopt filter-beds and, taking Paris as an example, decided to supplement the supply for the outer parts of Paris with water drawn from the Seine, they investigated the filters that existed all over the world and came to the conclusion, as far as he understood, that if pre-filters were used and a considerable amount of the preliminary work were done in that way, it was possible to filter at about double the rate through the sand-filters than was ordinarily obtained in this country. A modified form of filter was therefore adopted. It was apparent that if the rate of filtration through the ordinary sandfilters was increased, a very much larger quantity of water could be put through the same space than if the old traditional lines were followed. When he visited Cawnpore in India, the Ganges shifted its course in the hot weather about a mile from the pumping intake, and a trench, a photograph of which the Author had shown, had to be dug in order to bring the water to the vertical pumps which his firm built, and thus keep the water-supply running.

Going back in the history of the subject, it was interesting to find that old water-engineers knew that the film which was formed on the 
(Mr. C. Liddell Simpson.)

filter-beds was the filtering medium; but he did not think it was until Koch, the German, closely investigated the theory in regard to bacteria that it was taken as granted. Nobody looked very much into the matter until the Germans, who were very precise in the way they ran their filter-beds and investigated everything connected with water-supply, did so, and laid down what was really the theory of filtering. The French had also investigated the subject from their point of view, and the outcome of it all was that, by using pre-filters, it was undoubtedly possible to put in a very much more economical plant, so far as first cost was concerned, and obtain just as good results as the old sand-filter gave. It was most interesting to all mechanical engineers to see that a good many mechanical pumps and other plant had been used in connexion with the modified filters described.

Mr. Percx Griffith said he thought it would be of interest to deal with the subject on general lines, in order to emphasize the lessons of general application which the Author had endeavoured to bring before the Institution. The subject of filtration had been discussed from many various points of view by the Institution of Water Engineers, and in that way he had heard many sides of the question. He had also had personal experience of the mechanical filter which supported the Author's criticism of that type of filter, but nevertheless he would not quote this as involving a general condemnation of the system. In his case he had to deal with water from a boring which was highly charged with fine sand, and as the sand-bed was in contact with a bed of clay, the attrition caused by the water gave the sand a silty character that was very objectionable.

He had been impressed by the wonderful results obtained with mechanical filters, and the difticulty being a very urgent one, he had not time to make the preliminary experiments which would otherwise have been desirable. After spending a considerable sum of money on a set of mechanical filters, they proved to be much less efficient than he had expected, and he was naturally very disappointed. Ultimately, however, the filters proved useful, in 
that they indicated when an accumulation of sand occurred in the boring, and in that way enabled the pumping to be stopped before sandy water was delivered into the reservoir. It was, he suggested, a very important feature of the mechanical pressure filter that its relative efficiency was indicated by the back pressure which it threw. As the Author had pointed out, the efficiency was practically nil until a film was formed. That film immediately caused back pressure, and the rise of pressure was an indication of the time when the filter had arrived at the limits of its capacity and required to be cleaned.

Referring to the Paper generally, the Author said that the mechanical filter was inefficient, and as costly to install and to operate as the ordinary sand-filter. That was a very severe statement to make, and although his own experience with the mechanical pressure-filter was not favourable, he would hardly venture to condemn the system so drastically as the Author had done ; moreover, the Paper did not contain any evidence confirming the Author's criticisms. The centre of interest of the whole subject, as mentioned by the Author, was the film. The Author claimed that the effect of the film was purely mechanical, except at very slow speeds, and that it had no biological effect on the water. He (Mr. Griffith) suggested that opinions contrary to that would probably be offered in the course of discussion, as he believed that tests of mechanical filters were available to disprove the Author's statement.

He agreed with the Author that the use of coagulants was objectionable for several reasons. In the first place, they cost an appreciable sum; secondly, there was the loss of head, and the fact that the efficiency of the filters was more or less proportional to that loss of head up to its maximum; thirdly, there was the difficulty of maintaining a constant proportion of the coagulant, and fourtbly, there was the sentimental objection of the consumers to the "dosing" of a public water-supply with chemicals. The members would, of course, realize that the Author was describing and recommending a particular system ; but those who, like himself, had visited the Puech-Chabal installation in Paris had been, he 
(Mr. Percy Griffith.)

was sure, very much struck with the scientific character of its design and the absence of the rule-of-thumb methods so often adopted in this country.

In regard to the four illustrations given, he wished to point out that the Author did not enable them to judge of the efficiency of the results. Although he did not doubt the efficiency in each case, still he thought it would have been better if the Author had given more complete results as evidence of the efficiency of the working. For example, in the Magdeburg case he gave the percentage reduction of bacteria. The members would probably agree that this test, apart from absolute sterilization, did not show whether the few remaining bacteria did or did not include dangerous ones. The albuminoid ammonia and free ammonia tests were also referred to, and in that case the results were more complete than in any of the other three cases, but he was sure it would be admitted by the Author that those results were not a convincing proof of the efficiency of the system of filtration.

He hoped the Author would be able to furnish a little more information in regard to the reasons which induced $h i m$, in the Derwent Valley case, to advise the multiple-filtration system for the particular purposes required there. The treatment in that case was not required for purification purposes, but simply to remove the acidity and the colour, and (practically) to harden the water. The application of this system for that purpose had never, he thought, been urged before, and no doubt any remarks Mr. Sandeman could make on that particular point would be of great interest. At Accra the only test quoted was the albuminoid ammonia test, with, however, a very useful reference to the reduction of disease, which, in a climate such as existed on the Gold Coast, was no doubt the most practical test that could be applied to any treatment of the water-supply.

He suggested that the Tables given in regard to the watersupply at Cawnpore were not clear in regard to what the figures represented. He had to read the Paper very carefully before realizing that the figures in alt these Tables represented "Total Solids." This test was a very imperfect proof of the ultimate 
purification of the water. The Author had himself suggested that the speed of working filters should be stated in lineal feet per 24 hours or per hour, and he (Mr. Griffith) therefore suggested that in all cases where the Author had used the old notation of gallons per square foot the equivalent numbers in lineal feet per hour should be added. He had worked those figures out for his own information and found they greatly assisted him in comparing the various cases quoted in the Paper.

There was one other interesting point on which he desired to ask for information. In the early part of the Paper the Author spoke of organisms thriving in a high temperature. With that the members were familiar. It would be interesting to know whether the high temperatures prevailing at Accra and at Cawnpore had any effect on the working of the filters. He also suggested that if comparisons between multiple-filtration and the ordinary slow sand-filtration could be given on commercial linesthat was to say, the results recorded fully in terms of common standards of purity, together with the capital outlay and working costs in both cases-the figures would be very interesting. Of course, it would be necessary that the conditions should be similar to enable a fair comparison to be made. Such tests, however, would also be useful in estimating the true value of the mechanical filter used in conjunction with other systems.

Mr. H. F. Rutren trusted he would not be considered guilty of any discourtesy to the Author if he ventured to make the preliminary suggestion that the title of the Paper was a very wide one, and that it would be wholly impossible in the limits of a Paper of such a size to do justice to the subject of theory and practice in the filtration of water. He suggested it would be wise, in the interests of those who wished to refer to the Proceedings of the Institution at a later date, if the Paper were indexed under the title "The Puech-Chabal Multiple-Filtration System." $\mathrm{He}$ hoped it would not be considered, in any remarks he made, that he was in any sense desirous of saying anything against a system which had been proved in practice to be admirably adapted to the purpose to which 
(Mr. H. F. Rutter.)

it had been applied, but there were some statements in the Paper against which he ventured to bring forward a few criticisms.

The principal matter to which he desired to refer, in the interests of clearness of thought, occurred on page 240, where the Author stated: ". . . the theory became established that the efficiency of the filter as an agent for the purification of water depended almost entirely on the layer of slimy mud which has been observed to form on the surface of the filter after it has been brought into use." $\mathrm{He}$ thought the facts would be more clearly stated if, instead of the words "the theory became established," the Author had used the words "the dogma was for a time generally accepted." That dogma, like most other dogmas, would not bear careful investigation. It was quite true that a very large percentage indeed of the bacterial contents of water filtered through the slow sand-filter was removed at or near the surface; it was not true that the biological effect of the filter ceased at that point. On the contrary, the Author himself, a few pages further on, showed that he was quite aware of that fact when he stated: "Careful experiments have shown that in ordinary sand-filters having a depth of about 3 feet of sand, the number of bacteria found in samples of water drawn at various depths in the sand-bed is gradually reduced from top to bottom." That was perfectly true, and it was known before the beginning of the present century by actual experiments made by extracting samples of the filtrate at various depths below the surface. The colloidal envelope which, after the proper ripening of the filter, surrounded each grain of sand for practically the whole depth of the bed, had an immensely important function, although it must be admitted that a considerable proportion of the bacteria was removed at or near the surface.

The Puech-Chabal system did in several stages what was done in the ordinary slow sand-filter in two stages, because, from the nature of the case, it was almost a necessity that prolonged storage and subsidence should precede the passing of the water on to the slow sand-filter. The first of those two functions, namely, subsidence, was fulfilled in the Puech-Chabal system by what were called the "degrossisseurs." He suggested in parenthesis that the Author 
should restore the accent to that word and print it in italics, but he also thought it should not be beyond the wit of man to find an English equivalent for it. The function of the removal of a considerable proportion of the solid contents of the water was performed by the degrossisseurs. Whether or not the action of those degrossisseurs was so sure, so safe, so well to be trusted, as the action of light, air, and other agencies where the water had prolonged storage, was a question which he would not like to answer in the affirmative without more evidence.

$\mathrm{He}$ thought the Author had been inclined to lay somewhat undue stress on the more favourable costs of working which he claimed for the Puech-Chabal system. He quite admitted that there was a good deal to be said for the Author's claims, but unfortunately data were not given in the Paper from which a proper conclusion could be drawn; only bare statements were made, except in the case of the Cawnpore installation, and there the results were so complicated by the fact that the process was carried out in a sub-tropical climate that it was impossible to deduce from the figures any information that would help in dealing with a more temperate climate. The Author gave a contrast between the cost of cleaning the old sand-filters through which the water was previously filtered, and the cost of cleaning the pre-filters in the case of the new installation. Unfortunately, however, the cost of cleaning the old sand-filters was so high as to be beyond all comparison with that of filters in a temperate climate. The Cawnpore filters blocked up after about 9,000,000 gallons per acre had passed through them, which would be far too low a result in a temperate climate. That low result was undoubtedly due to the enormously active algal growth due to the high temperature and the sunlight. On the other hand, if the cost of the cleaning of the pre-filters at Cawnpore was taken, a figure was arrived at which might fairly be compared with the figure that would be considered reasonable in the case of the cleaning of slow sand-filters in a temperate climate.

That the adoption of the Puech-Chabal, system, in the cases brought forward by the Author was justified he was quite prepared 
(Mr. H. F. Rutter.)

to admit; there was no doubt that in all the cases mentioned it seemed to be a system which had adapted itself admirably to the results that were desired. Especially was that the case in the tropical climates where the water was so impregnated with the results of vegetable decay, and where oxygenation and re-oxygenation were absolutely necessary in order to bring about anything like a decent filtrate. With many of the remarks made by the Author as to mechanical filtration he thoroughly agreed.

At the end of the Paper a reference was made to what might be called the heroic methods of water purification, such as the use of ultra-violet rays, ozone, and methods of that kind. He entirely agreed with the remarks the Author made in that connexion in regard to the misleading character of the results which might often be obtained from tests of the numbers of microbes per cubic centimetre made immediately after the action of the apparatus. He had always felt that any results of that sort would be far more impressive if the tests were taken some hours after the treatment, at a distance of perhaps some few miles from the point at which the water first entered the mains, or after some few hours of storage in covered reservoirs.

Mr. Bertram BLounz: was glad that he was able to attend the Meeting, because he had had something to do with the water at Accra, and also with other tropical waters. He had read the Paper through, not only with great attention but with much instruction. The tropical waters of which Accra was a type were familiar to some people, but not to everybody. They were contaminated with the products of decay of tropical vegetation, the removal of which was an extraordinarily difficult matter. The installation at Accra, as was well known to the Author, had been put down under the advice of the late Mr. Walter Hunter, on a system such as the Author described in the Paper-he believed it was the actual system. It was a multiple filtration in which degrossisseurs or roughing filters were employed with a succession of filters-in fact, a systematic method of filtration. The water passed through the filters with, as he understood, a more or less satisfactory result. 
When advising about the Accra water-supply, he did exactly what he had done when advising about the supply at Mauritius, Nairobi (Uganda), and at Sekondi, and his experience of the water of Victoria Nyanza led him to the same conclusion. In all those cases he had found that methods of filtration, however elaborate, well designed, and systematic, as that described in the Paper undoubtedly was, were futile. He sincerely hoped that the present attempt at Accra, in which Dr. Simpson and himself had collaborated with $\mathrm{Mr}$. Hunter, would have a better result. He confessed, however, that he did not believe that that would be the case; he feared that the same result would be obtained as he had seen occur at other places, for the reason that the vegetable matter which came from the rapidly-growing and rapidly-decaying tropical material in all watersupplies like the Densu River, or the rivers at Nairobi and Sekondi, was not so easily oxidizable as the impure waters of the Seine and other European rivers, which were not so loaded with decaying vegetable matter. $\mathrm{He}$ had made a considerable number of experiments, and found that while such water was not amenable to pure filtration, it was amenable to chemical treatment. Some people considered that a dreadful term, the notion being generally held that chemical treatment had something improper about it, and that no chemical must, in fact, be added.

The Author had made an eloquent case against the use of precipitants, with which he (Mr. Blount) agreed; they were only coagulants, and if it was practicable to remove the stuff by other means, it was far better to do so. When, however, something existed which could not be oxidized by ordinary processes, but which could be oxidized by a simple chemical method, it should be used. In those particular instances which he had cited, the simplest of all methods was to use a catalyst in the form of iron, ferrous hydroxide changing easily to ferric hydroxide. The ferrous hydroxide was oxydized by air blown in by the ordinary Anderson process as modified and put into modern practice. That was effective, and, speaking with some experience of the matter, he believed it was the only effective method he had ever found for dealing with waters of that character. He hoped that when returns were made of the results 
(Mr. Bertram Blount.)

of treatment at Accra he would be proved to be wrong, but he was afraid that matters wonld turn out the otber way. He desired to emphasize that there was a broad distinction between the tropical waters of which he had been speaking and the ordinary water of dirty rivers like the Seine, at Choisey-le-Roi, or the dirty Thames water, which could be, and were, treated satisfactorily by methods of filtration which were carefully thought out in the way the Author had described, or by the sedimentation processes so successfully used with filtration afterwards.

Mr. LesLre C. WALKER said the filtration of water was of considerable interest to him, not only as a water engineer, but especially because he had for many years been connected with the purification of a river water, by means of a system of multiple filtration which was designed and constructed in 1890 at the Corporation Waterworks, Reading, by his father, the late Alexander T. Walker. He brought out that system in 1889 , together with a special drainage block for placing within the bottom of his multiple filters (patented in 1893), as he recognized the advantage of securing a uniform flow over the whole area of the filter media. The Walker multiple filters consisted of a series of gravel-beds arranged in tandem, through which the river water passed antecedent to sandbeds of the orthodox type. Each set of the multiple filters consisted of five water-regulating and cleansing chambers, alternating with five chambers containing the varying grades of gravel or other clarifying media, the depth of the latter being in each chamber 3 feet and the sizes of the chambers being commensurate with the work required of them. The water antecedent to the sandfiltration had therefore to pass by downward flow through a total depth of 15 feet of clarifying media and was then conducted by distributing channels on to the sand-beds. The preliminary purification thus effected removed 97 per cent. of the bacteria originally present in the river water, and that was, he believed, a result which would compare favourably with that obtained by the settlement of a river water in costly storage reservoirs; while under those conditions it naturally followed that the resultant 
work thrown upon the sand-beds was considerably relieved. He therefore agreed with the Author that there was much to be said for a multiple system of pre-filtration.

With regard to the question of mechanical filtration, that when worked in conjunction with the multiple filtration to which he had already referred, or any other system of multiple filtration of a similar character, and the injection into the clarified water of a minute quantity of free chlorine-all trace of the latter being subsequently removed by the interposition of a layer of carbon within the mechanical filter-his experience had been of a highly satisfactory character. "Doctoring" the water had been mentioned in the discussion. People were sometimes horrified at the idea, but they forgot that nearly every liquid or food they consumed was " doctored" in some way.

He found in his own experience that sand-filters cost somewhere about $£ 6,000$ per million gallons per day and mechanical filters about $£ 3,000$, while the cost of multiple filters was about $£ 2,000$ per million gallons per day, so that the combination of multiple filters and mechanical filters was much less costly than the combination of sand-filters and mechanical filters. The working cost of sand-filters with preliminary filtration was about 15s. per million gallons, while with mechanical filters or pressure filters the cost was about $3 s$. per million gallons, or only about one-fifth. That combination had been in use for a very long time dealing with a river water, and the results had been all that could be desired. The water was frequently examined by an expert water-bacteriologist, Dr. John C. Thresh, who had described the method adopted as producing a filtered water of the highest degree of purity, the water containing less than 10 bacteria per $\mathrm{cm}^{3}$ and no coli even in $100 \mathrm{~cm}^{3}$ of the finally filtered water. He could not help thinking, therefore that the figures quoted by the Author in relation to mechanical filtration must be the exception rather than the rule.

He understood that the water used at Nottingham was obtained from the Derwent Valley Water Board after it had gone through the system described, but of this he was not sure. He would be glad of further information from the Author on that point, and 
(Mr. Leslie C. Walker.)

whether it was a fact that mechanical filters had recently been put down at Nottingham. He would also like to know whether at Leicester, which also received its water from the Derwent Valley Water Board, mechanical filters were being put down at the present time.

He thought that the Author had a wrong conception of the function of a mechanical filter, when used in connexion with the treatment of "unfiltered" water with sulphate of alumina, for he stated that the action of a gelatinous film was relied on. As a matter of fact, there was no film action at all, but something entirely different, and quite, if not more, effective. The chemical reaction that took place in connexion with sulphate of alumina was as follows:-In the first place, there was sulphate of alumina dissolved in, and permeating, the whole body of the water. This dissolved alumina salt came in contact with an alkaline substance (either naturally present in or purposely added to the water), and from this union was produced an insoluble substance (hydrated oxide of alumina) which at the moment of its formation-that is, at the time it passed from the soluble to the insoluble stategathered to itself the minute particles of suspended matter, the bacteria, and also the dissolved organic impurities, including colour, present in the water: The function of the mechanical filter (when sulphate of alumina was used) was to arrest the hydrated oxide of alumina, and with it the impurities imprisoned in its substance; and he believed one of the objects that the maker of mechanical filters set himself to achieve was to avoid "film" formation and to retain the oxide of alumina throughout the body of the filtering media instead of simply on its surface.

Mr. Walcer Clemerce, in replying to Mr. Liddell Simpson, who had referred to the filters at York and to the installation of Jewell filters as pre-filters, said he thought it should be pointed out that those mechanical filters did not deal with the raw water of the River Ouse, but with water which had already been partially decanted. It was true that the inlet to the pre-filters was at such a level that it was not possible to take advantage of the full 
capacity of the settling tanks, but nevertheless a large amount of silt was taken out of the water before it was passed on to the mechanical filters, which required cleaning, under normal circumstances, every 24 hours. Mr. Liddell Simpson had stated that the sand-filters were retained simply for the sake of tradition. He had seen the filters at York on certainly two occasions, and he had never seen a waterworks installation kept in better order than the plant at York under Mr. Humphreys. The sand-filters were worked with great care. A very thick bed of filtering materials was used, consisting of 3 feet of sand and 2 feet 6 inches of gravel below it, and the speed adopted, under 2 inches per hour, was very slow. Allowing for a total depth of 10 feet, the water underwent a treatment in the final filters of at least 60 hours, which ought to, and no doubt did, bring about a high degree of purification in the final effluent. He felt certain that if figures were given it would be found that, although no doubt with the elimination of matters in suspension a large number of bacteria disappeared in the double process of decantation and the passage of water through the Jewell filters, the greater part of the organic purification of the water was carried out by the sand-filters which were retained. He had been informed that heavy growths of green algæ occurred on the final filters at York, from which it must be inferred that the rapid filters did not eliminate the spores of the plants, and that the effluent from them still contained much organic matter in solution, as green algæ did not develop in the absence of organic matter.

He thought Mr. Percy Griffith, in laying stress upon what he called "back pressure"-which he (the Author) preferred to call "loss of head"-with mechanical filters, had not sufficiently taken into account the great difference there was in the character of an artificial film created by a congulant such as sulphate of alumina and the natural film which became established, as he had described in the Paper, through a considerable depth in the sand-bed in slow sand-filtration. The artifical film invariably caused a considerable loss of head, whereas when a slow sand-filter had been working for several months with a natural bacterial coating on the sand grains, he 
(Mr. Walter Clemence.)

found the loss of head to be 2 inches or 3 inches only when the filter was working at its maximum speed of 4 inches vertical fall per hour.

With regard to the Tables of total solids at Cawnpore, it would have been better, perhaps, if he had used the words "silt by weight test." The Ganges water at Cawnpore, though it was very turbid, was, after filtration, one of the purest river waters in the world. Once the turbidity had been removed, a blue water of very high organic purity remained. The system of multiple filtration at Cawnpore was adopted for the purpose of removing the extremely fine silt in the Ganges water rather than to improve the bacteriological or chemioal conditions of the water, which were excellent before that system of filtration was adopted. That was why he had given no figures at all with regard to bacteria or chemical condition of the filtered water at Cawnpore. From reports he had seen he understood that the results obtained since the system of multiple filtration had been adopted had been equal to-he did not see that they could be expected to be better than-what they were before with sedimentation followed by ordinary slow sand-filtration. $\mathrm{He}$ thought that if Mr. Griffith would read the Paper again he would see that the whole theory of multiple filtration as set forth therein was based on the necessity of biological action within, instead of on the surface of the final filter. Absolute sterilization was not necessary, and the vital statistics of those towns where sand-filtration was in use showed that the small number of bacteria usually found in the effuent from such filters did not as a rule include pathogenic organisms. The figures for albuminoid ammonia had been given in the Tables of results obtained at Accra, as affording a convenient index of the reduction of organic matters in a water contaminated with decaying vegetation.

With regard to the effect of high temperatures on the working of filters in tropical climates, his experience was that the results obtained were the same generally as in temperate climates, and excellent results were obtained even where open sand-filters were exposed to a tropical sun, and where the temperature of the water was constantly between $80^{\circ}$ and $90^{\circ} \mathrm{F}$. 
Mr. Rutter had made some criticisms in regard to the title of the Paper, which, however, he preferred to retain. Mr. Walker had rightly claimed for his late father the credit of having been the pioneer, in this country at any rate, of the system of double filtration. Roughing filters had been in use in connexion with several large water undertakings in England for many years, and he (the Author) gained his first experience with multiple filters during an association, extending over several years, with the Antwerp Waterworks Company. Careful experiments carried out at Antwerp by Dr. Kemna led to the construction, of which the Author had charge, of a large installation designed for the purpose of still further clarifying the water after sedimentation with sulphate of alumina. But Dr. Kemna was a firm believer in the surface film in slow sand-filtration, and the Antwerp installation was so designed as to allow the formation of a film on the final filters. A wider experience of the system had convinced the Author that better results were obtained without the surface film, and M. Armand Puech had always insisted that the film should be prevented from forming on the surface, though the Author did not wish to suggest that he would be prepared to follow him in the theory of the action of a slow sand-filter which he had endeavoured to explain in the Paper.

As Mr. Rutter desired an equivalent for the word "degrossisseur," reference might be made to the Tables in Appendix II (page 297), where it would be seen that from considerations of space the word "rougher" had been used in connexion with the plant at Accra. The word to which Mr. Rutter took exception was becoming generally used to indicate something more scientific than a mere strainer, and it conveniently distinguished between that part of a multiple-filtration plant which merely improved the physical character of the water, and the pre-filter which, from its slower speed, was capable of performing, in some degree, all the functions of a true filter.

With regard to the question of the blocking of the filters at Cawnpore, it must be borne in mind that Cawnpore was not in the Tropics; it had quite a cool climate in the winter, although the 
(Mr. Walter Clemence.)

sun-heat was very great in the summer. Trouble had formerly been experienced from growths of algæ, but it had been usually limited to a period of about two months in the hot weather, just before the rains, when the river was clear. As most of the members knew, alga did not grow very well in a turbid water, so that the moment the monsoon rains began, the algæ invariably disappeared and were not found again until the following May. No trouble had been experienced from this cause since the pre-filters of comparatively slow speed had been introduced, as they appeared to eliminate the spores of alge completely. As a general rule the rapid blocking of the filters at Cawnpore had been caused by the extremely fine silt of the Ganges, a photomicrograph of which had been shown, and also by the fact that sulphate of alumina had to be used in the settling tanks. A certain amount of that passed on to the sandfilters and no doubt caused some of the trouble. He thought if Mr. Rutter would read the Paper rather more carefully he would see that great pains had been taken to give details of the actual work required with multiple filtration at Cawnpore, and seeing that coolie labour could be obtained there for a few annas per day, it would have been ridiculous and misleading to state the cost in money.

Mr. Bertram Blount had made some most interesting remarks with reference to the plant at Accra. The late Mr. Hunter provided in his original scheme for the adoption of the Anderson iron process, if it should eventually turn out to be necessary. The Author hoped it would not, because he had strongly advocated multiple filtration alone from his experience of both systems with the same kind of water at Antwerp, and he felt confident that, with proper attention to the working of the plant, and with good aeration and oxidizing, the figure for albuminoid ammonia, which had been taken as the index of contamination in the Tables given in the Paper, might be reduced to the figure which Mr. Bertram Blount considered safe, namely, 0.008 part per 100,000 . It would be seen from the Tables given in the Appendix that very good reduction had already taken place, the figure for albuminoid ammonia being reduced by 80 per cent. The best result, taken after a breakdown in the pumping plant, when the filters had to be left standing for nearly a 
week, showed a reduction from 0.059 to 0.012 part per 100,000 . He hoped that this result might be improved upon; but it was only fair to say that the plant had not yet been worked with anything like the full quantity of water which should be passed through it. He was familiar with the history of the use of iron in connexion with the treatment of the water of the River Nethe at Antwerp during a period of thirty years. In the case of preliminary filtration through spongy iron as well as the Anderson system, the iron treatment had always been followed by thorough aeration and slow sand-filtration, and possibly received more than a fair share of the credit for the final result. But the Nethe was a tidal river and the water varied greatly in hardness, and it was discovered that the iron process, though successful with a hard water, failed to effect any marked degree of purification when the water was soft. Eventually the process was abandoned at Antwerp in favour of multiple filtration. Iron treatment had been superseded at Choisyle-Roi by pre-filtration and aeration. It had also been abandoned at Agra, India, and other places where the water was moderately soft.

The analyses received from Accra showed that the hardness of the water varied from $4^{\circ}$ to $8 \cdot 5^{\circ}$, and even the higher figure indicated a softer water than was ever found at Antwerp. He had suggested to the Government, that in order to carry out a satisfactory test of the filters it was desirable that they should be run for a month at the full speed of 500,000 gallons daily, for which they were designed. The cost of pumping would not be very high, and it would then be possible to get some accurate figures with regard to the capabilities of the plant. He had every confidence that this would show that the fear expressed by $\mathrm{Mr}^{\text {r }}$. Blount, that it might be necessary to supplement filtration by the use of chemicals at Accra, would turn out to be unjustified.

In reply to a question by Mr. Walker, he (the Author) had no information as to the adoption of mechanical filters at Nottingham and Leicester. These towns derived a part only of their supplies from the Derwent Valley, and this water was filtered at Bamford in the manner described in the Paper. 


\section{Communications.}

Mr. James Carson wrote that he thought the title of the Paper would more properly have had the word "theory" omitted, for beyond a few vague references to bacteria, etc., there was no attempt in it to enlighten anyone on what the actual functions of a filter were, or what took place in it; nor did it appear that the Author was quite certain on the point. This was to be regretted, because, first, there was not the least need for uncertainty, and secondly, a step in the right direction had been taken in the division of the filtering process, though' it was quite obvious that the Author had no idea of how right the step was.

In view of the researches to which he would allude presently, and, in fact, to troubles which had manifested themselves in all filters as used now, it was certain that filters, so called, should be divided into two distinct classes, one, in which the filter was really a mechanical instrument, performing the purely mechanical operation of straining and removing suspended matter, and the other, in which the bacterial action was conducted, and which would no doubt, but for popular prejudice, be more rightly called a bacteria bed, just as the term had been applied by Dr. Dibdin to the coke beds used in the treatment of sewage. As would be plain from the researches to which he would allude, fine bacteria beds should be rigorously protected from the entrance of suspended matter, and should remain undisturbed as far as possible.

It was now over twenty-five years since the writer was asked by Dr. W. E. Adeney, F.I.C., of the Royal University of Dublin, to assist him in a research on the purification of sewage, and to ascertain, if possible, what the chemical changes were which took place during the self-purification of a polluted water. At that time the scientific world was divided into two camps on the question of what took place in a filter. One held that all changes were the result of direct oxidation by atmospheric oxygen, and all sorts of extraordinary materials were proposed and used for the filter, with the idea of increasing this effect. The other, influenced by the work of Pasteur, 
Koch, Warington, P. F. and G. C. Frankland, Winogradsky, and others, held that the changes were entirely due to the work of bacteria, and as was the custom in those days, a separate and distinct "genus" was invented, or hypothecated, for each stage or change.

Dr. Adeney's research fully cleared up these points, and although the writer had been completely out of touch with these matters since 1898 , he did not think that his results had ever been challenged. His work had been referred to and quoted by the Royal Commission on Sewage Disposal in its 5th and 7th Reports as of fundamental importance, and so it was regarded in the United States of America. They had not gone very far with the research when it was found that the existing methods of water analysis were only empirical and misleading when employed for the investigation of these points. The albuminoid ammonia process of Dr. Wanklyn was open to the grave objection that it afforded empirical results only and gave negative results with such an important body as urea, and Dr. Franklin's combustion methods suffered, amongst other drawbacks, from a serious "equation of personal error." It was, moreover, slow.

Eventually Dr. Adeney invented, not only a simple method, but a simple apparatus, for determining the organic matter by means of the dissolved gases in the water, and the writer made several of these instruments for him and others. To such accuracy was the method developed that they found it practicable to determine one part of organic carbon in ten millions of water, and it was possible to follow daily, if desired, the changes which went on in the water under examination. When accustomed to the use of the apparatus, he could easily make five or six analyses in a day. The principal conclusions they arrived at as the result of a research extending over several years, and involving thousands of analyses, as all determinations were made in triplicate, and controlled by "blank" experiments, were as follows :-

The first great conclusion was: "That the fermentation of organic matters in water proceeded in two distinct and progressive stages, the first being what we called the 'carbon stage,' in which 
(Mr. James Carson.)

the oxidation of the organic matter to carbon dioxide, water, and ammonia took place." After this was completed, but not till then, the oxidation of the ammonia to nitrates took place.

The second great conclusion was: "That the second, or nitrification, stage proceeded more slowly than the water would take up atmospheric oxygen when under natural or open-air conditions, and that, therefore, if the first, or carbon, stage was completed, the water, if given free access to the atmosphere, would certainly and absolutely purify itself." No doubt this point, namely, the completion of the carbon stage, was what was referred to in Major Clemesha's report, quoted by the Author, as the "safety change," though it was almost apparent on the face of the report that Major Clemesha, while recognizing that there was such a stage, was not aware of what it was, or when it took place. As it was now admitted that all the oxidation of organic matter in water was due to bacterial action, the wrong and folly of adding chlorine, lime, or other germicides in any form to sewage liquors could be seen, as the bacterial action should be encouraged rather than destroyed. A moment's consideration would show that so long as the pabulum romained in the water, bacterial action would be established and would proceed immediately the water was removed from sterile conditions.

Their results also showed the futility of bacterial counts, except under conditions where the water was known to have had time for the complete fermentation of all organic matter, including the free ammonia, as when all was oxidized, the bacteria died down, leaving, even in a highly polluted sewage effluent, only a slight sediment of bacterial debris. Dr. MeWeeney of Dublin examined many of the samples from a bacterial point, and his evidence, if the writer's memory did not fail him, was most remarkable, showing that when the carbon stage was complete, there was a disappearance of all pathogenic organisms.

A couple of instances would show the intense greed for oxygen evinced by saprophytic bacteria-that is, the bacteria that fed on waste organic matter. A flask of filtered sewage effuent was kept carefully sealed for about $2 \frac{1}{2}$ years, and slowly evolved marsh gas, hydrogen, and nitrogen derived from the reduction of the 
waste organic matter in the sewage. In another case, when using a crude manganese salt as a precipitant, the sludge on being dried in air frequently showed large patches of white manganese monoxide on breaking the lumps. The vital necessity of removing the suspended matter would be realized by thinking of what occurred. Imagine a particle of organic matter in water. It was promptly covered with a layer of bacteria, which not only sought to oxidize it, but proceeded to multiply and reproduce. As, however, the outer layer of bacteria cut off the supply of oxygen from the inner, the function of these altered, and putrefactive changes were set up. This was proved repeatedly. The brown stain mentioned by the Author was doubtless due to peaty humus. They produced this artificially by allowing a filtered sewage to percolate extremely slowly down a glass tube filled with lumps of pumice. The resulting water was brown, and the colour answered all chemical and physical tests for humus.

Little consideration was necessary to apply their results to the facts stated by the Author. The "filtering film," consisting of organic debris, etc., stopped the natural purification till all the carbon was oxidized. In the case of solid particles, the process was slow and accompanied by putrefactive changes. All suspended matter should, therefore, be rigorously removed as a preliminary. After that, sufficient oxygen, supplied either by frequent aeration in cascades or by the formation of thin films of liquid by passage through a filter, would do the rest with certainty. If the water was to flow in open channels, it was not essential to secure further oxidation by bacterial action in the filter than would suffice for the oxidation of the carbon. Any scheme of water treatment which did not conform to these conditions was working on wrong lines, and that is why he said that the division of the filters as propounded by the Author was a step in the right direction, even when, as he believed from reading the Paper, it was taken in ignorance of what took place during the self-purification of water.

The Author referred (pages 242 and 245) to the depth of penetration of bacterial life in a filter. They would inevitably penetrate as far as they found food or pabulum, and then would 
(Mr. James Carson.)

die off. In the report quoted on page 288 it was stated that filtration had no effect on the free ammonia. Dr. Adeney's results would show that this was due to the filtration referred to taking place before the carbon stage had been completed. As the result of a subsequent research on sewage purification, it was found that the addition of one to three grains per gallon of nitrate of soda to a sewage from which all suspended matter had been removed absolutely ensured sufficient oxygen for the completion of the carbon stage in any sewage they could find in the country. An infinitesimal addition of this substance should therefore be of great benefit to a relatively pure potable water, and he would be greatly interested to know of this being tried. The addition should increase the power of a filter enormously, as it was quite a common experience with them to see a large tank of sewage effluent so treated in a state of brisk effervescence, due to the liberation of carbon dioxide.

He wished to thank Dr. Adeney for kindly revising this Communication and correcting his memory on several points which had become not quite clear through the lapse of years.

Mr. GEorge H. Hughes wrote that he differed from the Author in reference to his remarks on lines 3 and 4 , page 242 , ". . . that the formation of a film, either natural or artificial, on the surface of the filtering medium is unnecessary and undesirable." There was no doubt that the elimination of the grosser impurities by the multiple system of roughing filters and pre-filters rendered the surface film of the final sand-filters more efficient as finishers, and increased their mean capacity with a decreased number of cleanings; but the glutinous film remained, and in a better condition than in a single filter, where all the work had been performed. The multiple system was really a system of graders and aerators. By the employment of pebbles in the roughing filters, it was made possible to remove the arrested impurities at cleaning times by compressed air from below the bed, and this saved an amount of scraping which would otherwise have been performed with a single sand-filter. 
When it was considered that the relative sizes of the smallest spaces between the finest sand grains and bacteria were as the diameter of a shilling and a sand grain (of 0.005 of its diameter)that is, the sieve mesh being 200 times greater than the object to be arrested - it was a forcible fact that straining alone was impossible without some substance filling these voids. It was an ascertained fact that the surfaces of the sand grains became coated with a glutinous substance (which was believed to be due to the nitrobacteria in the raw water). In a single filter particles of vegetable and organic matter, also particles of inorganic substances, were arrested on the surface of the sand, partly by the straining action and partly by the adhesive nature of the film; this produced what the German investigators termed the "Schmutzdecke," the coating of the sand grains only being termed the "Zoogloea." The writer considered that the removal of the coarser substances left a "Zooglœa" film, which was not only on the surface, but penetrated into the bed a short distance.

It was worth while to consider the "Zoogloea" as of nitrobacterial origin, and to compare it with the substance forming the spider's web, and the organic impurities (and probably other species of bacteria), as flies, which became entangled in the sticky slime on the surfaces of the pebbles or sand grains composing the filtering media. The nitro-bacteria had their home in this glutinous film, otherwise they would be washed through the bed by the flow of water; hence the necessity of not exceeding too rapid a rate of the water through a filter. Dr. Koch's investigations gave the limit as $100 \mathrm{~mm}$., or about 4 inches in height per hour, or 8 feet per 24 hours, and this gave just about 450 gallons per 24 hours per square yard of filter area.

The writer's theory of the purification effected being that the nitro-bacteria formed a sticky home for themselves, near the surface, and being aerobic they required a certain amount of air, which they obtained near the surface. This home also formed their hunting-ground and trap for their food supply, and possibly for their victims - that is, other bacteria. Pathogenic bacteria arrested in their passage and deprived of food-stuffs were destroyed before 
(Mr. George H. Hughes.)

they passed through. This theory enabled the water engineer to design a filtration system to secure the following essential features for the purpose: (1) Removal of grosser impurities; (2) aeration of the water to aid development of nitro-bacteria and to oxidize other substances in the water; (3) to retain the nitro-bacteria in the beds; and (4) to destroy pathogenic bacteria.

The writer would be glad to know if the Author had observed any glutinous coating to the pebbles in the roughing filters, as he considered that the bacterial action commenced there, and passed all through the system, until finally arrested in the slow sandfilter.

The writer contended that there was a surface film-that is, of "Zoogloea" - on the final sand-filters, and it was evident this must be so, otherwise it would not be possible to effect the final purification, and at the same time clean the sand-filters by scraping about $\frac{1}{2}$ inch off the top; if there were no surface film, it would be necessary to remove the sand deeper in the bed, or to provide some other means for removal of the debris, such as blowing jets of air or reversal of flow, somewhat similar to that required in a mechanical filter. It was fortunate for the water engineer that the purification was effected on, or very close to, the surface, as this enabled the removal of the layer and its replacement after cleaning-very easy operations. This wonderful natural means of purification enabled one to appreciate the delicate provisions of our Creator, "The Master Engineer," for the use and benefit of man. It was known that pollution entering a stream or river became dissipated after a certain distance of travel, and the writer had no doubt that when further knowledge was acquired it would show that the purification was very largely due to bacterial action, as well as the old theory of oxidation. In the same manner the puritication of water percolating through a pervious soil was purified by the nitrifying organisms contained therein, hence the purity of most underground water, so that there was in nature a multiple system of purification and filtration on the principles referred to.

The writer wished to call the attention of the Author to an evident defect in the distribution of the raw water through the 
settling-tanks, Fig. 8 (page 264). The supply from the 20-inch main was shown from the left-hand side, and the outlets at the right-hand top corners, causing streams of water to pass diagonally across the tanks 1,2 and 3. The rapidity of the flow would carry a fairly large amount of particles in suspension before they had time to deposit. In his opinion, it would have been a more efficient method if the flow had been reduced to a minimum by conducting the raw water to a sill, or weir, the whole width of each tank, so as to secure a change of the whole of the water. As shown, the areas of the two triangular sections of the settling-tanks were in a stagnant condition, and this no doubt would account for the development of alge and the comparative failure of them. Providing that suitable wash-outs were furnished, there should be no great difficulty in removing the sludge, and the work on the roughing filters would be materially reduced. Algæ quickly developed in a stagnant water; once established they could be removed by a dose of copper sulphate 1 to 3 parts per million, and no trace of copper would be found in the filtrate.

In conclusion, the writer considered it unwise to pin one's faith to any particular system, but to welcome all reliable methods, and to apply such as were most suitable for the conditions which obtained.

Mr. D. C. LeITcH wrote that the particulars collected by the Author regarding the process and results of multiple filtration were of great interest. It seemed likely that the bacterial slime on the surfaces of the grains of sand in these filters, described on page 247 , was also present in a greater or less degree on the surfaces of the gravel in the degrossisseurs, and some further information as to the nature and dimensions of the material used in the installations referred to would be useful. Apparently, better results might be expected from the use of material with a rough or porous surface than from ordinary water-worn gravel.

Another point of great importance was the depth of filtering material used in the degrossisseurs. No information was given as to this, but it affected, as much as the velocity of flow, the time during 
(Mr. D. C. Leitch.)

which the water under treatment was in contact with the nitrifying bacterial slime. In the diagrams of multiple filters a considerable depth of water was indicated above the surface of the filtering material in the degrossisseurs. It was suggested that the aerobic conditions, which favoured the growth of nitro-bacteria, would be improved by placing the layer of filtering material in each degrossisseur as near the water surface as possible. Within certain limits, the degree of purification effected by each degrossisseur bore, no doubt, some relation to the depth of filtering material, and if the nitro-bacteria extended, as stated by the Author, to a " considerable depth" in sand, it seemed likely that they would also do so in gravel. It was evidently important, as regards economy of construction, to obtain the necessary degree of purification in as few stages as possible, and to effect it largely in the degrossisseurs. In order to do this, it was important to know what thicknesses of filtering material could be used with advantage. In existing installations this could be determined by experiment; perhaps this had been done in some of the cases described by the Author.

The Author remarked (page 283) that a coarse sand did not necessarily allow a more rapid percolation of the water than a fine sand, basing this conclusion on the fact that the interstitial volume was about the same in both. But this reasoning overlooked the fact that in the finer material the interstices were individually much smaller, and the loss of head in passing them proportionately greater.

The settling-tanks at Cawnpore, referred to on page 278, appeared to have been so singularly ill adapted to their intended purpose that no useful conclusion could be drawn from the experiments with them. Why the water should be merely circulated over the surface did not appear; it would have been easy to arrange for it to enter each of the three divisions at the bottom and to be drawn off at the top. It certainly seemed, as sediment could be more easily removed from a tank than from a degrossisseur, that it was as well to get rid, by settlement, of any suspended material coarse enough to be readily eliminated in that way. The Author's objection to the use of settling-tanks (page 281), that they might not be cleaned at proper intervals, appeared to 
apply with equal force to multiple filters. These, if neglected, might not perhaps harbour pathogenic bacteria, but might allow them to pass.

The Author concluded (page 290) that in a system of multiple filtration the final sand-filters should be as deep as possible. This presumably meant as deep as nitrifying organisms could penetrate. Apparently, it was not less important that the gravel in the degrossisseurs should also have the maximum depth to which such organisms could extend.

Mr. L. E. Mather wrote that the Author had made a comparison between multiple filtration and mechanical filtration to the detriment of the latter, which was not borne out by the writer's experience. In the early days of mechanical filtration it was true the results were not always satisfactory, but since improvements had been made in the design of the plant, especially in connexion with the arrangements for washing the bed, and adding the chemicals, it had been proved by some of the foremost waterworks engineers in the country that a regular result could be obtained, with a high bacteriological purification. In fact, there was no difficulty, with a properly designed installation, in obtaining a water free from suspended matter with a bacteriological purification of 95 to 98 per cent.

He would like to point out that in a number of cases mechanical filters had been used as roughing filters to work in conjunction with sand-beds, and when used in this way they had given excellent results, inasmuch as they had removed practically all the suspended matter, which in many cases had meant a bacteriological purification of 50 to 60 per cent. When used as roughing filters, their function would appear to be the same as that of the multiplefiltration plant described by the Author, and he ventured to say that mechanical filters could be relied upon to give equally good results when used for this purpose, with the advantage of a considerably less initial cost. No claim, however, was made for a high efficienoy with mechanical filters, unless the water was treated chemically in the first instance, as they would fail in the same 
(Mr. L. E. Mather.)

sense as the multiple-filtration plant had failed in connexion with the Derwent Valley water, with the result that at Leicester and at Nottingham they had found it necessary to provide mechanical filters with complete chemical treatment to deal with the water supplied to them from Derwent Valley, after it had passed through the Puech-Chabal system. At Sheffield, water from the same source was dealt with satisfactorily in a mechanical-filtration plant without any preliminary filtration.

In regard to the cost of treatment by mechanical filtration, this of course varied according to the character of the water dealt with, but in every case that had come under the writer's notice the cost had not been higher than would amply justify the adoption of this method, because it must be borne in mind that apart from the purification effected as regards suspended matter and bacteria, practically the whole of the colour and acidity in the water were also removed. The cost of treatment where two installations dealt with about 5 million gallons per day, including chemicals, carting, labour and sundries, worked out at $6 s .8 d$. per million gallons.

Another point that he would like to emphasize was that the wash-water required to cleanse mechanical filters rarely exceeded 1 per cent. of the quantity filtered, and further, that with this system there was no growth of algæ during summer, or freezing of the beds during winter.

Captain C. G. Moor (1st London Sanitary Company) wished to point out that the Author appeared rather to neglect the great advantages of the process of treatment of water by a minute addition of bleaching powder. This reagent had several advantages, not only as an emergency method, but as a routine method of making a water definitely safe in respect of its power to convey typhoid and cholera. The amount to use depended on the amount of matters in the water that would absorb or react with bleaching powder. It was quite unnecessary to aim at killing all bacteria. The coli-typhoid group and the cholera organism were killed by bleaching-powder solution in a very high degree of dilution, and they could be destroyed without killing many of the more resistant 
bacteria, which had no hygienic significance in water. An advantage of the bleaching-powder method was that it could be applied at any given place with a minimum of apparatus, and in a very short space of time. Unlike the ozone or ultra-violet ray methods, no costly apparatus was required.

The objection felt by some people against "dosing the water with a chemical foreign to its nature" was not founded on any really logical reasoning, since after the reaction had taken place there was no bleaching powder left in the water, because it was broken up and changed into harmless lime salts which were natural to and occurred in most of the best spring water in the world. Bleaching-powder treatment should be applied after sand-filtration, not before; if it were applied before, the weak solution might fail to kill bacteria enclosed in particles of organic matter, and would be wasted in reacting with organic matter which would be filtered out in the ordinary way. A Paper and discussion on the bleachingpowder treatment of water might furnish valuable information.

In Army work the writer was convinced that the method was of the highest possible value, and he believed that a full inquiry into its merits would result in the members of the Institution giving it more favourable attention than it had perhaps received at present.

Mr. William Paterson wrote that when it was noted that fifty out of sixty pages of the Paper were devoted to the description of a particular type of multiple-filtration plant and only a small proportion of the remaining ten to "Theory and Practice in the Filtration of Water," it might be suggested the contents would be more clearly indicated by the title "Multiple Filtration as an Aid to the Working of Slow Sand-Filter Beds."

He thought there was no justification for the Author's inference on page 241 , that those who did not support the theory, "that the bacterial purification of water by filtration is chiefly due to the mechanical action of straining," must necessarily agree that "the formation of a film on the surface of a filter was a hindrance rather than an aid to purification," or be advocates of multiple 
(Mr. William Paterson.)

filtration and disciples of Puech-Chabal. It was asserted that " the formation of a film, either natural or artificial, on the surface of the filtering medium is unnecessary and undesirable," although it had been established by our leading biologists that the surface film was the principal seat of bacterial activity. The biology of slow sand filter-beds had been the subject of earnest study for many years, and any new theory advanced must be critically reviewed. In the writer's opinion, the Author had focussed his attention on one aspect of the film only.

It appeared only reasonable that purification took place at the point where the impurities were held up to contact with the purifying agencies, whether bacteriological, chemical or physical. In slow sand filter-beds, fed with turbid water, their retention was secured on the surface of the sand, while in those fed with comparatively pure water they might penetrate the bed for some distance before being arrested. In the first case the bacteria were held on the comparatively thin close-grained surface layer, in the other by the looser and deeper surface strata. In both cases a filter layer had been formed varying in density and construction. Many slow sand filter-beds were fed with comparatively pure natural waters, and the same penetrative action took place that the Author would have them believe was the exclusive result of multiple filtration. Every waterworks engineer was agreed that the lower and more uniform the turbidity of the water supplied to slow sandbeds, the better and more economical their working, but few might consider it desirable to push preliminary purification as far as the Author would have them take it.

On page 284 it was stated that "Bacterial action is relied on to effect nitrification by natural means, and it appears to be established that the bacteria themselves perish as a result of the disappearance of organic matter to support them." Again, on page 293, " nitrifying bacteria which gain access to the water after sterilization will continue to multiply until the organic matter is reduced by their agency, when the organisms themselves will disappear." This suggested the danger that preliminary purification might be pushed so far that the nitrifying bacteria on the final filter perished for 
lack of the organic matter necessary to maintain their life, and were non-existent when changed conditions made their presence essential for efficient purification.

One was informed on page 284 that "Chemicals are never employed in multiple filtration as coagulants to arrest the passage of bacteria." It was doubtful whether the results secured at Magdeburg (as indicated on page 252) could be obtained unless the water had a coagulant present. It would be noticed that the supply there was usually turbid and polluted with refuse from factories, etc. Such a raw water was in a very similar condition to a coagulated supply, and the impurities present had the same characteristic adhesive properties. The water at Derwent Valley Works had no natural coagulant and no appreciable colour removal was effected. Unfortunately for the Author's claim, "no chemicals used," the towns supplied with the water from these works had independently to consider the installation of plant to remove the colour "by the use of chemicals."

If further evidence were required of the indifferent results obtained without a coagulant, it was had on reference to the Cawnpore Tables (pages 279 and 280). The water of the Ganges was of totally different nature from that obtaining at Magdeburg; there was no natural coagulant present, but at certain seasons of the year enormous quantities of silt in an extremely fine state of division, many individual particles being much smaller than bacteria and devoid of their adhesive properties. The Author gave no data of the final results obtained here, either physical or bacteriological, except in one line on page 279 , where it was shown that the water discharged by the slow sand-filters contained a larger amount of matter in suspension than when it entered, the increase being $2 \cdot 3$ parts per 100,000 on 4 th September and 2 parts per 100,000 on 13th November 1912. He would account for this by the escape of the fine filtering medium from the slow sand-filters, but this was a debatable point. Having seen the installation at Cawnpore and noted the penetrative action of the fine silt through the degrossisseurs and pre-filters, the writer was of opinion that it was simply what must be expected. The fine silt of the Ganges 
(Mr. William Paterson.)

penetrated the finest filtering medium, the individual particles being more microscopic and less adhesive than bacteria. Coagulation was essential to effect their removal. Assuming that the Author's explanation were accepted, what useful purpose did a last line of defence serve that allowed the enemy to get through and augment his ranks with deserters?

Although the Author suggested that settling-tanks served little useful purpose, Table No. 9 (page 280) showed they actually secured 68 per cent. reduction in the suspended matter, while the first, second, and third degrossisseurs only secured $1 \cdot 39,2 \cdot 08$, and $4 \cdot 17$ per cent. reduction respectively. He explained that these small percentages of purification were accounted for by the exceedingly fine nature of the suspended matter, but the same argument made the increase just referred to in the amount of suspended matter passing through the slow sand-filters all the more significant. The Author's argument, "The great disadvantage attending the use of settling-tanks in any form is that the periodical cleaning of them is frequently neglected," was typical of the view he seemed to take of the claims of every system of purification other than multiple filtration. He admitted the attention required for cleaning out sedimentation tanks was so infrequent that it might be overlooked, and concluded from this that sedimentation was not to be recommended. The logical inference was that so much attention was required to keep the various stages of multiple filtration in order that it was unlikely to be overlooked. Properly designed sedimentation tanks effected preliminary purification better and cheaper than any other method. They should be constructed, at least, in duplicate and fitted with convenient sludging arrangements. Their size must be determined from knowledge of the water, but could be reckoned in hours' capacity rather than days. In a well-known instance abroad, the operation of existing slow sand-beds fitted with pre-filters had been disappointing because of the fine clay which penetrated the final filter-beds. The consulting engineer not only recommended the installation of rapid-filtration plant for the extension, involving an outlay of over $£ 100,000$, but suggested that the existing slow sand- 
beds be fed with coagulated water. At Clydebank, Glasgow, and Irvine, Ayrshire, the slow sand filter-beds had been abandoned and rapid gravity-filtration plants installed, in each case of $6,000,000$ gallons capacity.

Anyone reading the last paragraph on page 285 would conclude that "rapid filtration" was a failure in India. The single word "alone" hardly relieved the Author of the responsibility of this statement. No responsible person would for one moment consider the installation of rapid-filtration plant "alone"; coagulation and sedimentation were essential and invariably implied when the term " high-speed filtration" was used. The installation referred to at Naini Tal was erected by a foreign firm who presumably did not give full consideration to the special conditions. After the installation of plant at Cawnpore the Government of India spent three lakhs of rupees $(£ 20,000)$ on a searching investigation into the most suitable methods of purifying the highly polluted waters of that country. India was the battle-field of filtration systems during the period 1911 to 1915 . The most successful proved to be not slow sand-beds (even when assisted by multiple filtration) but rapid filtration with coagulation, sedimentation, and sterilization. The strongest advocate of mechanical filtration, reading Major Clemesha's report, would agree that it was fair and unprejudiced, and not a condemnation of mechanical filtration. Major Clemesha's criticism, that "where the amount of silt is very great" the percentage of wash-water was high, could be entirely overcome by the provision of suitable sedimentation tanks, with which every well-designed plant was fitted. The Bombay Sanitary Authorities were now installing at Poona (the summer capital) a Paterson rapid-filtration plant of $4,000,000$ gallons daily capacity. The nature of the problem here would be appreciated when it was stated that the raw water at times contained about $1,000,000$ frecal bacteria per $\mathrm{cm}^{3}$, so that even $99 \cdot 9$ per cent. bacterial purification might still leave 1,000 dangerous bacteria per $\mathrm{cm}^{3}$ in the filtered water. Similar plant was being installed for the Government of India, at Jammu (capital of Kashmir State) and elsewhere.

The Government of India proved to their satisfaction during 
(Mr. William Paterson.)

the period of 1911 to 1915 that rapid gravity filtration plant combined with sterilization "tends to greater security," and with them " this should outweigh all other" considerations in the design of an installation for treating water for potable purposes" (page 292.)

Perhaps the most conclusive reply to the Author's drastic criticisms on the value of mechanical filtration was provided by the decisions of those Authorities who had in the last few years investigated the merits of this type of filter, in comparison with slow sand-beds and multiple filtration.

Mr. A. Beeby Thompson wrote that he thought a Paper of unusual merit would have its value enhanced by the addition of the Author's views concerning the behaviour of the filters under varying climatic conditions. As temperature was an important factor in the fertilization of bacteria, one would naturally expect a greater throughput per unit area of filter under warm conditions than in cold, and if this were so there would be, in some countries, marked variations of throughput at different seasons. It would, for instance, be reasonable to expect very different working conditions between the treatment of the Ganges water, where at certain seasons large volumes of melted snow swelled the river, and the waters of a West African river never derived from snow and always meandering through more or less shallow swamps.

It was interesting to note that Accra was at length supplied with good water. When engaged on the water problem there some 15 years ago, he experienced the discomforts of being restricted to a gallon of repulsive looking water daily, the dregs of the last season's rains that had been collected in tanks.

Mr. W. P. WaLken wrote that, with regard to the cost of mechanical filtration (page 291), since the adoption of rapid gravity filters at the Cheltenham Waterworks the total cost of filtration had been greatly reduced. Formerly upwards of seven men were constantly engaged cleaning slow sand-filters where now one man did this work easily. The period between scraping was frequently 7 days, and now it was not uncommon to exceed a run of 120 days; 
the mechanical filters were cleaned and attended to by the enginedriver, so that no additional labour was required for that purpose. The raw water was taken from the River Severn, and was of a very variable character and exceedingly turbid sometimes. The turbidity occasionally registered 107 units with Lovibond's tintometer. Over 96 per cent. of the colour was removed by the filters. The surface area of sand scraped from the slow sandfilters in 1915 was 179 square feet per $1,000,000$ gallons of water filtered. It was thus seen that mechanical filtration at the Cheltenham Waterworks at Tewkesbury was less costly, and the filters more easily cleaned than slow sand-filtration in open beds.

Mr. Walter Clemence wrote that while the communication of Mr. James Carson formed a welcome addition to the discussion, certain criticisms by the writer afforded an apt illustration of the difficulty of reconeiling the results of experiments on a small scale with those obtained in practice, where the engineer encountered conditions which were conveniently absent in a well-equipped laboratory. If the Author of a Paper made a statement based on conviction bred of a lifelong experience, it might be criticized as being a dogmatic assertion. If, on the other hand, he put forward his views with becoming modesty in order to invite information from other workers, he ran the risk of being told that he was ignorant of his subject.

The Author was well aware of the work of Dr. Adeney and other scientists noferred to by Mr. Carson, who had done well to refer to the "equation of personal error" which must always be allowed for in considering the results of laboratory researches. Recognizing this, Dr. Kemna of Antwerp, who was one of the leading authorities on the subject of water filtration, had invariably supplemented his preliminary experiments in the laboratory with a practical trial under working conditions before recommending any alteration in existing methods of filtration, and the Author had the privilege, as an engineer, of assisting in and noting the results of those experiments which eventually led to the construction of a large multiple-filtration installation at Waelhem, for the Antwerp water-supply.

Z 2 
(Mr. Walter Clemence.)

In many other instances the construction of a multiple-filtration plant had been preceded by a trial, extending over a considerable period, of a small installation dealing with a few thousand gallons per 24 hours, and every step in advance in the application of the system had been taken, not in ignorance or uncertainty as suggested by Mr. Carson, but as a consequence of careful reasoning based on accurately recorded results of practice. Multiple filtration had been adopted recently for sewage purification and also for the recovery of indigo and other valuable substances after use in textile industries. It had been found that the adoption of double filtation, referred to by $\mathrm{Mr}$. Carson, was attended with practical difficulties. In modern installations on a large scale the degrossisseurs and pre-filters were divided into a large number of compartments fitted with some mechanical appliance for rapid cleaning, the total filtering area provided being sufficient to secure a physically clear water being supplied at all times to the final filters. This step in the right direction was taken many years ago. It was not taken in ignorance of what had been done in the laboratory, but in collaboration with such well-known scientists as Dr. Kemna, Dr. Miquel, Dr. Calmette, and others on the Continent; while in England Drs. Rideal and Thresh had recognized in their writings the soundness of the idea of multiple or stage filtration.

The Author considered that Mr. Carson was hardly justified in assuming that Major Clemesha was unaware of the nature of the "safety change" referred to in his report quoted in the Paper. But whatever it was, the change referred to stook place during some treatment of the water antecedent to filtration, and had therefore nothing to do with the subject of the Paper, which dealt with the purification of water by filtration. The report quoted by the Author on page 288 referred to rapid filtration which bad been found to effect no reduction in the free ammonia content. This was due to the fact that insufficient time was allowed for nitrification in the rapid passage of the water through the filter, while the frequent disturbance of the filtering materials during cleaning interfered with the formation in the bed of colonies of nitrifying bacteria. In slow sand-filtration, on the other hand, complete 
elimination of free ammonia was ordinarily taken as the standard of purity, and at Antwerp under Dr. Kemna it was a rule that the effluent from all the final filters should be tested several times a day by the foreman in charge, who had orders to close down any filter if a Nessler test, easily and rapidly made, indicated the presence of free ammonia in the effluent.

Mr. George H. Hughes had referred to the "film," and appeared to agree with the Author that the prevention of the formation of the "Schmutzdecke" on the surface of the sand was desirable. The Author was of course aware that the "Zooglœa" film which formed on the surface of the sand grains within the filter must also form on the grains on the surface lityer, but from observation and reasoning he did not consider that the film was in any sense a continuous film extending from particle to particle of the filtering medium, or that it so obstructed the interstices between the particles as to act mechanically as a strainer. The formation of such a film within the filter would at once be indicated by an increase in the "loss-ofhead," and this had not been noted when bacterial action in the filter had become established, and the presence of the "Zoogloa" confirmed by analysis of the effluent. A comparison of the photograph of sand, Fig. 13, Plate 1, with the scale would show that a coating of bacterial slime $\frac{1}{T_{0} 0} \mathrm{~mm}$. in thickness on each grain of sand would not seriously obstruct the interstices between the grains. But the slow passage of the water in minute streams through from six to eighteen inches of sand, every particle of which was coated with an active nitrifying slime, resulted in the complete oxidation of organic matter in solution.

This produced a condition of the water in which bacteria, whether nitro-bacteria or pathogenic organisms, could not exist; but, as Mr. Hughes suggested, if the speed was too great they might be washed through the filter beyond the point at which organic purification of the water had been completed. The standard speed of 4 inches per hour was adopted by Dr. Koch as a result of investigations on the working of filters on which a "Schmutzdecke" had formed. With filters in which the formation of this surface film was prevented from forming, the speed could be safely increased 
(Mr. Walter Clemence.)

to 6 inches per hour; beyond this speed the results appeared to be variable, and from information received as to the working of a large number of installations in which open sand-filters formed the final elements in a system of mutiple filtration, the Author concluded that a speed of 6 inches per hour in the final filters represented the limit of safety at the present time.

It was undoubtedly true, as stated by Mr. Hughes, that bacterial action took place in the roughing filters, and the analyses given in Appendix II (page 297) confirmed this, although the results were variable owing to the necessity for frequent cleaning of the degrossisseurs. The pebbles in these were quickly covered with mud, which no doubt contained a large number of bacteria.

With regard to the settling-tanks at Cawnpore, these were originally used as decanting basins in which the water was allowed to rest for a certain number of hours, being drawn off by floating arms from each tank in rotation. The arrangement shown in Fig. 8 (page 264), and referred to by Mr. Hughes, was adopted as the best means of circulating the water over the surface of all the tanks before passing it to the multiple-filtration plant. The Author was opposed to the use of settling-tanks in any form, and would have preferred the Cawnpore installation to be supplied with raw Ganges water from the by-pass inlet B, except in case of emergency. Suitable washouts were provided in the case of the settling-tanks at Cawnpore, Benares, and other places in India, but the amount of silt in the raw water during the monsoon was so great that it could not be effectively dealt with by sedimentation, and in some cases the tanks had been almost entirely blocked. At Benares the Author once noticed a deposit of silt reaching to the surface of one of the tanks, which was fifteen feet in depth.

Mr. D. C. Leitch had referred to the same subject. The reason for adapting the Cawnpore tanks for use with the multiple-filtration plant was stated clearly on page 263. The cleaning of a settlingtank was one of those operations about which it was easier to write than to perform. The Cawnpore tanks were each 300 feet by 200 feet by 10 feet deep, and from 3 to 4 feet of slimy mud had to be removed by hand labour at a normal cleaning time. The 
cleaning of the multiple filters, on the other hand, could not be neglected. With a turbid water the degrossisseurs became completely blocked with silt so that water could not pass through, and they were then rapidly cleaned by air, and flushed with raw water so that all accumulations were frequently removed. As regards economy of construction and working, Mr. Leitch might with advantage refer to the plan on page 264, which was drawn to scale, and compare the space occupied by the settling-tanks, now unnecessary, with that occupied by the degrossisseurs and pre-filters.

Mr. L. E. Mather had put forward some rather indefinite claims as to the advantages of mechanical filters with statements as to their initial and working costs which he did not support by figures or references to any particular plant. The Author had once used a pressure filter made by Mr. Mather's firm (Mather and Platt, Ltd.), but the cost, added to that of the foundations, gearing, chemical apparatus, etc., was by no means favourable when compared with that of the open sand-beds used at the same works. In this particular filter the false bottom supporting the filtering materials was dished, so that there was a greater thickness of filtering materials in the centre of the bed than near the sides. This appeared to the Author to be a disadvantage, particularly in a pressure filter, as there would be a tendency for the water to pass through the line of least resistance at the outside of the bed instead of at an even speed over the whole surface. Mr. Mather admitted that mechanical filters were inefficient without the use of chemicals, and the Author would remind him that the Paper was limited to the consideration of theory and practice in filtration, and claimed that his conclusions with regard to the advantages of slow speed filtration over rapid filtration were justified. A supplementary apparatus was always necessary with a mechanical filter, the operation of which was practically limited to straining.

The figures given by Mr. Mather as to the cost of working would be of more value if the conditions were known. Where a water was relatively pure and merely required treatment to neutralize peaty acids, the cost of treatment should be less than the figure given by Mr. Mather, and particulars of working costs 
(Mr. Walter Clemence.)

were of little value in the absence of information as to locality and conditions. The statement that the amount of filtered water required to clean mechanical filters rarely exceeded 1 per cent. of the quantity filtered was again unsupported by any information as to where such results were obtained. Mr. Humphreys, the Engineer to the York Waterworks, indicated that the amount used in cleaning the mechanical filters dealing with previously decanted water was 4 per cent.* Major Clemesha found (page 287 ante) that with the turbid waters of Bengal as much as 20 per cent. was sometimes required. These appeared to be extreme cases, and for an average water the figure would seem to lie between 4 and 20 per cent.

Mr. Mather's suggestion, that the multiple-filtration plant at Bamford had failed in dealing with the Derwent Valley water, was not supported by replies to inquiries made by the Author. The whole of the information with regard to this installation to be found in the Paper was given as received by the Author from responsible officials of the Derwent Valley Water Board, who appeared to be of opinion that the adoption of this system was fully justified. The Author did not understand why, in the experiment quoted in Appendix I, the crushed limestone, which had given such excellent results in reducing the acidity of the water, should have been removed from the filters before making the experiment with sulphate of alumina for the purpose of eliminating colour and still further reducing the plumbo-solvent character of the water. The Author had made inquiries since the Paper was read and understood that at Leicester the water from Derwent Valley had given trouble with hot-water pipes (presumably lead). But the Bamford filters were constructed before the reservoirs were complete, and the character of the water to be impounded was not accurately known. The degrossisseurs were, however, designed in such a way that there would be no difficulty in adding any chemicals required to correct plumbo-solvency or eliminate colour, and such chemicals would be afterwards removed far more efficiently by the quadruple filters at Bamford than by any rapid filter.

* Proceedings, Institution of Water Engineers, vol. xv, p. 72. 
Those members who saw the multiple installation at RoubaixTourcoing during the visit to Paris in July 1914 would remember the simple and efficient apparatus used there for adding a chemical for removing the colour from the absolutely black waters of the Lys. A similar apparatus could be erected at Derwent Valley for $£ 50$, and the fact that the use of mechanical filters was under consideration at Leicester and Nottingham was certainly not due to any difficulty of applying chemical treatment with the multiplefiltration plant at Bamford, if it were found to be advisable.

Captain C. G. Moor would find references to the use of bleaching powder as a sterilizer on pages 292 and 293 of the Paper. In any case its use was only an aid to filtration, and the Author was supported in his views as to its employment by Dr. Kemna, who agreed that in the case of a carefully filtered water, sterilization was unnecessary.

Mr. William Paterson, in his defence of rapid filtration, admitted that no responsible person, would for one moment consider the installation of rapid-filtration plant alone. The chief reason for the adoption by the Author of the title of the Paper was to confine the discussion to a consideration of the theory of filtration, and to elicit from the advocates of rapid filtration their views as to the work actually performed by such filters as compared with what conld be accomplished by slow sand-filters of the classical or "Simpson" type, or of the more modern system referred to in the Paper as "multiple filtration." Mr. Paterson might with advantage refer to the remarks of Mr. James Carson (page 318), who had so admirably explained what took place in filters of this type, and agreed that the idea was scientifically correct.

Mr. Paterson was in error in stating that the Tables on page 279 showed that the effuent from the final filters at Cawnpore contained a larger amount of matter in suspension than the water entering the filters. Apart from the fact that the Author quoted the figures in order to show that the test for "total solids" was frequently misleading, a laboratory test for "total solids" must always include solids in solution as well as solids in suspension, and all analyses of water passed through a bed of Ganges sand showed a 
(Mr. Walter Clemence.)

slight increase of "total solids" due to certain soluble but harmless mineral matters in the sand. This fact was referred to in several Government reports by Captain Dunn, I.M.S., and others, and the increase took place when the filters were formerly supplied with water decanted with sulphate of alumina and to the same extent. The two analyses referred to by Mr. Paterson were by Dr. Rideal and Dr. Hanbury Hankin respectively, and these two great authorities, knowing the cause of the increase, were quite unlikely to blame the system of multiple filtration on that account. Mr. Paterson was not justified in anticipating that the Author would account for the increase by the escape of filtering medium from the final filters. The construction of the filters and their slow speed rendered this impossible, and the cause of the slight increase in "total solids" being well known to those immediately concerned, the point was not debatable.

At the time when Mr. Paterson visited Cawnpore, the filters were being supplied, and had been supplied for some time, with water from a canal and not from the Ganges, and the best answer to his statement that the fine silt of the Ganges penetrated the finest filtering medium was to be found in the records of the working of the filters given in the Paper. These were confirmed in an official report recently issued by the Government of the United Provinces, which also contained the following paragraph:- " There is very little doubt that the new plant (multiple filtration) gives a safer water than under the old system (settling-tanks and coagulation) and provides greater flexibility as regards the final filters, and that the actual maintenance charges are considerably less with the new plant than they would have been under the old system."

The Author had spent much time in careful investigation of the physical properties of the silt carried down by the Ganges, and was quite unable to agree with Mr. Paterson that many individual particles were smaller than bacteria or devoid of adhesive properties. The finest particles consisted of clay granules, the adhesive properties of which were only too well known to those who had to deal with water containing clay in suspension. He had prepared a large number of slides by mounting samples of the silt 
in a medium with a suitable refractive index, and had used a selection of these for the photographs on Plates 1 and 2. By using special colour screens as light filters, it had been possible to show in the photomicrographs Figs. 18 and 20 the smallest particles of silt to be found. These had been measured with the micrometer under considerably higher powers than those employed in taking the photographs reproduced in the Paper, and the smallest particles found were larger than any nitro-bacteria which had at the present time been recognized as such. The rapid filter at Nani-Tal was supplied by Messrs. James Simpson and Co., Itd., which was a sufficient guarantee that it was a perfect machine of its type, and that the conditions were well considered.

Mr. Paterson's selection of the Poona installation as an illustration of "high-speed filtration" appeared to be rather an unhappy one. On the assumption that every precaution was to be taken with a raw water containing at times one million frcal bacteria per $\mathrm{cm}^{3}$ (the intake was apparently adjacent to a sewage outfall), the sequence of treatment was to be coagulation, sedimentation, rapid filtration, and sterilization. Mr. Paterson admitted that, even if 99.9 per cent. bacterial purification could be effected by coagulation, sedimentation, and rapid-filtration, the filtered water might still contain 1,000 dangerous bacteria, so that it might be assumed that filtration was to be followed by sterilization. This might, of course, effect the destruction of all the bacteria, but it was still only a single line of defence against the passage of large numbers of dangerous bacteria, and any breakdown or interruption or even partial failure of the sterilizers would be disastrous.

But there was another aspect of the case. Mr. Paterson did not claim that coagulation, or sedimentation, or rapid filtration could bring about the elimination of organic matters in solution. If the filtered water at Poona contained 1,000 dangerous bacteria per $\mathrm{cm}^{3}$, it must be organically impure, as no bacteria could exist in the absence of organic matter, and as the sterilization, if effective, must destroy nitro-bacteria as well as the dangerous organisms, this organic matter in solution, of the same origin as the freal 
(Mr. Walter Clemence.)

bacteria would remain in the water after the elaborate system of treatment to which it had been subjected.

In reply to the last paragraph of Mr. Paterson's communication, the Author believed that the last occasion on which the merits of various systems of water purification were investigated in the only practical way by comparing the results of all types of filters, etc., at the same time, on the same water, and over a considerable period was in the summer of 1910 at Marseilles, where the Authorities carried out a trial of practically every modern system, including sterilization by ozone, light treatment, and chlorine, rapid filtration with coagulation, multiple filtration, and slow sandfiltration, the latter both with submerged beds and with various "sprinkler" systems. The official report confirmed generally the views of the Author as to the advantage of slow speed in filtration.

In reply to Mr. A. Beeby Thompson, the Author: had not noticed any increase in the number of bacteria in the effluent from properly worked sand-filters in warm climates over that found under normal conditions in temperate climates. From a comparison of analyses over considerable periods, it would appear that the number of bacteria usually bore a direct relation to the quantity of organic matter in the raw water, where this was supplied direct to the filters from rivers or storage reservoirs. In multiple filtration it was found to be good practice to mix the effluent from all the units of each series of the preliminary filters into a common collecting canal before passing it on to the next series. In this way a good average character in the effuent from the pre-filters could be relied on, with corresponding regularity in the chemical and bacteriological condition of the effluent from the final filters.

The Author had made a special study of biology in connexion with filtration and had collected specimens of algæ and other organisms from many tropical countries. Algæ were universal in the distribution of species, and types common in England and temperate climates generally were constantly met with in tropical and sub-tropical climates. Taking the range of temperature of waters on which open sand-filters were employed at from $35^{\circ}$ to $85^{\circ}$ F., the plants did not seem to be greatly affected by 
temperature. Light was, of course, an important factor in their development, but in a water deficient in organic matter in solution they did not thrive, but had a tendency to abnormal forms. If the spores could be eliminated by pre-filtration, effecting reduction of organic matters, algre did not develop on the final: filters even when these were exposed to a tropical sun.

The figures quoted by $\mathrm{Mr}$. W. P. Walker with regard to the Cheltenham filters were interesting, and enabled a comparison to be made between that installation and the Cawnpore filters referred to by the Author. There was a remarkable agreement in the aren of surface of the slow sand-filters scraped per million gallons of water filtered, namely, 179 square feet at Cheltenham and 171 square feet at Cawnpore. The Cheltenham figure was an average for the year, whereas the Cawnpore figure was obtained during the period covering the hot weather and monsoon. Possibly at Cheltenham the figure was increased somewhat by the coagulant used, and this also appeared to restrict the output from the filters. But Mr. J. S. Pickering, the Engineer to the Cheltenham Waterworks, had stated that the maximum speed of the final filters when yielding the full supply was $31 \frac{1}{2}$ gallons per square foot per 24 hours (page 285). One million gallons through 179 square feet filtering surface represented a column of water 895 feet high, and there appeared to be some discrepancy between the figures given by Mr. Pickering and Mr. Walker's statement. Taking the best run of a filter at Cheltenham at 120 days, and the speed $31 \frac{1}{2}$ gallons per square foot per 24 hours for the whole period, the height of a column of water passed would be 581 feet, against 209 days and 937 feet with the Ganges water at Cawnpore (page 267). The comparison of the figures was interesting, but the local conditions were not the same, and, as Mr. Walker made no reference to the cost of chemicals or labour required for the coagulating plant at Cheltenham, apart from the rapid pre-filters, he could hardly be held to have justified his claim that the process in use at Cheltenham was less costly than multiple filtration, while an examination of the figures quoted above lent no support to his statement that the filters were more easily cleaned than open beds. 
(Mr. Walter Clemence.)

The open beds at Cheltenham were cleaned more frequently than those at Cawnpore per million gallons of water treated, and it was unfortunate that Mr. Walker had not given further details as to chemicals used, labour cleaning sedimentation tanks, etc., so as to enable the actual total cost of working to be calculated.

[Just before going to press, a Communication from Mr. J. E. WaLKER (Associate Member), of Calcutta, was received, containing interesting information about filtration in India and Burma. The points raised by Mr. Walker had already been dealt with in the discussion and Author's Reply.] 
Fig. 12. Course Sund in Protillers

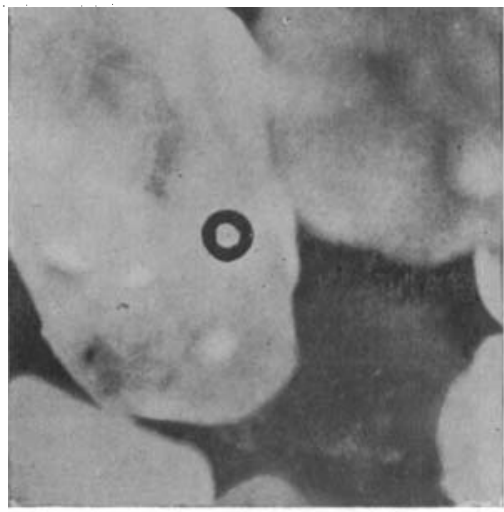

Fig. 14. Silt Particles in Raw Water at Inlet to Settling Tank No. 1.

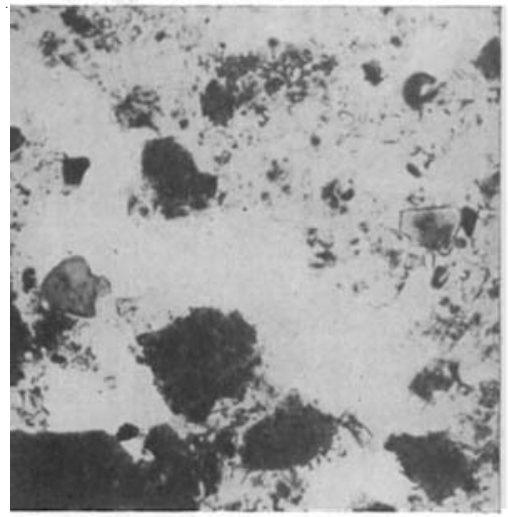

Fig. 16. Silt Particles in Water from Settling Tank No. 3 .

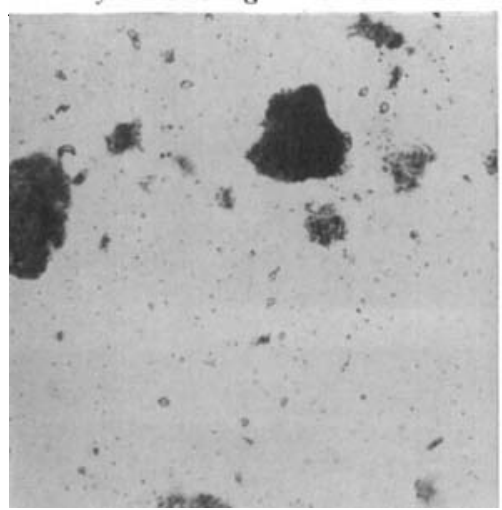

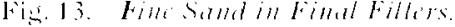

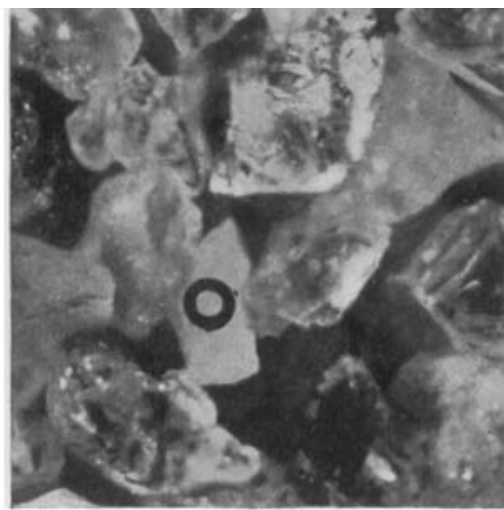

Fig. 15. Silt Particles in Water from Settling Tank No. 2.

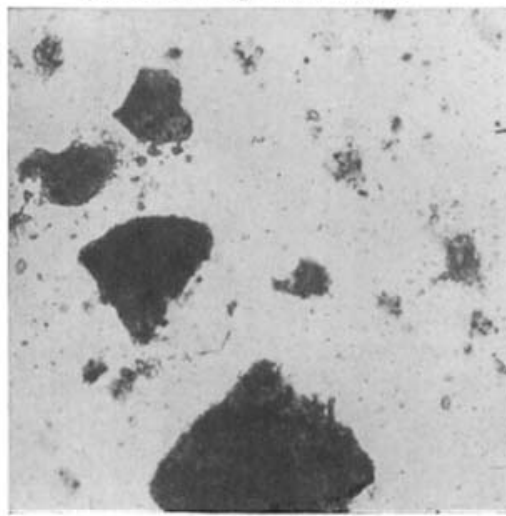

Fig. 17. Silt Particles at Inlet to Multiple Filters.

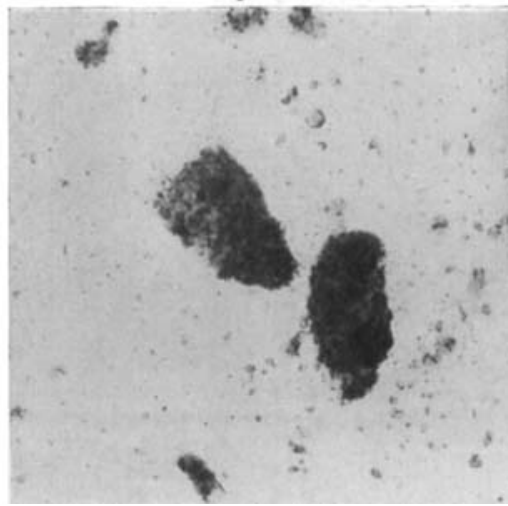


FILTRATION OF WATER. Pliki?

Silt Particles $\frac{1}{10} \mathrm{MM}$. $\frac{1}{100} M M$.

Fig. 18. After Degrossisseur No. 1.

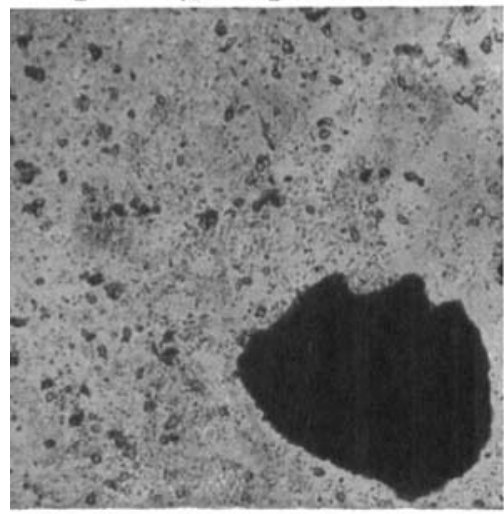

Fig. 20. After Degrossisseur No, 3.

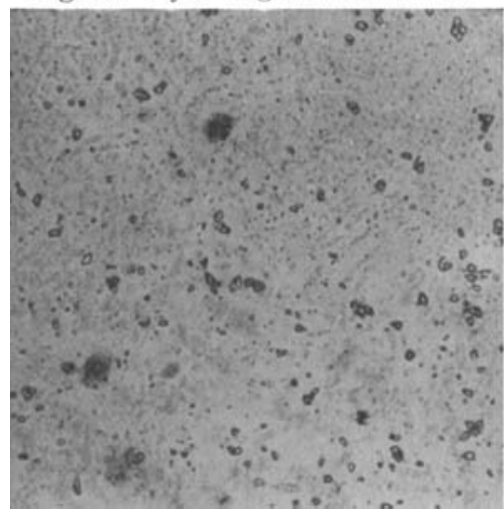

Fig. 22 T. Typhosus

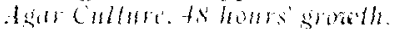
$\frac{1}{100} \mathrm{M} M$.
Fig. 19. After Degrossisscur No. 2.

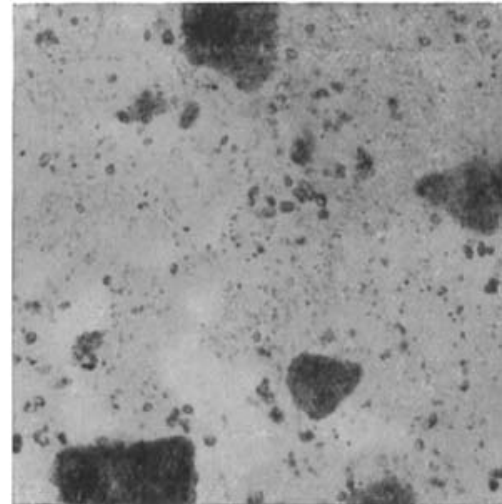

Fig. 21. After Pre-filters.

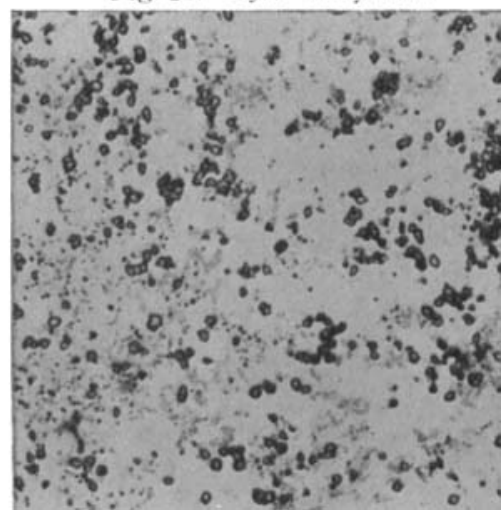

Fiss. 23. Sp Cholede lstativa. f gar cullute to hours gronth. $\frac{1}{1000}$ M M

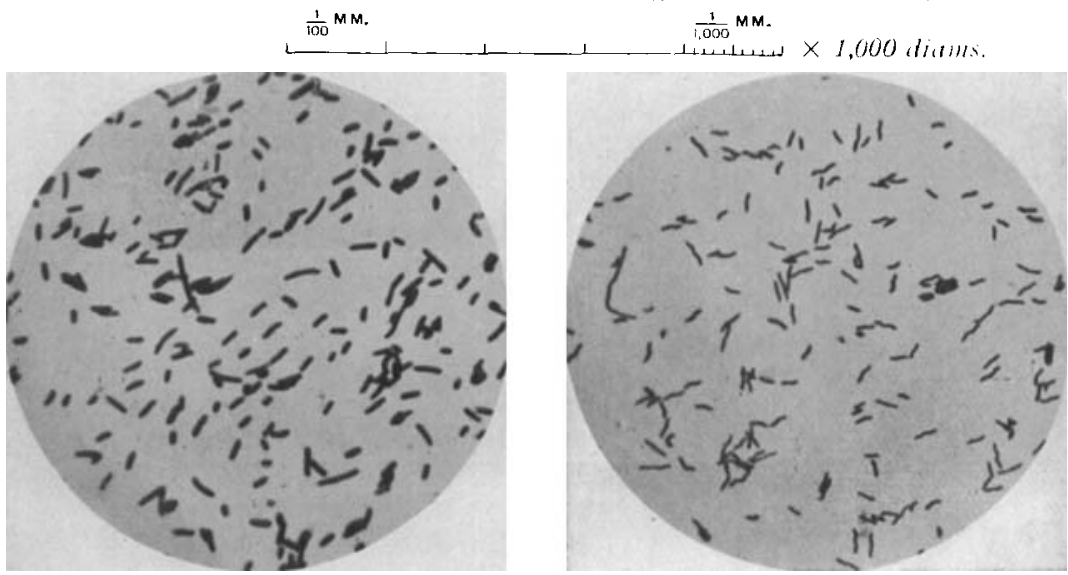

